\title{
Power dynamics at work
}

Citation for published version (APA):

Hovens, D. (2021). Power dynamics at work: an ethnography of a multilingual metal foundry in the DutchGerman borderland. [Doctoral Thesis, Maastricht University]. LOT. https://doi.org/10.26481/dis.20211014dh

Document status and date:

Published: 01/01/2021

DOI:

10.26481/dis.20211014dh

Document Version:

Publisher's PDF, also known as Version of record

\section{Please check the document version of this publication:}

- A submitted manuscript is the version of the article upon submission and before peer-review. There can be important differences between the submitted version and the official published version of record.

People interested in the research are advised to contact the author for the final version of the publication, or visit the DOI to the publisher's website.

- The final author version and the galley proof are versions of the publication after peer review.

- The final published version features the final layout of the paper including the volume, issue and page numbers.

Link to publication

\footnotetext{
General rights rights.

- You may freely distribute the URL identifying the publication in the public portal. please follow below link for the End User Agreement:

www.umlib.nl/taverne-license

Take down policy

If you believe that this document breaches copyright please contact us at:

repository@maastrichtuniversity.nl

providing details and we will investigate your claim.
}

Copyright and moral rights for the publications made accessible in the public portal are retained by the authors and/or other copyright owners and it is a condition of accessing publications that users recognise and abide by the legal requirements associated with these

- Users may download and print one copy of any publication from the public portal for the purpose of private study or research.

- You may not further distribute the material or use it for any profit-making activity or commercial gain

If the publication is distributed under the terms of Article $25 \mathrm{fa}$ of the Dutch Copyright Act, indicated by the "Taverne" license above, 


\section{POWER DYNAMICS AT WORK}

An Ethnography of a Multilingual Metal Foundry in the Dutch-German Borderland 
Published by

LOT

phone: +31 205252461

Kloveniersburgwal 48

1012 CX Amsterdam

e-mail: lot@uva.nl

The Netherlands

http://www.lotschool.nl

Cover illustration: Photograph taken by Daan Hovens during his fieldwork in the metal foundry in 2017, with credits to Zahar Koretsky for his help with selecting a suitable cover illustration.

ISBN: 978-94-6093-387-5

DOI: https://dx.medra.org/10.48273/LOT0602

NUR: 616

Copyright (C 2021: Daan Hovens. All rights reserved. 


\title{
POWER DYNAMICS AT WORK
}

\author{
An Ethnography of a Multilingual Metal Foundry in \\ the Dutch-German Borderland
}

\author{
DISSERTATION
}

to obtain the degree of Doctor at Maastricht University, on the authority of the Rector Magnificus, Prof. Dr. Rianne M. Letschert in accordance with the decision of the Board of Deans, to be defended in public on Thursday the 14th of October 2021 at 10:00 hours

by

Daan Hovens 


\section{Supervisors}

Prof. dr. L. Cornips

Prof. dr. J.J.G. Schmeets

\section{Co-supervisors}

Prof. dr. J.D. ten Thije (Utrecht University)

Dr. S. Tienken (Stockholm University)

\section{Assessment committee}

Prof. dr. V. Mazzucato (Chair)

Dr. J. Mortensen (University of Copenhagen)

Prof. dr. A. Pennycook (University of Technology Sydney)

Dr. L.C.S. Thissen 


\section{Acknowledgments}

In line with the theoretical perspective of my dissertation, I could easily argue that a wide range of humans and non-humans have enabled me to produce this work. It will be impossible to mention all of them here, however, so I restrict myself to a number of human beings who have been especially important in different ways.

To begin with, writing this dissertation would never have been possible without the cooperation from, and generous sharing of information and experiences by diverse actors in and around the metal foundry, including its workers, labour recruiters, (former) directors and managers, as well as people living nearby the foundry. To protect their anonymity, I cannot mention their names here, but I would like to thank all of them wholeheartedly.

Another major expression of gratitude goes to my supervisors Leonie Cornips, Hans Schmeets, Jan ten Thije, and Susanne Tienken. On the one hand, having four different supervisors with four different viewpoints was a challenge at times, but on the other hand, this practice also helped me to start making independent decisions more easily. In the following paragraphs, I will address each of them personally.

Leonie, your positive energy and enthusiasm is a fuel that has probably made me get through my PhD trajectory more smoothly, and that has certainly made it more fun. Moreover, your digital response times are unrivalled. Whenever a deadline approaches, I tend to go and work nightshifts and hand in my writings at an hour that most people are asleep, and you had usually sent me feedback already by the time I woke up again around noon. I am also very grateful that you pointed out posthumanism as a possible approach for me to explore, and I hope that we can continue our discussions about this approach even after my $\mathrm{PhD}$ is over.

Hans, your attempts to understand concepts from a different field than your own, and our early joint attempts to put these concepts in a visual overview have helped me get a better grasp of the theories I was working with, and I have profited from this ever since. On top of that, you were always there to help me with any practical concerns, and your famous garden parties in Maastricht have certainly provided positive fuel for my $\mathrm{PhD}$ trajectory as well. I hope we can soon pick up some of the 'unfinished business' that we still have at this moment, such as the organisation of a conference at Statistics Netherlands (CBS). 
Jan, I first got to know your work when I was writing an MA thesis in which I advocated the use of lingua receptiva in the Dutch-German borderland. Almost ten years later, you have accompanied me on a now practically finished PhD trajectory. Meanwhile, you have introduced me to the lingua receptiva network from the Dutch Language Union (Taalunie) and the impressive field of functional pragmatics. I am aware that you did not always agree with the decisions I made during this trajectory, but I am grateful for all the efforts you nevertheless put into critically reading my work, which has certainly helped me write a better dissertation.

Susanne, I am very lucky that I could convince Leonie to get you on board as well at the start of my PhD trajectory. I originally got to know you as my MA thesis supervisor in the Euroculture programme, and an entire PhD project later, I am still as happy with our cooperation as I was back then. No matter whether I gather quantitative data from a survey (as I did for my MA thesis), or qualitative data from ethnographic fieldwork, you always actively think together with me, and you are always comfortable with my habit to regularly change the basic framework of a paper I am working on - or at least you manage to hide your discomfort well.

On top of these official supervisors, there are a number of 'shadow supervisors' who have provided valuable feedback during one or several stages of my PhD trajectory as well, and whom I would like to thank here. First of all, my partner Huiyun Cheng (a.k.a. paranymph I), who is always ready to discuss any ideas with me, with one discussion partly inspiring the framework of chapter 3 , and another one helping me gather inspiration for the data interpretation of chapter 5; secondly, John Harbord (a.k.a. paranymph II), the Academic Writing Advisor from Maastricht University, whose consultation meetings were always about much more than grammar and punctuation alone, and whose relative outsider view always helped me express my thoughts more clearly; thirdly, my colleagues Louis van den Hengel and Ruud Hendriks, who generously introduced me to the field of posthumanism, and whose feedback helped me improve chapter 4 before it got published; fourthly, Christien Franken, Dorte Lønsmann, Janna Klosterman, and Janus Mortensen, who all read and commented on chapter 4 during different occasions as well; fifthly, all the journal editors and anonymous peer reviewers who have shared their thoughts on chapters 3 , 4 , and 5 with me before publication; and finally, everyone who has attended and given feedback during the numerous presentations I gave about my project, with special thanks to Janus Spindler Møller for sharing a crucial insight that partly inspired chapter 4 (which I explain in chapter 2.7). 
One more supervisor I met during the past years was Charles van Leeuwen, who oversaw my trajectory of becoming an officially qualified teacher for Dutch universities. His personal style made this whole trajectory a very pleasant experience, and the introductory course on sociolinguistics that we taught together helped me read up on classic authors and texts in this academic field. On a similar note, I would also like to express my gratitude to Annika Richterich, with whom I taught an introductory course on Foucauldian discourse analysis and semiotics for two years, which proved to be thought-provoking for the development of my theoretical framework as well. For certain, I should also mention the students I taught during the past years in this respect, who together with me struggled to understand at times quite abstract theories and concepts.

My PhD trajectory would not have been nearly as smooth and pleasant without the privilege of being surrounded with great colleagues and peers. Hence, I would first of all like to thank Nantke Pecht, Pomme van de Weerd, and Veerle Spronck, whose PhD trajectories largely overlapped with mine, with whom I have attended many conferences, seminars and/or graduate school sessions, and with whom I shared an office most of the time. Special thanks also go to llias Alami, the 'guy next door' who could light up any working day with a joint lunch, and to Zahar Koretsky, a fellow $\mathrm{PhD}$ candidate with a shared interest in posthumanism, who helped with selecting my cover illustration. Furthermore, many thanks to my international peers Katherina Kappa and Sue Goossens, who together with Pomme and me established the somewhat short-lived 'CoBrA-MaMa' reading group, and organised an inspiring seminar at the University of Copenhagen. And last but not least, many thanks to all fellow PhDs from the Languageculture team that have not yet been mentioned; to all fellow PhDs and colleagues from ITEM (especially Julia Reinhold, Lavinia Kortese, Marloes de Hoon, and Nina Büttgen); to all members from the Maastricht University Choir (especially Caspar Cluitmans, Felicitas Biwer, Juliët Beuken, Menno de Bruin, and my fellow tenors); to everyone who helped me with the struggle to get chapter 3 published 'open access' (especially Aagje Swinnen and Emilie Sitzia); to two invaluable helping hands with regard to different HR-related issues, Bas Knoet and Ilse Gronenschild (†2019); to the department secretaries Anja Servais, Ineke Stevens, and Lilian Essers, who were always in for a short chat in Limburgish with me; to my fellow board members from Levende Talen Limburgs, who always made me think again about what position Limburgish should (not) have in society; as well as to Bianca Dijkstra, Karlien Strijbosch, and Renée van de Vall. 
A special paragraph in this section should also be dedicated to my relatives in Tegelen and elsewhere, with a special mention for my parents Dré Hovens and Willie Wilbers, as well as Marcel Beelen and Gerrie Wilbers (+2017). In recent years, I have come across several articles on the topic of so-called "first-generation students", who tend to struggle more in academia. I guess there are several sociological explanations why I have never felt a lot of struggle myself, but two explanations certainly are the basic trust that my relatives have always given me even when I decided to study things that did not immediately guarantee a steady job for the future, and the practical means that they have provided me with to focus on my studies during many important occasions. Furthermore, in relation to this, I would also like to express my gratitude to a few 'family-friends' who have always expressed a genuine interest in my academic endeavours, including Esther Roth, Lut Callaert, and Peter Hammer.

Despite the growing length of this section, there are still a few more names that should certainly be mentioned here: Graham Sedgley, who did the final proofreading of this dissertation; Justyna Piotrowska and Zofia Sagnowska, who translated a number of Polish utterances for me that partly appear in chapter 4; the anonymous translators from gengo.com, who helped me with translating the summaries of this dissertation; and Bruno Latour, whom I have never met in real life, but whose writings made me feel an excitement that I had not felt about any theoretical text anymore ever since I first discovered the field of philosophy as a teenager.

To conclude, I would also like to express my gratitude to all the members of the Assessment Committee of this dissertation, for taking the time to read and comment on my work. After all, the best thing that any author can hope for is to be seriously read, and I am very happy that you have done so and are willing to share your thoughts with me. 


\section{Contents}

Transcription Conventions XIII.

List of Tables $\quad$ XIV.

List of Figures $\quad$ XV.

$\begin{array}{lll}\text { Publications } & \text { XVII. }\end{array}$

Chapter 1: Introduction 1.

1.1 Research question, data, and aims 4 .

1.2 Linguistic ethnography and blue-collar workplaces 9.

1.3 A posthumanist approach to power and language 11.

1.4 Power and language in the Meuse-Rhine border area 14.

1.5 Dissertation outline 18.

Chapter 2: Methodological Reflections 21.

2.1 Introduction 21.

2.2 Getting access to a PhD position 23.

2.3 Getting access to cross-border data 25.

2.4 Getting access to a metal foundry 30.

2.5 Getting access to production work practices 34 .

2.6 Getting access to workplace discourse and informed consent

41.

2.7 Getting access to academic audiences 48 .

2.8 Getting access to professional audiences 51 .

2.9 Conclusion and discussion 53.

Chapter 3: Language Policy and Linguistic Landscaping 57.

3.1 Introduction 57.

3.2 Theory: Language policy as linguistic landscaping 59.

3.3 Linguistic landscaping in the Meuse-Rhine borderland 61.

3.4 Methodology and data 65.

3.5 Linguistic landscaping through labour recruitment practices

67. 
3.6 Linguistic landscaping and the construction of a 'Dutch' work environment 71.

3.7 Linguistic landscaping and the position of the "old guard" 76.

3.8 Conclusion and discussion 79.

Chapter 4: Workplace Learning through Human-Machine Interaction 83.

4.1 Introduction 83.

4.2 Language and workplace learning in blue-collar work environments 84.

4.3 Methodology 87.

4.4 Transience and language diversity in the Finishing
Department

4.5 A posthumanist approach to workplace learning in the Finishing Department

91.

4.6 Human-machine interaction as a means to distinguish newcomers from experts

94.

4.7 Human-machine interaction as a communicative mode 97.

4.8 Human-machine interaction as a joint negotiation of work practices 103.

4.9 Conclusion and discussion 108.

Chapter 5: Emerging Production Work Assemblages 111.

5.1 Introduction 111.

5.2 Language and power in blue-collar work environments 113.

5.3 Background, data, and methods 115.

5.4 'Screwed': The breakdown of a work assemblage after
non-human resistance

5.5 "Do it yourself just once": The breakdown of a work assemblage after human resistance 127.

5.6 Conclusion and discussion 137.

Chapter 6: Conclusion and Discussion 141.

6.1 The perspective of 'local' majoritised speakers 141.

6.2 The interactional role of machines 143.

6.3 Emerging competitiveness at work 144.

6.4 Theoretical and practical takeaways 146. 
Zusammenfassung (Deutsch)

165.

Summary (English)

166.

Samevatting (Limburgs)

167.

Samenvatting (Nederlands)

168.

Streszczenie (w języku polskim)

169.

Impact Paragraph

171.

About the Author

177. 


\section{Transcription Conventions}

The transcription symbols used in this dissertation belong to the conventions from the Gesprächsanalytisches Transkriptionssystem 2 (GAT 2; Selting et al. 2009). Mainly due to specific workplace conditions (such as loud sounds) and the general aims of this dissertation, I have made a few minor adjustments to these conventions. For example, I have not counted the syllables of unintelligible speech, and I have not differentiated between pauses shorter than one second.

Pause in seconds

Micro pause (shorter than one second)

Overlapping speech

Transcriber unsure

Unintelligible speech

Contiguous utterance

Sound lengthening

Emphasis

Questioning intonation

Additional description from transcriber

\section{(.1)}

(.)

[hahahaha]

(das)

$(x x x)$

$=$

:

WORK

?

((the machine makes a snapping sound)) 


\section{List of Tables}

Table 1: The number of permanent and temporary workers in the foundry in August 2017, divided by department and citizenship.

Table 2: Overview of the dissertation chapters.

20.

Table 3: The same as table 1.

34.

Table 4: Overview of the fieldwork data gathered in each production department. 44.

Table 5: The number of production workers and other workers (e.g., HR managers, salespeople, and engineers) in the metal foundry, divided by citizenship, in August 2017. 71.

Table 6: The same as table 1.

115. 


\section{List of Figures}

Figure 1: Map showing the Meuse-Rhine border area.

15.

Figure 2: Map visualising the relative share of cross-border labour commuters among the total number of people employed in different subregions of the Dutch province of Limburg and the German state North Rhine-Westphalia in 2017.

Figure 3: Impression of my fieldwork announcement in three languages (Dutch, German, English) on a noticeboard in the foundry's Core Shooting Department.

Figure 4: English version of my fieldwork announcement for production workers in the metal foundry. 40.

Figure 5: The same as figure 1.

62.

Figure 6: Commemoration stone with Limburgish text, reading: "The first stone was placed by $\mathrm{Mr}$ [name anonymised by author] on 19-02-1993".

Figure 7: The blasting machine 'speaking' Dutch through a displayed message, and English through various buttons in the bottom right corner of the photograph.

104. 
Figure 8: The control panel of the blasting machine. The "emergency stop" button is in the bottom right corner. I have circled the "start stralen" button. 106.

Figure 9: The spatial organisation of BEN's workstation.

118.

Figure 10: The spatial organisation of the workers at the cutting table. 127.

Figure 11: The spatial organisation of the workers at the cutting table during line 1 of extract 6.

Figure 12: The spatial organisation of the workers at the cutting table during line 12 of extract 6 .

134. 


\section{Publications}

Chapter 3 of this dissertation has been published in the journal Language Policy (Hovens 2021), chapter 4 has been published in the Journal of Linguistic Anthropology (Hovens 2020), and chapter 5 has been submitted to another international, peer-reviewed journal. 
Introduction - 1

\section{Introduction}

Extract 1. Work interaction in the Finishing Department, 14 August 2017 (participants: PER, VIN, DAA, and a sand-blasting machine)

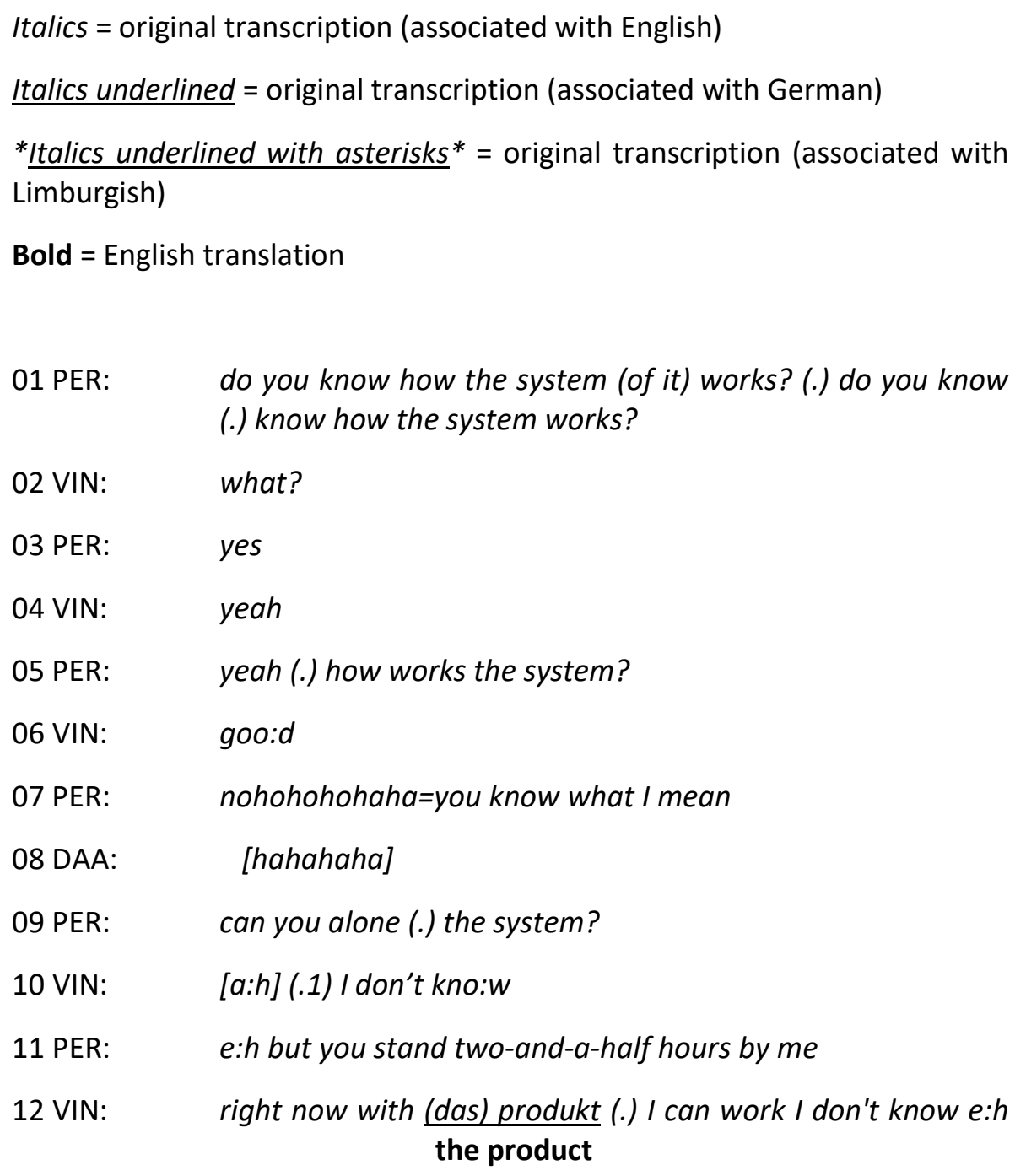


2 - Power Dynamics at Work

13 PER: [how] how do you then? (.) how works (.) (machine is) (.) (I wait) (.) how do you then? (.) how do you (.) eh watch that=eh the machine eh (.) *in de dreej* (.) how do you in the three

then? (.3) you have (.) stands two-and-a-half-hours by me you have see what I have done (.) can you self?

14 VIN: $\quad$ yea:h I can I can work alone

15 PER: $\quad$ I can WORK alone no:h (.) can you work (with=in) (.) (what)

(.) the machine? (.2) *hae snap 't gaar neet* (.2) (xxx) (.1) he doesn't get it at all

can you (.1) now (.) go the machine on (.) three seconds? (.2) wha=what are you doing (.) (in) (.) (in that e:h) (.) (xxx) (now) (.) (xxx) (now)

The above interaction was audio-recorded in a production department of a metal foundry in the Dutch province of Limburg, in the Dutch-German borderland. It exemplifies a commonly observed situation, where two people, whose individual language repertoires did not overlap much, had to work together. "PER" was an older $(>50)$ permanent contract worker from Limburg, who had worked in the foundry for over 20 years, and who spoke Dutch and a local variety from Limburg (known as "Limburgish"; see Cornips 2013) as his first languages, and German and English as his second languages. "VIN" was a younger $(<30)$ temporary contract worker from Poland who had worked in the foundry for about two months, and who spoke Polish as his first, and English as his second language, which he occasionally combined with words that are typically associated with German (as in line 12). Hence, they used English as a lingua franca when speaking with each other (see Hülmbauer, Böhringer, and Seidlhofer 2008). "DAA" refers to me, the author of this dissertation, a younger $(<30)$ participant-observer at the time, who had been doing linguisticethnographic fieldwork in the metal foundry for about 1.5 months, and who spoke Dutch and Limburgish as his first, and English, German, Swedish, and some French as his second languages.

In the above interaction, PER checks whether VIN is able to perform particular interactions with a machine on his own, as he is about to leave their workstation. He refers to these interactions as "the system". VIN does 
not seem to understand this reference (line 2), and after PER asks him to explain "the system" (line 5), VIN misinterprets this question either intentionally or unintentionally (line 6). PER does not appear to believe that VIN has misunderstood him ("you know what I mean"), yet still, he rephrases his initial question as "can you alone the system?" (line 9). VIN indicates that he knows what PER means now ("a:h"), and adds that he is not sure whether he can work with "the system" alone (line 10). Rather than explaining "the system", PER then seems to start blaming VIN for not having paid sufficient attention during the past 2.5 hours (line 11). VIN responds to the implied blame by specifying that he knows how to handle the product that they have been working with so far, but he seems unsure whether that equals knowing "the system" (line 12). PER asks VIN to tell him how to work with the current product then (line 13), and VIN responds that he knows how to do that (line 14). PER does not believe that VIN has understood him, however, which he makes clear in a code-switch (see Muysken 2000) to Limburgish (line 15). Afterwards, PER shows VIN how to perform the job with the machine.

At first sight, this work encounter might seem odd. PER, the expert worker, uses extensive utterances while actively trying to make sure that VIN, the newcomer, understands how to perform his job. VIN's responses, on the other hand, are very brief, and in one instance (line 6), he even seems to be joking. This is not how one might expect someone to behave, who has come all the way from Poland to the Netherlands to earn money in a metal foundry (among other workplaces), and who has no job security to rely upon. Why is VIN not more actively trying to make sure that he understands his job, so that he has a better chance to stay and earn money in the foundry for a longer time? Why does PER seem so motivated to check whether VIN understands his job, despite VIN's apparent lack of interest? What explains PER's code-switch to Limburgish, and his switch from a second-person pronoun ("you") to a first-person pronoun ("I") and a thirdperson pronoun ("hae" / he) to refer to VIN in line 15? Who does PER seem to be addressing primarily in his utterances, VIN or me? What kinds of hierarchical workplace relations are reproduced or renegotiated in this way? And who seems to be more insecure about his job in the end, PER or VIN? 


\section{4 - Power Dynamics at Work}

\subsection{Research question, data, and aims}

The brief interaction between PER and VIN, both of whom will return in chapter 4, touches upon three central themes of this dissertation, namely language diversity, job insecurity, and human-machine interaction. Apart from their different attitudes towards VIN's workplace learning process, their apparent difficulty to communicate might seem rather surprising as well. In the fields of applied linguistics, linguistic ethnography, and sociolinguistics, it has become well established nowadays that people do not need to speak an 'entire' language to achieve all sorts of transactional and relational communicative purposes, that the idea of an 'entire' language is problematic in and of itself, and that it is more accurate to think in terms of diverse communicative resources (see García and Wei 2014; Jørgensen and Varga 2011). Indeed, bringing together people like PER and VIN, whose individual language repertoires do not overlap much, does not necessarily have to lead to a lot of misunderstandings in a workplace (see, e.g., Franziskus, De Bres, and Gilles 2013; Pennycook and Otsuji 2015; Theodoropoulou 2020). Over time, people may in fact develop a shared repertoire of communicative resources that are suited for their specific needs, and that makes them identifiable as a community of practice (Eckert and McConnell-Ginet 1992; Lave and Wenger 1991; Wenger 1998).

Moreover, in posthumanist fields such as actor-network theory (Latour 2005), new materialism (Bennett 2010), and posthumanist applied linguistics (Pennycook 2018), a well-established insight today is that both human and non-human actors (hereafter: actants) contribute to the achievement of specific purposes, and that non-human actors even make human-human communication redundant at times. The development of a car that makes it impossible to drive without wearing a seatbelt, for example, decreases the necessity to tell people that they have to remember to wear one (Latour 1992, 226). Hence, in a strongly mechanised work environment such as the metal foundry, where people like PER and VIN often spent more time interacting with machines than with each other, it may not only be that people do not need to speak an 'entire' language. They often may not have to speak one at all, if language is understood in its conventional, typically verbal sense.

Despite all this, however, the interactions between PER and VIN do not immediately appear successful. An explanation may be found in the transience of their work relation (Haberland and Mortensen 2019; Mortensen 2017), as they had never worked together before. An additional 
explanation may be found when considering PER's code-switch to Limburgish, through which he told me that VIN "doesn't get it at all". How much was PER really trying to check whether VIN would be able to work with the machine on his own, and how much was he trying to show me -a researcher with an explicit interest in language diversity- that it was very difficult to achieve a work-related purpose with a minoritised speaker like VIN? Previous linguistic-ethnographic studies of blue-collar work environments have shown how language can be used as a gatekeeping mechanism, legitimising why certain minoritised speakers do not get access to certain benefits, such as a permanent contract, a permanent residence permit, or a different job with a higher salary or a higher social status (Duchêne 2011; Holm, O'Rourke, and Danson 2020; Kraft 2019; Kraft 2020a; Piller and Lising 2014). In the metal foundry, this gatekeeping mechanism had started to lose some of its previous force, as the company had opened up to first-generation migrant workers with (more) diverse language backgrounds (including VIN). Hence, PER's apparent attempt to influence my research findings can be interpreted as an attempt to go against this historical, sociolinguistic development.

To achieve relevant purposes in the metal foundry -such as productivity, workplace safety, and job satisfaction- several dimensions thus had to be considered. The question was not only which verbal and non-verbal resources people needed to achieve such purposes, or how much non-human actants such as machines could make the need for human-human interaction redundant, but also how much different people in the foundry felt that the given language diversity at work was legitimate. Indeed, one take-away from this dissertation is that scholars with an interest in language and society should at least be aware of the possible social implications when they argue that 'not much language' is needed to achieve certain purposes. After all, while opening up for a linguistically more diverse workforce may create opportunities for migrant workers to earn more money than they would have done elsewhere (a positive development in and of itself), it may also weaken the negotiating position of workers who strive for higher salaries and/or more job security, as it provides employers with a larger potential labour pool to choose from. Thus, promoting the idea that 'not much language' is needed might actually further stimulate processes of labour market liberalisation and increase social tensions in the workplace and society at large.

Power, defined as "acting with effect" (Watson 2016, 171), is a term used in this dissertation to describe how specific purposes are achieved, or 


\section{6 - Power Dynamics at Work}

not. Power dynamics, then, refers to the human-human and humanmachine interactions which produce particular effects, which may, or may not, contribute to specific purposes, and which hierarchise the relations among the interacting actants. For example, while the interaction between PER and VIN from extract 1 might have contributed to VIN's ability to work with a particular machine, and hence, to the foundry's productivity, it probably did not contribute to his job satisfaction. Furthermore, the hierarchical workplace relation that emerged through this interaction was complex and multidimensional, as argued above. Similarly, referring back to the example from Latour (1992), an interaction between a human and a car that makes it impossible to drive without wearing a seatbelt might contribute to the purpose of safety, while the hierarchical relation between the human and the car (who is 'steering' whom?) has multiple dimensions as well. Hence, to better understand the functioning of power dynamics in the metal foundry, and to discuss how these dynamics did (not) contribute to certain purposes, this dissertation addresses the following research question:

How do power dynamics emerge in a contemporary multilingual blue-collar work environment in a cross-border region?

Through its detailed study of daily and nightly work interactions in a blue-collar work environment, the dissertation adds to existing linguisticethnographic studies of power dynamics and language in the workplace, as studies of blue-collar life-worlds are still relatively uncommon. Its discussion of the perspective of 'local' majoritised blue-collar workers like $P E R$, and its posthumanist perspective on the interactional role of machines are two more innovative elements, which have rarely appeared in linguistic ethnographies to date. One additional innovation can be found in its critical yet constructive discussion of the findings. As the still ongoing COVID-19 pandemic has underlined, many blue-collar jobs are crucial, and many are done by first-generation migrant workers such as VIN. In a region like the Dutch province of Limburg, where the population is not expected to grow significantly anymore, or even to shrink (Statistics Netherlands 2020b), these migrant workers can be an important asset for the economy and society. Hence, arguably, it is not only in the interests of the migrant workers themselves, but also in the interests of 'local' workers like PER, and 
of different companies and society at large, to develop a better understanding of power dynamics and their effects, and to discuss how they may become a force for the good, so that 'local' and migrant workers both feel happy to take on a blue-collar job and stay in this region, thereby contributing to the sustainability of its economy and society.

The empirical data of the dissertation have been gathered primarily between 3 July and 15 October 2017, when I worked as a participantobserver in the metal foundry. As a typical example of a blue-collar workplace (see next section), many workers in the foundry had temporary contracts and diverse language backgrounds. The dimension of language diversity was further amplified through the foundry's location in a border area (see also Franziskus, De Bres, and Gilles 2013; Franziskus and Gilles 2012). At the time of my fieldwork, the foundry had around 500 workers. Most of them (around 70\%; table 1) worked in one of its four production departments, which were: the Core Shooting Department (where sand cores were produced to mould metal); the Melting Department (where the metal was melted); the Casting Department (where the molten metal was moulded using the sand cores); and the Finishing Department (where the metal products, after hardening, were sawn, ground, blasted, welded, and quality-checked, among other actions; see also extract 1). Table 1 shows the number of permanent and temporary workers in each department in August 2017, divided by citizenship. 


\begin{tabular}{|c|c|c|c|c|c|c|}
\hline & $\begin{array}{l}\text { Core } \\
\text { Shooting }\end{array}$ & Melting & Casting & Finishing & $\begin{array}{l}\text { Non- } \\
\text { production }\end{array}$ & Total \\
\hline Dutch & $\begin{array}{l}48(55 \%) \\
28 \text { perm } \\
20 \text { temp }\end{array}$ & $\begin{array}{l}18(69 \%) \\
15 \text { perm } \\
3 \text { temp }\end{array}$ & $\begin{array}{l}33 \text { (45\%) } \\
19 \text { perm } \\
14 \text { temp }\end{array}$ & $\begin{array}{l}72(48 \%) \\
46 \text { perm } \\
26 \text { temp }\end{array}$ & $\begin{array}{l}159(100 \%) \\
148 \text { perm } \\
11 \text { temp }\end{array}$ & $\begin{array}{l}330 \text { (67\%) } \\
256 \text { perm } \\
74 \text { temp }\end{array}$ \\
\hline German & $\begin{array}{l}17(20 \%) \\
4 \text { perm } \\
13 \text { temp }\end{array}$ & $\begin{array}{l}7(27 \%) \\
4 \text { perm } \\
3 \text { temp }\end{array}$ & $\begin{array}{l}27(37 \%) \\
19 \text { perm } \\
8 \text { temp }\end{array}$ & $\begin{array}{l}38(25 \%) \\
6 \text { perm } \\
32 \text { temp }\end{array}$ & $\begin{array}{l}0(0 \%) \\
0 \text { perm } \\
0 \text { temp }\end{array}$ & $\begin{array}{l}89(18 \%) \\
33 \text { perm } \\
56 \text { temp }\end{array}$ \\
\hline Polish & $\begin{array}{l}11(13 \%) \\
1 \text { perm } \\
10 \text { temp }\end{array}$ & $\begin{array}{l}0(0 \%) \\
0 \text { perm } \\
0 \text { temp }\end{array}$ & $\begin{array}{l}4(6 \%) \\
0 \text { perm } \\
4 \text { temp }\end{array}$ & $\begin{array}{l}16(11 \%) \\
0 \text { perm } \\
16 \text { temp }\end{array}$ & $\begin{array}{l}0(0 \%) \\
0 \text { perm } \\
0 \text { temp }\end{array}$ & $\begin{array}{l}31(6 \%) \\
1 \text { perm } \\
30 \text { temp }\end{array}$ \\
\hline Other & $\begin{array}{l}11(\mathbf{1 3} \%) \\
0 \text { perm } \\
11 \text { temp }\end{array}$ & $\begin{array}{l}1 \text { (4\%) } \\
1 \text { perm } \\
0 \text { temp }\end{array}$ & $\begin{array}{l}9(12 \%) \\
0 \text { perm } \\
9 \text { temp }\end{array}$ & $\begin{array}{l}24(16 \%) \\
8 \text { perm } \\
16 \text { temp }\end{array}$ & $\begin{array}{l}1(1 \%) \\
1 \text { perm } \\
0 \text { temp }\end{array}$ & $\begin{array}{l}46(9 \%) \\
10 \text { perm } \\
36 \text { temp }\end{array}$ \\
\hline Total & $\begin{array}{l}87(\mathbf{1 0 0 \% )}) \\
33 \text { perm } \\
54 \text { temp }\end{array}$ & $\begin{array}{l}26(100 \%) \\
20 \text { perm } \\
6 \text { temp }\end{array}$ & $\begin{array}{l}73(100 \%) \\
38 \text { perm } \\
35 \text { temp }\end{array}$ & $\begin{array}{l}150(100 \%) \\
60 \text { perm } \\
90 \text { temp }\end{array}$ & $\begin{array}{l}160(100 \%) \\
149 \text { perm } \\
11 \text { temp }\end{array}$ & $\begin{array}{l}496(100 \%) \\
300 \text { perm } \\
196 \text { temp }\end{array}$ \\
\hline
\end{tabular}

Table 1. The number of permanent (perm) and temporary (temp) workers in the foundry in August 2017, divided by department and citizenship. The category "non-production" includes, among others, Human Resource (HR) managers, Information Technology (IT) staff, and engineers. The categories "Dutch", "German", and "Polish" may include first-generation migrants who have obtained Dutch/German/Polish citizenship at some point in their life. ${ }^{1}$

During my fieldwork, I spent most of the time in the three largest departments (i.e., the Core Shooting, the Casting, and the Finishing Department). In the Core Shooting and the Finishing Department, people typically worked alone or in pairs with a particular machine. Many people in these two departments could speak Dutch, German, and/or Limburgish, but there also was a significant minority (including VIN) who could neither speak nor understand any of these varieties, and who often used English as a lingua franca with other workers (as in extract 1). In the Casting Department, people typically worked in groups at two different conveyor belts, and everyone I met there could speak at least Dutch or German. Overall, German appeared to be the most frequently spoken lingua franca

\footnotetext{
${ }^{1}$ The figures presented are the sum of the data about all agency workers in the foundry in August 2017, which I have received as an anonymised Microsoft Excel file from one of the agency's recruiters, and the data about the metal foundry's employees, which I have collected through email communication with an HR manager from the foundry. As the HR manager filled in some gaps in the data from August 2017 with data from 2018, minor differences might exist between the actual figures and the figures presented here.
} 
Introduction - 9

in the production departments. The use of English as a lingua franca was a relatively new phenomenon in the foundry, and many senior production workers (including PER) were not very comfortable with this communicative mode, which was very closely connected with the increased language diversity at work.

In the next section, I place this dissertation in the wider field of blue-collar workplace studies in linguistic ethnography. Afterwards, I discuss its theoretical, posthumanist approach to power and language. I then briefly introduce the Meuse-Rhine border area, where the metal foundry was located, before ending the chapter with a general overview of the remaining chapters of the dissertation.

\subsection{Linguistic ethnography and blue-collar workplaces}

The previous studies that I build upon in this dissertation carry diverse labels, including linguistic anthropology, (interactional) sociolinguistics, and linguistic ethnography. These academic fields overlap a lot, and the exact borders between them are unclear (Wilson 2018, 42-43). In general, they all share an interest in the relationship between language use and other social phenomena, so this dissertation may carry any of the mentioned labels. Yet, for the sake of consistency, and as both this dissertation and most previous work I discuss is based on ethnographic fieldwork, I have decided to use the label linguistic ethnography most of the time. Creese and Copland (2017, 340) define this field as "an interpretive approach which studies the local and immediate actions of actors from their point of view and considers how these interactions are embedded in wider social contexts and structures". Considering my aim to better understand local workplace (inter)actions and their effects (i.e., power dynamics), and considering the important role of participants' perspectives for the interpretation of my research findings (see previous section and further below), this definition matches the nature of my current work quite well.

More specifically, this dissertation can be situated in a gradually emerging and expanding field of research that is typically based on ethnographic fieldwork, and that is concerned with the use of language in blue-collar work environments (Lønsmann and Kraft 2017). I am aware that the use of blue-collar as an umbrella term for this field has been problematised (Gonçalves and Kelly-Holmes 2021; Pennycook 2021), and not every linguistic-ethnographic study that may be categorised as part of 
the field uses it (e.g., Kleifgen 2013). The term probably originates from the United States, where references to (stereo)typical colours of work uniforms have been commonly used to distinguish, among others, white-collar office workers and blue-collar manual workers (Gibson and Papa 2000, 68; Wickman 2012). One problem that has been addressed in relation to such distinctions is that they are etic (i.e., made by observers) rather than emic (i.e., made by the observed workers themselves; Gonçalves and KellyHolmes 2021, 12). Another problem is that the term blue-collar often comes with connotations of being "unskilled" (Gonçalves and Kelly-Holmes 2021, 2), an ideology that can be used to legitimise workers' exploitation. In addition, the term often comes with connotations of "masculinity" (Gonçalves and Kelly-Holmes 2021, 2; Pennycook 2021, 228-229), an ideology that overlooks female blue-collar workers (see, e.g., Goldstein 1997; Gonçalves and Schluter 2017).

Nonetheless, most researchers, including the critics mentioned above, are still using the term blue-collar today. Alternative terms, such as working class, or proletariat and precariat (Standing 2011), do not solve the abovementioned issues. Furthermore, despite the associated problems, the established term blue-collar has been useful for researchers in the sense that it fulfils an apparent need to compare perspectives from different work environments that may not share one or several defining core characteristics, but that do share a particular "family resemblance" (Wittgenstein 1999). Hence, Lønsmann and Kraft $(2017,138)$ define bluecollar workers rather loosely as "labourers in the primary or secondary sectors, whose job is often, but not always, temporary, and low-status". Other characteristics that often apply to blue-collar work may still be added to this definition, such as physically demanding (Gibson and Papa 2000,68), and perhaps even "language poor", in case "language" is understood in a narrow, typically verbal sense (Pennycook 2021, 231-232). Besides that, as temporary, low-status, physically demanding, and "language poor" work can be found outside of the primary sector (e.g., agriculture) and the secondary sector (e.g., manufacturing) as well, the definition may have to become even broader. Indeed, several linguistic-ethnographic studies that have used the label blue-collar focus on work environments outside of these sectors, especially cleaning companies (Gonçalves and Schluter 2017; Holm, O’Rourke, and Danson 2020; Strömmer 2021).

In general, linguistic-ethnographic studies of blue-collar work environments discuss how language, as a resource, is used to make social distinctions between people at work. In this way, they differ from 
traditional variationist-sociolinguistic studies, which have related specific linguistic features to broad, predefined (i.e., etic) social categories such as working class (e.g., Labov 1972). Rather, their focus on emic social distinctions is often related to language diversity (e.g., Goldstein 1997; Piller and Lising 2014; Sunaoshi 2005). Furthermore, their approaches to language and social distinctions often draw on one of the following three concepts or legacies: firstly, linguistic capital (Bourdieu 1991), a languagepolitical construct that provides concrete benefits to speakers of certain language varieties, and not to others (e.g., Duchêne 2011; Holm, O'Rourke, and Danson 2020; Kraft 2019); secondly, community of practice (Eckert and McConnell-Ginet 1992; Lave and Wenger 1991; Wenger 1998), a socialcultural construct that makes a relative distinction between people based on how much they become part of a particular in-group, if at all (e.g., Gherardi and Nicolini 2002; Holmes and Woodhams 2013; Theodoropoulou 2020); and thirdly, the discursive, interactional construction of interpersonal relations, sometimes referred to as face (Arundale 2020; Brown and Levinson 1987; Goffman 1967), through which people may (re)produce certain hierarchical workplace relations, such as those between a manager and a subordinate (e.g., Handford and Matous 2015; Holmes and Stubbe 2015; Kleifgen 2013).

This dissertation builds upon the three abovementioned theoretical legacies as well, even though its ontological starting point is somewhat different due to the applied posthumanist perspective. Thus, although the dissertation can be broadly situated in a field of linguistic-ethnographic studies of blue-collar work environments, it also differs from these studies with regard to some of its theoretical positions. In the next section, I discuss these positions in more detail.

\subsection{A posthumanist approach to power and language}

Posthumanism is another broad umbrella term. It encompasses a family of theoretical and methodological approaches, such as actor-network theory (Latour 2005) and new materialism (Bennett 2010), which all share a concern for decentring the human subject or agent (i.e., anthropocentrism) in the humanities and the social sciences (Pennycook 2018, 10). Thus, similar to postcolonialism, the prefix "post" in "posthumanism" may be interpreted in a programmatic rather than a descriptive sense. After all, the idea is not that we have come to live in a posthumanist world (whatever 


\section{2 - Power Dynamics at Work}

that may be), but that it is valuable to experiment with other than humancentred approaches. Authors often mention 'green' or environmental arguments for this point, such as concerns about climate change (e.g., Fox and Alldred 2020), animal welfare (e.g., Cornips 2019), or the COVID-19 pandemic (e.g, laon 2020). This dissertation has less of an environmentalist appeal, even though industrial workplaces such as the metal foundry produce a significant carbon footprint. Instead, as a basic starting point, it considers what a posthumanist approach to power and language can bring us, linguistic ethnographers, in terms of insights about our research proceedings and data.

The previously mentioned definition of power that I use in this dissertation, "acting with effect" (Watson 2016, 171), is not exclusively posthumanist. In fact, the definition is taken from a text that is concerned with the concept power in practice theory, a field that includes both posthumanist and other approaches. What makes posthumanist approaches typically stand apart, however, is their understanding of agency, or "the capacity to act with effect" (Watson 2016, 170). Essentially, the claim is that not only humans, but also non-humans (such as dogs, trees, screwdrivers, and stones) have this capacity, although this typically requires that different human and non-human actants temporarily associate with each other, like a chain or a network (Latour 1986; Latour 2005, 71-72). To take the screwdriver as an example: this tool has the capacity to install and remove certain screws (e.g., slotted drives). However, it cannot install or remove every single kind of screw (e.g., cruciform drives). Thus, as an affordance (Gibson 2015), a screwdriver enables particular human beings (excluding new-born babies, people without fingers, etc.) to install or remove particular kinds of screws. Together, as a temporary chain, network, or assemblage (Bennett 2010; Deleuze and Guattari 1980; Latour 2005), a particular human being and a screwdriver have "the capacity to act with effect" with regard to installing or removing certain screws. The human actant or the screwdriver-actant considered alone would not have this capacity. And once they form such a chain, network, or assemblage and "act with effect", they exercise (or, to use a theoretically more consistent phrasing, 'do') power.

Structure, in a typical posthumanist approach such as actor-network theory, is basically just a very large assemblage of human and non-human actants (Latour 2005, 178). Hence, an important theoretical position is that a particular structure (such as neoliberalism or racism) cannot be used to explain anything, but that it is the structure itself that needs to be explained 
by exploring how and why diverse human and non-human actants produce it (Latour 1986). Through their 'local' agency, they each have the capacity to affect the structure in some way. For example, with regard to the structural phenomenon of mechanisation (i.e., the delegation of work tasks from humans to machines), many different actants are involved: governments, companies, or universities may invest in technological innovations; company directors, entrepreneurs, or shareholders may invest in the mechanisation of particular workplaces; different kinds of machines may be developed easily and work flawlessly (from the company's perspective) once they are put in these places; and different employees may be both willing and capable to work with these machines. In case any one of these actants does not 'cooperate', however, the structural phenomenon of mechanisation might not emerge at all, or it will at least look (very) different from what it would have looked like in an alternative scenario. Thus, structure should not be understood in a fixed and stable sense, but rather, indeed, as a continuously emerging, organic assemblage (Bennett 2010, 23-24).

The discussed posthumanist positions have consequences for the conceptualisation of language as well. Essentially, a posthumanist approach to language requires that human actants are decentred as the sole contributors to processes of semiosis or meaning-making (Canagarajah 2018; Pennycook 2018). More specifically, the use of language is conceptualised as taking place in a particular space, in which diverse nonhuman actants (including space itself) also participate in the ongoing interactions and contribute to the meanings that emerge there. Meaning, in this case, can be understood as indexicality (Agha 2003), or perhaps even in a somewhat functionalist sense, that is, as the way that something or someone functions in practice (see, e.g., Redder 2008). For example, a screwdriver, as a non-human actant, enables a use as an installer or remover of particular screws by particular human actants, and this might indeed be the meaning that it acquires in practice. At the same time, however, the screwdriver also enables other kinds of use or meaning, such as the use of the screwdriver as a weapon to hurt someone. Which exact meaning a screwdriver acquires in the end is the situated, temporary, and emergent outcome of the interactions between diverse human actants (who might make use of memories from past experiences) and non-human actants, each with particular affordances for use or meaning, and the same goes for verbal resources such as the word "screwdriver". 
14 - Power Dynamics at Work

In the end, all the human and non-human contributors to such meaning-making processes can be said to constitute a semiotic assemblage (Pennycook 2018, 54-55) or a spatial repertoire (Canagarajah 2018; Pennycook 2018, 47-51). A disputable question is whether language as a concept should be defined as being equal to semiotic assemblages or spatial repertoires (i.e., language in a broader, expanded sense; Cornips and Van den Hengel 2021), or whether it should rather be considered a specific subcategory of these broader semiotic concepts (i.e., language in a narrower, typically verbal sense; Canagarajah 2018; Pennycook 2018, 51). In line with the generally emic approach of my dissertation, I have decided to use the term language in the narrower sense most of the time, and where I do use language in a broader sense (typically, in relation to machines), I have decided to use single quotation marks ('language') to acknowledge this unconventional, etic usage. After all, my primary aim of this dissertation is not to discuss how we should conceptualise language, but to discuss how the social-cultural practices that we conventionally think of as language or discourse are just one out of several kinds of 'forces' within the ongoing power dynamics in the workplace. In this way, the dissertation adds to previous linguistic-ethnographic studies about the use of language as a resource in blue-collar workplaces, as it aims to broaden this established perspective by pointing out that there are more actants than human beings, and more forces than discourse alone, which, regardless of any possibly involved intentionality, all affect the ongoing power dynamics at work.

\subsection{Power and language in the Meuse-Rhine border area}

In this section, I briefly introduce the Meuse-Rhine border area, where the metal foundry is located. Since the history of this border area is extensively discussed in chapter 3 of this dissertation, I focus primarily on the present situation here.

In line with the discussed posthumanist approach to power and language, the Meuse-Rhine border area can be conceptualised as one or several assemblages, which give rise to something that may be termed language policy. Furthermore, to accommodate relevant historical dimensions, these assemblages could be thought of as broad scales that stretch over time (Canagarajah 2018, 46). As I discuss from a somewhat different perspective in chapter 3 , however, I have found it more helpful to 
imagine the border area as a landscape (Brambilla 2015). One reason for this is that, as opposed to the somewhat abstract image of a scale, a landscape can be vividly imagined with layers, paths, fossils, buildings, and other traces from human and non-human history. Another reason is that the term landscape enables the construction of a derived verb, landscaping, which vividly captures how someone who may be interested in affecting language practices in a particular landscape can face all kinds of obstacles which have emerged historically, and which, as human or non-human actants, resist change. These two images are quite applicable when discussing the sociolinguistic situatedness of the Meuse-Rhine border area today, as I further show below.

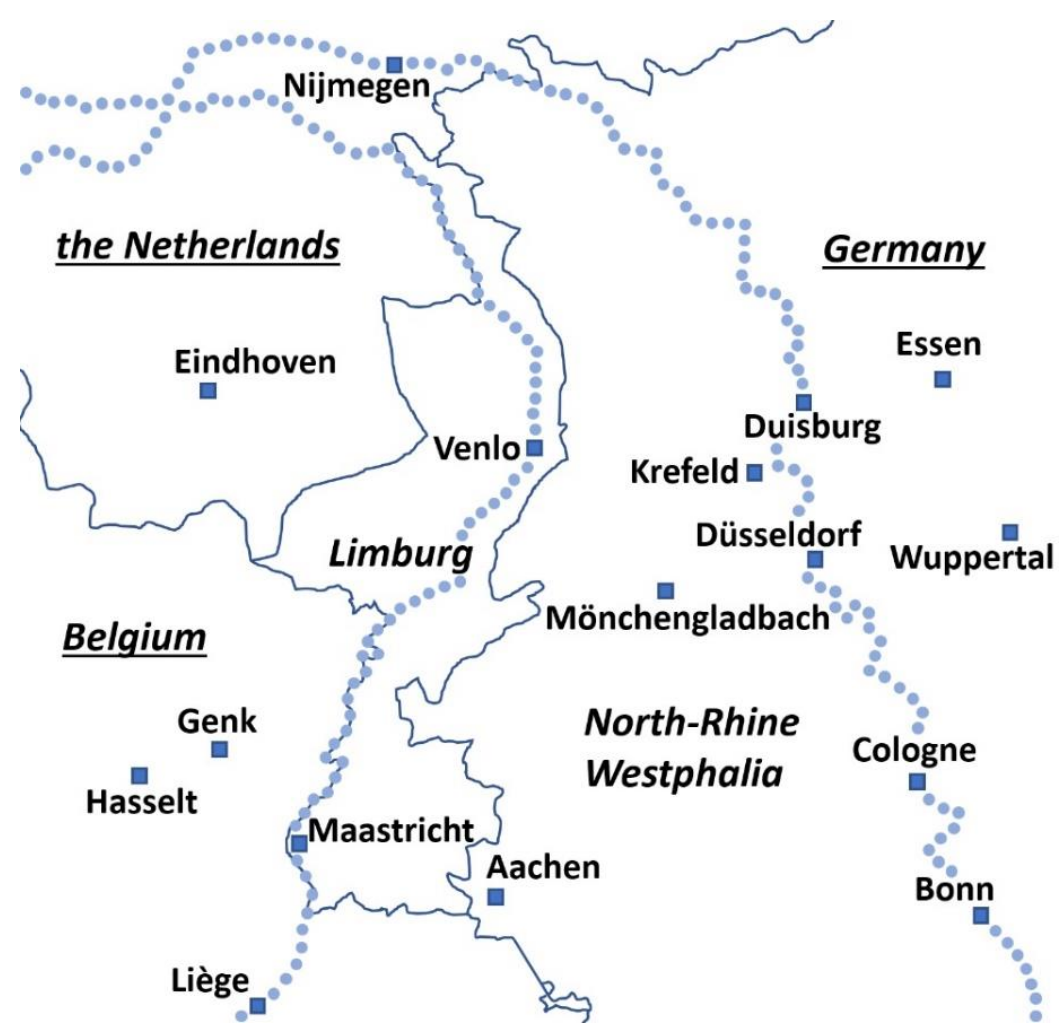

Figure 1. Map showing the Meuse-Rhine border area. The dotted line on the left represents the Meuse river flowing through the Dutch province of Limburg. The dotted line on the right represents the Rhine river flowing through the German state North-Rhine Westphalia (map created by author). 
16 - Power Dynamics at Work

The Meuse-Rhine border area in this dissertation roughly refers to the Dutch province of Limburg and the German Rhine-Ruhr metropolitan region (which is part of the German state North Rhine-Westphalia; figure 1). The metal foundry that I focus on is located in the northern part of Limburg, within walking distance of the Dutch-German border (about 2.5 kilometres away). During my fieldwork in 2017, many workers from the foundry lived in Germany, while no one lived in Belgium (the Dutch-Belgian border being about 30 kilometres away). Moreover, I observed many people speaking German in the foundry, while I did not observe anyone speaking (a variety of) Belgian-Dutch, Flemish, French, or Walloon. Therefore, even though the Meuse-Rhine border area clearly includes a part of Belgium as well, I focus exclusively on the Dutch-German part in this dissertation.

Today, there are two formal cross-border regions, or Euroregions, in the Meuse-Rhine border area: the Euroregion Meuse-Rhine and the Euroregion Rhine-Meuse-North. Euroregions have been defined as "formalized cooperation initiatives between sub-national authorities, often including private and non-profit actors located close to a border in two or more countries" (Svensson and Nordlund 2015, 372). They are typically allied with larger political-economic projects that aim to establish a crossborder labour market, with people living on one and working on the other side of a national border, which would supposedly boost border-regional economies (see, e.g., Actieteam Grensoverschrijdende Economie en Arbeid 2017). The research institute from Maastricht University that finances my PhD project, the so-called "Institute for Transnational and Euroregional cross-border cooperation and Mobility" (ITEM), can be considered an ally of such broader projects as well. Despite years of policy stimulation, however, cross-border commuting is still quite a rare phenomenon in Europe (see, e.g., Eurostat 2018; Van Houtum and Van der Velde 2004), and the same applies to the Meuse-Rhine border area (Statistics Netherlands 2021). Hence, it is clear that Euroregions do not simply 'have' power, and that many (potential) actants in a cross-border assemblage or landscape need to cooperate for a cross-border labour market to emerge.

One obstacle for cross-border commuting that is often mentioned, among others, is national language differences (see, e.g., Actieteam Grensoverschrijdende Economie en Arbeid 2017, 34). Such differences can be considered as effects produced by entire national assemblages or 
(linguistic) landscapes. After all, it is not a given that, say, people in the Netherlands speak Dutch, and people in Germany German. A whole range of actants needs to cooperate to make this happen, which may include language laws, lawmakers, law enforcers, citizens, teachers, school textbooks, printing technologies, media outlets, public signs, priests, bibles, etcetera (see, e.g., Jacobs 2008; Johnson 2013). Ironically, before such nation-state assemblages or national-linguistic landscapes emerged, crossborder communication in the Meuse-Rhine border area appears to have been relatively easy, as people in the area typically spoke mutually intelligible local language varieties (see Cornelissen 2015; Giesbers 2008), which are known as "Limburgish" in the Dutch province of Limburg today (Cornips 2013). Over time, however, traditional local varieties from the Dutch and the German part of the border area diverged linguistically from each other, and in most places in the German part, they have become nearly extinct (Cornelissen 2008; Cornelissen 2015; Giesbers 2008). Thus, when Euroregional and other actants take measures in an attempt to facilitate cross-border communication in the Meuse-Rhine border area, they try to (partly) overcome the (socio)linguistic divisions that have emerged in this border landscape over time.

Euroregions have been often referred to as "laboratories of European integration" (see, e.g., Knippenberg 2004). Considering the general insignificance of cross-border labour commuting in Euroregions, however, it may be more enlightening to look more closely for specific laboratories out there. The metal foundry that I focus on in this dissertation could in fact be considered one such laboratory. Not only did a significant number of workers that I met in the foundry in 2017 live across the border in Germany, a significant number even originated from other European Union (EU) member states such as Poland, as well as non-EU countries such as Syria. Hence, if all these workers managed to deal with potential (socio)linguistic obstacles, and if they (together with relevant tools, machines, and other actants) managed to produce economically valuable goods, then one might conclude that it should be possible for similarly 'successful' assemblages to emerge elsewhere in the EU (and beyond) as well. An additional argument for this point is that the metal foundry can be considered a critical case due to the absence of a lingua franca that every single worker in the foundry could understand, and due to the temporary nature, or transience (Haberland and Mortensen 2019; Mortensen 2017), of many interpersonal relations in this work environment, which gave people less time to deal with potential (socio)linguistic obstacles. In other words, if 
diverse actants in this particular work environment managed to deal with these potential (socio)linguistic obstacles, then actants in arguably less challenging (work) environments should be able to do so as well.

Finally, as a comparison, it can be valuable to look at workplace 'laboratories' in Luxembourg, an officially trilingual (French-GermanLuxembourgish) microstate that receives by far the largest number of crossborder labour commuters in Europe (Decoville et al. 2013). Partly for this reason, workplaces in Luxembourg have caught some attention from linguistic ethnographers, specifically a supermarket and an Information Technology (IT) company (Franziskus 2016; Franziskus, De Bres, and Gilles 2013; Franziskus and Gilles 2012). In general, Horner and Weber (2008) have observed that the increasing presence of German-speaking and, particularly, French-speaking cross-border commuters in Luxembourg has been accompanied with an increased use of, primarily, French as a lingua franca at work, which has given rise to ideas of the Luxembourgish language, a marker of national identity, being under threat. The previously mentioned linguistic-ethnographic studies present a somewhat more nuanced and complex picture, with different communicative modes, such as receptive multilingualism (Ten Thije and Zeevaert 2007), being used, and different language-ideological stances being taken. An interesting example is how a German-speaking cross-border worker in a supermarket used Luxembourgish routine and formulaic phrases to foster good interpersonal relations with a Luxembourgish-speaking colleague (Franziskus, De Bres, and Gilles 2013, 261-264). In this way, the study also confirmed the idea that people do not always have to be able to speak an 'entire' language at work, neither for transactional, nor for social or relational purposes.

\subsection{Dissertation outline}

To recap, this dissertation addresses the question of how power dynamics emerged in a contemporary multilingual blue-collar work environment in a cross-border region, specifically a metal foundry in the Dutch province of Limburg, in the Dutch-German borderland. It applies a posthumanist perspective on power and language, which entails a decentring of human actants and discourse as the sole contributors to power dynamics. Apart from this theoretically innovative element, the dissertation adds to existing insights by discussing the perspective of both majoritised and minoritised speakers, while reflecting upon the idea that the foundry may be 
considered a 'laboratory' for European integration, or more precisely a critical case for the ability of often-temporary majoritised and minoritised speakers, in addition to machines, to deal with possible social and/or linguistic obstacles at work and to constitute a productive work assemblage. Ultimately, the dissertation not only aims to achieve a better understanding of emerging power dynamics in this way, but also to discuss how power dynamics may become a (more) positive force, contributing to relevant purposes such as productivity, workplace safety, and job satisfaction, as well as to the overall sustainability of a given economy and society.

To accommodate its broad range of perspectives from different participants and academic theories, the dissertation has an explorative outline, with an empirical core consisting of one methodological chapter (chapter 2) and three journal articles (chapters 3-5). The starting concept of a chapter is typically one that I began my fieldwork with, particularly community of practice (Eckert and McConnell-Ginet 1992; Lave and Wenger 1991; Wenger 1998) and linguistic landscape (Landry and Bourhis 1997). While I have not abandoned these concepts and still find them useful for the purpose of describing power dynamics, I have simultaneously expanded their possible meanings by relating them to a posthumanist vocabulary, especially the concepts affordance (Gibson 2015), spatial repertoire (Canagarajah 2018; Pennycook and Otsuji 2015; Pennycook 2018), and assemblage (Bennett 2010; Deleuze and Guattari 1980; Latour 2005), and by exploring the potential of the linguistic landscape concept in a more metaphorical sense (partly inspired by Brambilla 2015). When it comes to scale, the first two empirical chapters focus on the metal foundry in general, while the other two focus on specific micro-interactions. Furthermore, while chapters 2 and 3 primarily feature Limburgish-speaking workers, the main participant of chapter 4 is an English-speaking migrant worker from Poland (VIN), and the main participants of chapter 5 are German-speaking cross-border commuters from Germany. Table 2 presents an overview of the different chapters, and the different elements that readers can expect to find in them.

Finally, I would like to credit the previous linguistic-ethnographic works from Goldstein (1997) and Kleifgen (2013) for having inspired the general title of this dissertation. While Goldstein's work is called Two Languages at Work, and Kleifgen's work is called Communicative Practices at Work, I have decided to continue their tradition by similarly using the phrase "at work" (with its multiple meanings of "being in a workplace", 


\section{0 - Power Dynamics at Work}

"actively working", and "having effects") in the title Power Dynamics at Work. I hope this dissertation does justice to the legacy that these authors have started.

\begin{tabular}{|c|c|c|c|c|}
\hline \multicolumn{5}{|c|}{ Power dynamics at work } \\
\hline & Chapter 2 & Chapter 3 & Chapter 4 & Chapter 5 \\
\hline Department & $\begin{array}{l}\text { All } \\
\text { departments }\end{array}$ & $\begin{array}{l}\text { All } \\
\text { departments }\end{array}$ & $\begin{array}{l}\text { Finishing } \\
\text { Department }\end{array}$ & $\begin{array}{l}\text { Core Shooting } \\
\text { \& Casting } \\
\text { Department }\end{array}$ \\
\hline $\begin{array}{l}\text { Primarily } \\
\text { used } \\
\text { fieldwork } \\
\text { data }\end{array}$ & $\begin{array}{l}\text { Fieldnotes \& } \\
\text { documents }\end{array}$ & $\begin{array}{l}\text { Interviews \& } \\
\text { documents }\end{array}$ & $\begin{array}{l}\text { Audio } \\
\text { recording \& } \\
\text { photographs }\end{array}$ & $\begin{array}{l}\text { Audio \& video } \\
\text { recordings }\end{array}$ \\
\hline $\begin{array}{l}\text { Primarily } \\
\text { featured } \\
\text { language }\end{array}$ & Limburgish & Limburgish & English & German \\
\hline $\begin{array}{l}\text { Starting } \\
\text { concept(s) }\end{array}$ & Positionality & $\begin{array}{l}\text { Linguistic } \\
\text { landscape \& } \\
\text { language } \\
\text { policy }\end{array}$ & $\begin{array}{l}\text { Community of } \\
\text { practice }\end{array}$ & $\begin{array}{l}\text { Community of } \\
\text { practice \& } \\
\text { power }\end{array}$ \\
\hline $\begin{array}{l}\text { Posthumanist } \\
\text { concept(s) }\end{array}$ & $\begin{array}{l}\text { Affordance \& } \\
\text { emplacement }\end{array}$ & Assemblage & $\begin{array}{l}\text { Affordance \& } \\
\text { spatial } \\
\text { repertoire }\end{array}$ & Assemblage \\
\hline $\begin{array}{l}\text { Published in } \\
\text { journal }\end{array}$ & $\begin{array}{l}\text { Unpublished } \\
\text { dissertation } \\
\text { chapter }\end{array}$ & $\begin{array}{l}\text { Language } \\
\text { Policy }\end{array}$ & $\begin{array}{l}\text { Journal of } \\
\text { Linguistic } \\
\text { Anthropology }\end{array}$ & $\begin{array}{l}\text { Submitted to } \\
\text { peer-reviewed } \\
\text { journal }\end{array}$ \\
\hline
\end{tabular}

Table 2. Overview of the dissertation chapters 
Methodological Reflections - 21

\section{Methodological Reflections}

\subsection{Introduction}

This chapter reflects on the research process that led to my dissertation. More specifically, it discusses how I gained access to specific data, and why I made certain methodological, theoretical, and ethical choices before, during, and after this data collection period. As part of this discussion, I particularly reflect upon my positionings as a researcher, and the relation between these positionings and the choices I have made.

Positionality has been defined as "the stance or positioning of the researcher in relation to the social and political context of the study-the community, the organization or the participant group" (Coghlan and Brydon-Miller 2014, 627). Ethnographers who reflect about their positionalities often highlight the impact of (combinations of) broad social identity categories such as age, class, ethnicity, gender, race, and sexuality on their research processes and findings. Bell $(1999,30)$, for example, has pointed out how she as a female researcher did not seem to get access to certain 'masculine' discursive practices (such as swearing) in specific maledominated, industrial work contexts. Somewhat similarly, Hawkins (2010, 254) has observed how white interviewees (unlike black interviewees) seemed to withhold their ideas about race and racism to him (a black researcher). In a regional minority language area such as the Dutch province of Limburg, someone's (perceived) race or ethnicity might also impact how easily people start speaking the regional minority language (in this case, Limburgish) with this person (Cornips 2020a). With regard to sexuality, La Pastina $(2006,732)$ decided to lie about his gay identity to his research participants to avoid this identity influencing their behaviour (and, thus, his data) in a way that he considered undesirable.

Apart from these broad social identity categories, other researcher positionalities have been highlighted as well. A classic example is how much an ethnographer can or decides to get involved in any studied practices, which may range from "non-participation" to "complete participation" (Spradley 1980, 58). Concerning such distinctions, a typical point of reflection is that it may be more challenging for 'complete participants' to notice the "tacit cultural rules at work" (Spradley 1980, 62). Furthermore, Lønsmann's (2016) has reflected on the question how the acts of variably positioning herself as an independent researcher, a consultant, and a (PhD) 


\section{2 - Power Dynamics at Work}

student, among others, influenced which people and workplaces (i.e., which data) she got access to as an ethnographer. Although such positionalities may appear to be more situated, emergent, and negotiable than seemingly stable social identity categories like gender and race, several authors have underlined that the relevance of these 'stable' identities also varies from one situation to another, and that their exact meanings are not fixed but fluid (e.g., Bell 1999, 32; Hawkins 2010, 255; Lønsmann 2016, 28-29). Thus, in all cases, identity appears to be a transient outcome of a complex, situated interaction between the researcher and various other 'forces' at work.

An open question is how and why particular identities or positionalities become relevant in particular situations, or become imbued with specific transient, situated meanings (see also Mortensen 2017). A useful concept for approaching this question is affordance, which was coined by Gibson in the field of ecological psychology in 1979 (see Gibson 2015). Following this author, an affordance is something that an environment "offers", "provides", or "furnishes" for a specific animal (Gibson 2015, 119). For the purpose of this chapter, the animal is the ethnographic researcher, whose capabilities to construct certain identities or positionalities may be simultaneously enriched and constrained by specific elements in the surrounding environment. For example, if I come across a written document that I am able to read, this might provide me an opportunity to make myself stand out as a language expert in a specific environment. Similarly, as discussed above, specific features of my body (such as my skin colour) can also be considered affordances, which at least encourage the construction of certain identities or positionalities, while discouraging others. Thus, which identities or positionalities become relevant in a specific situation, and which exact meanings they become imbued with, can be considered a temporary result from emerging interactions between diverse elements of both me and my environment.

One additional useful concept is emplacement, which has previously been used in the field of rhetoric (Pigg 2014; Rickert 2013), and which has recently been adopted in the field of applied linguistics by Canagarajah (2018) as an alternative way to imagine linguistic competence. Specifically, Canagarajah $(2018,50)$ has pointed out how this concept "accommodates a qualified human agency, while it gives spatial resources and semiotic repertoires considerable significance in meaning construction". For the purpose of this chapter, the concept emplacement enables me to capture the temporary results from the interacting forces 
(i.e., both my individual choices and the other forces at work) that together emplaced me as a researcher. In other words, the concept strikes a nice balance between my individual agency as a researcher, the opportunities and constraints that I faced in this respect (i.e., the relevant affordances), and the other agentive forces that 'emplaced' me. Following this line of thought, I define positionality as emplacement. Thus, in this chapter, I reflect on the individual choices and the other forces behind my emplacements as a researcher, the effects of these emplacements on the research data I was able to gather, and the ethical considerations I have had in these respects.

The first-person narrative of this chapter follows a more or less chronological order and, as a somewhat innovative element, the narrated time stretches beyond the data-collecting period alone. In the next two sections, I first discuss my general motivations for doing what has become a linguistic-ethnographic study of workplace interactions in a metal foundry in the Dutch province of Limburg, near the Dutch-German border. In the three sections that follow, I discuss how I managed to get access to the metal foundry for my fieldwork, how I (partly) managed to get access to production work practices in the foundry during my fieldwork, and how I (partly) managed to get access to workplace discourse and informed consent. Afterwards, I discuss the process of reaching academic and professional audiences for my research, before ending with a general conclusion and discussion section.

\subsection{Getting access to a PhD position}

In August 2016, I decided to apply for a PhD position at Maastricht University. In the Netherlands, PhD candidates are typically treated as employees rather than students. The vacancy stated that I would have to conduct linguistic-ethnographic fieldwork in a workplace with cross-border workers, somewhere near the border between the Dutch province of Limburg and the German state North Rhine-Westphalia (i.e., the MeuseRhine border area). One thing that attracted me about this vacancy was the geographical setting. I had lived in Limburg during the first eighteen years of my life (1988-2006), and I had still regularly visited and stayed in Limburg since 2006. My first language even was a local variety of "Limburgish", a name used to refer to local West Germanic language varieties traditionally spoken in Limburg. Together, Limburgish varieties have acquired a political 


\section{4 - Power Dynamics at Work}

status as a regional minority language, but they have no standard variety, and they are commonly referred to as "dialects" (see Cornips 2013). My proficiency in one such variety probably also contributed to my emplacement as a suitable candidate for the advertised position. By testing my Limburgish communication skills during my job interview (which was otherwise conducted in standard Dutch), my then-potential supervisors even gave me an opportunity to position myself in this way, as no formal, widely used certificates or qualifications to prove such skills existed.

My interest in the PhD position was not only based on an identification with 'Limburgishness', however. While looking back at my early life experiences during my master's studies in Euroculture (i.e., European studies with a focus on social-cultural issues) at the Universities of Göttingen (Germany), Uppsala (Sweden), and Osaka (Japan), I had become fascinated by the strong impact that Dutch and German nationstate integration processes had had in the Meuse-Rhine border area over the course of just a few generations. At least up until World War II, most people in this area could use mutually intelligible, local language varieties when speaking with each other, but as many of these varieties had become nearly extinct on the German side of the border (Cornelissen 2008), this was no longer possible when I grew up there. Parallel to this development, personal cross-border contacts had decreased as well (Giesbers 2008). As a consequence, even though I had lived, gone to schools, gone to pubs, and had part-time jobs within walking distance of the Dutch-German border, I had never really got to know anyone who lived 'on the other side' during the first eighteen years of my life. Apart from a few people with a German migrant background in my school, 'Germans' had mostly been a rather faceless group of people to me, who often came shopping in the (Limburgish) city of Venlo during weekends and (German) holidays. Thus, although the Dutch-German border had been open for goods, services, people, and capital in many ways, it used to be very much 'closed' in my daily life and mind (see also Strüver 2005).

The 'closedness' of national borders in the Meuse-Rhine border area was a primary area of concern of the research institute that was going to finance the advertised PhD position as well. This institute was ITEM, the "Institute for Transnational and Euroregional cross-border cooperation and Mobility", which itself was financed primarily by Maastricht University and the Dutch province of Limburg, and partly also by the city of Maastricht and the Euroregion Meuse-Rhine (ITEM 2018). In its self-presentations, ITEM typically stresses how the institute "solves problems", "tackles 
bottlenecks", and "reduces barriers" with regard to cross-border cooperation and mobility in the Meuse-Rhine border area and beyond (see, e.g., ITEM 2018). Hence, it was clear that the PhD researcher was expected to produce some sort of impact for the Euroregional labour market, for example by sharing tips about how to overcome possible language barriers at work. As I generally believed in the idea that more cross-border cooperation and mobility would be positive for the economic development and societal vibrancy of Limburg, a vision possibly influenced by my international studying experiences, this all sounded good to me.

A new and slightly frightening aspect of the advertised $\mathrm{PhD}$ position for me was the ethnographic fieldwork that I would be expected to do. During my previous studies, I had mostly been used to analysing written language (e.g., through a content or discourse analysis), which I could comfortably do from home. Admittedly, for my master's thesis in Euroculture, I had executed survey research as well, which involved approaching and visiting two secondary schools in the Meuse-Rhine border area (Hovens 2012). Moreover, during my second master's studies in Journalism at the University of Groningen (the Netherlands), and during my brief career as an online journalist and web editor in 2015 and 2016, I had become used to approaching different kinds of people and institutions. While applying for the PhD position, these previous experiences provided means to position myself as a suitable candidate despite lacking familiarity with ethnographic fieldwork, and I clearly tried to use them as such. Nonetheless, to spend a longer period of time in one particular institution (in this case, a workplace), and to audio- and video-record communication practices there represented a new level of entering people's daily lives and thoughts to me, and I was not sure how I would go find, approach, and convince potential participants to cooperate with me on such a seemingly 'intrusive' project. In the next sections, I discuss how I dealt with this challenge after my application turned out to be successful.

\subsection{Getting access to cross-border data}

I officially started with my PhD project in January 2017. In general, my supervisors left me free to find my own way through this project, while ITEM entrusted all research-related instructions to them. There was one thing that my supervisors were absolutely clear about when I started, however: I had to find a workplace to execute my linguistic-ethnographic 


\section{6 - Power Dynamics at Work}

fieldwork as soon as possible. Hence, one of the first questions I faced was where to find a workplace with cross-border workers.

As Statistics Netherlands (Dutch: CBS) had no available data about cross-border workers yet at that stage, I had to rely on other means to answer this question. One such means was to consider my personal experiences. As discussed in the previous section, I never really got to know any person who lived on the other side of the Dutch-German border during the first eighteen years of my life. The two main part-time jobs that I had as a teenager were kitchen assistant in a retirement home, and baking assistant in a bakery. In both workplaces, I had never come across any cross-border workers. In 2013, however, I briefly had two part-time jobs in Limburg again. These provided some additional experiences for consideration, which later proved useful for other purposes as well (see sections 2.4 and 2.5). The first was a job as an order picker in a logistics distribution centre, where I met a lot of cross-border workers, as well as many labour migrants from Poland. The second was a job as a packer of large aluminium products in a metal factory, where I met a small number of cross-border workers, and hardly any labour migrants from Poland. Depending on the exact work environment, the number of cross-border workers thus seemed to vary significantly, and there seemed to be some relation with the presence of labour migrants from Poland.

Another means to explore the cross-border labour market was to talk with people who dealt with this market on a professional basis. Therefore, during the first three months of 2017, I had five meetings with academic colleagues (including colleagues from Statistics Netherlands), and one meeting with a member of the German-Dutch Society in Aachen (Germany); I attended two non-academic conferences that brought together regional stakeholders (such as bureaucrats, labour recruiters, and representatives of different schools) with an interest in cross-border issues; and I visited three institutions that dealt with cross-border workers on a daily basis, namely a Cross-Border Information Point in the German state North Rhine-Westphalia, an office of the Dutch Employee Insurance Agency (Dutch: UWV) in Limburg, and a temporary employment agency (Dutch: uitzendbureau) in Limburg. 


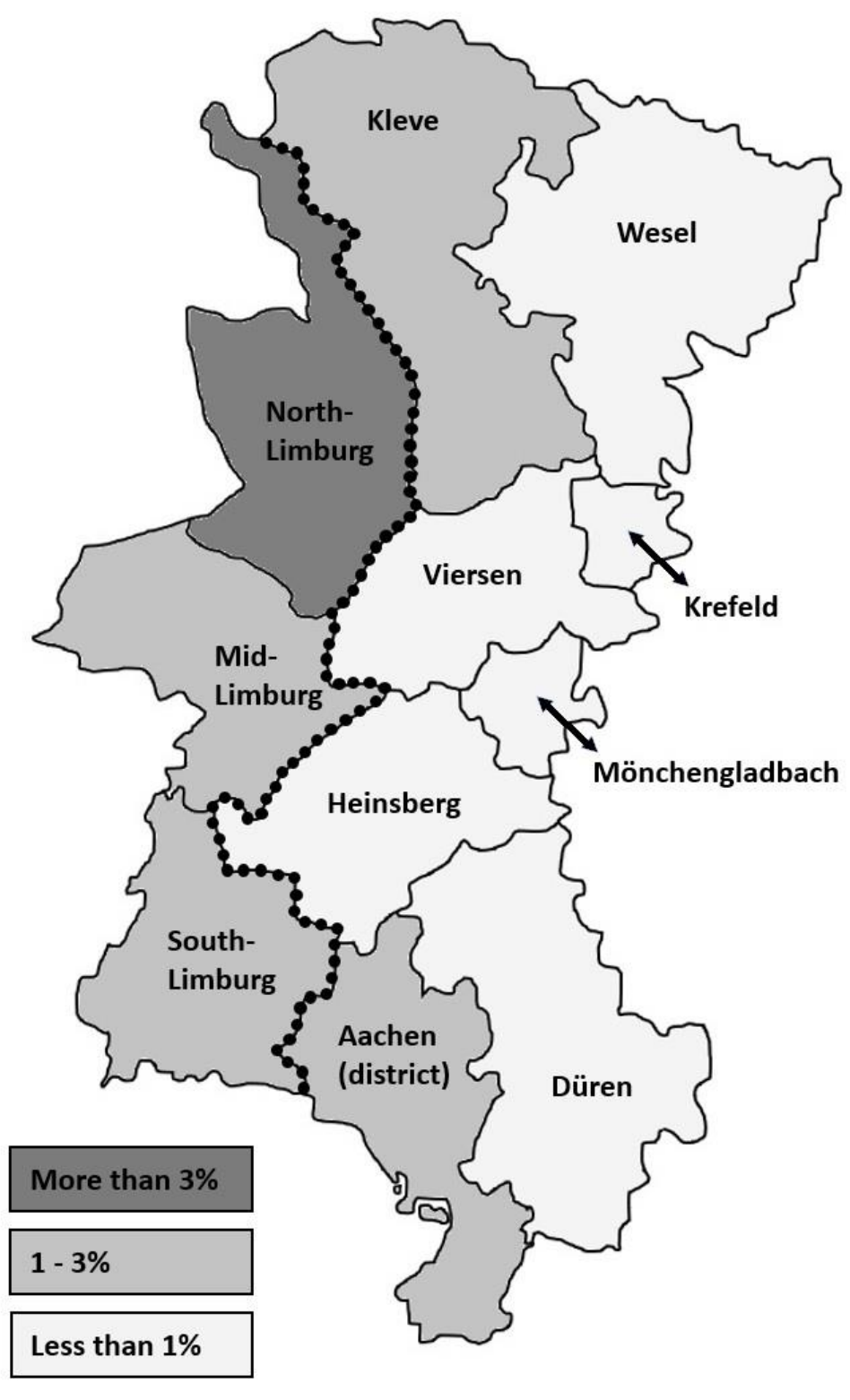

Figure 2. Map visualising the relative share of cross-border labour commuters among the total number of people employed in different subregions of the Dutch province of Limburg and the German state North Rhine-Westphalia in 2017. The data and the general idea of this map, which I have drawn myself, both come from Statistics Netherlands (2021). 
The overall picture that emerged from these meetings matched my personal experiences, and was later also confirmed and specified by data from Statistics Netherlands (2021). In brief, my findings could be summarised in five points. First of all, it was clear that cross-border commuters represented only a fraction of the total number of people employed in Limburg and North Rhine-Westphalia (figure 2). Thus, crossborder commuting did not appear to be a very common phenomenon (see also Van Houtum and Van der Velde 2004). Secondly, I found out that commuting from North Rhine-Westphalia to Limburg occurred more frequently than commuting in the opposite direction, which figure 2 illustrates as well. Thirdly, figure 2 shows that the largest concentration of commuters from Germany could be found in North-Limburg, possibly because this subregion hosted many logistics distribution centres. Fourthly, during my meetings at the abovementioned institutions, I learnt that many commuters from Germany in Limburg were doing jobs with little to no formal educational requirements, such as order-picking in distribution centres, and production work in factories. And fifthly, data from Statistics Netherlands (2021) showed that among the comparably high number of commuters from Germany in North-Limburg, almost one third (29\%) had Polish citizenship. Furthermore, as North-Limburg was the subregion with the highest percentage of residents with a Polish migrant background ${ }^{2}$ in the Netherlands in 2017 (just over 2\%; Statistics Netherlands 2020a), it became clear that German was probably not the only language that played a significant role in cross-border workplaces in North-Limburg.

As North-Limburg stood out as a subregion with a relatively high number of cross-border labour commuters, and was the subregion that I was already most familiar with myself, and where I had a network of people who could provide me with information and accommodation if necessary (a social affordance), I decided to focus on finding a workplace there. Furthermore, the relatively large number of cross-border labour commuters with Polish citizenship in North-Limburg represented an interesting, additional dimension for my research. Without them, cross-border commuting would be an even less significant phenomenon in the MeuseRhine border area. In the political discourse about the promotion of cross-

\footnotetext{
${ }^{2}$ According to Statistics Netherlands, someone has a Polish migrant background in case (s)he was born in Poland, or in case (s)he has at least one parent who was born in Poland.
} 
border commuting in this area, however, Polish people and the Polish language were hardly ever mentioned (e.g., Actieteam Grensoverschrijdende Economie en Arbeid 2017). None of the academics I met during the first months of 2017 talked about them, and during the two conferences with regional stakeholders that I had attended, they were not mentioned either. To be honest, despite my brief work experiences in 2013, I had also never associated cross-border labour market integration in the Meuse-Rhine border area with Polish-speaking people. Tellingly, they were neither mentioned in the PhD vacancy that I had applied for, nor in the research proposal that I had written for my application.

The only people who appeared to be aware of the significance of Polish-speaking commuters were the employees from the institutions (especially, the temporary employment agency) that worked with such commuters on a daily basis. Clearly, their work environment encouraged different imaginations of the Meuse-Rhine labour market. Regarding politicians, bureaucrats, and academics like myself, imaginations of this labour market might have been influenced by the numerous artifacts (such as maps and public signs) in our daily environments that can be associated with "banal nationalism" (Billig 1995). Besides that, the observed tendencies reminded me of a text by Favell (2009), who had argued that the eastward enlargements of the European Union had been (partly) guided by a discriminatory or racist logic to make Western European nation-states less dependent on labour migrants from "the South" (primarily, Morocco and Turkey). Political imaginations of an integrated Meuse-Rhine labour market may well have been guided by a similar logic, as local and regional politicians (influenced by public opinion) were probably more eager to openly welcome commuting Dutch or German citizens than labour migrants from, primarily, Poland.

Considering the significant presence of German-speaking and Polish-speaking people in specific workplaces in North-Limburg, and the probability that the number of such linguistically diverse workplaces in Limburg would further increase in the future, as the population of this province did not grow significantly anymore, or even shrank (Statistics Netherlands 2020b), I thus had found a rationale for studying (socio)linguistic practices in a workplace with cross-border commuters in North-Limburg. The most obvious workplace to look for in this case would probably have been a distribution centre, as there were so many of them, and as many cross-border commuters worked there. In practice, however, I decided to go for a different type of workplace. 
30 - Power Dynamics at Work

During several of my meetings in early 2017, I learnt about the existence of a metal foundry in North-Limburg, where a large number of cross-border commuters were doing production work. Somehow, this workplace intrigued me. The Dutch province of Limburg used to have a large industrial sector in the $19^{\text {th }}$ and $20^{\text {th }}$ century (though not nearly as large as the one in the neighbouring Rhine-Ruhr area in Germany), and industrial companies were increasingly presented and documented as part of Limburg's historical heritage (e.g., Dings 2017). By 2017, many industrial companies had disappeared, but the metal foundry had managed to survive thus far. Compared to many distribution centres, the foundry was relatively old (over 70 years), and I heard that it used to be family-owned. Thus, as an affordance, the foundry could provide my research with a clear historical dimension, and this might, in turn, provide a glimpse on developments and tensions surrounding 'Limburgishness' in different ways. Therefore, during those first months of 2017, the foundry soon became the preferred place for my fieldwork. The only question was how to gain access to this workplace, which I further discuss in the next section.

\subsection{Getting access to a metal foundry}

Many cross-border workers from Germany and labour migrants from Poland who worked in the metal foundry were temporary workers recruited by a temporary employment agency. When I met several international labour recruiters from this agency in January and February 2017, they seemed quite enthusiastic about my research project. The most senior recruiter told me (in Limburgish) that the companies they worked with were not always happy to accept temporary workers who could not speak Dutch or, in the case of certain international logistics companies, English. The problem was, however, that there were not enough people with the desired linguistic profiles according to him. Therefore, he hoped that my research would help to alter people's mindsets, and make both companies and (potential) workers become what he called "future-proof", by finding a way to work with speakers of different languages. He was also quite positive about my idea to not just observe people and conduct interviews, but to work among other workers as well. Although not having an academic background himself, he believed that this was the way to find out 'what it is really like' to work and communicate in a particular company. Later, I learnt that some recruiters from the agency also (very briefly) worked in particular companies themselves sometimes, to get a sense of 
what kinds of jobs they were recruiting people for. My ethnographic approach thus seemed to resonate with a knowledge-gathering method that they were familiar with and seemed to believe in.

In line with his enthusiasm, the senior recruiter offered to help me get access to the metal foundry. He proposed that he would contact the foundry's management and ask them to let me do my fieldwork there. While judging my slim body type, which did not really enable an emplacement as a strong, industrial production worker, he did wonder for a moment whether I would actually be fit to work in the foundry. When I mentioned that I had worked in a metal factory once before, however, his concerns seemed to be allayed.

As I had read about the usefulness of having personal contacts who can vouch for you as someone to be trusted when trying to enter a workplace as an ethnographer (Holmes and Stubbe 2015, 21), I initially felt quite happy about the help that the senior recruiter offered to me. I also believed that the enthusiasm from the temporary employment agency would probably satisfy ITEM, as it underlined the societal relevance of my research project. While waiting for a response from the recruiter and/or the foundry's management, however, my enthusiasm gradually gave way to concerns about my independence as a researcher. As the senior recruiter initiated the contact with the foundry's management, I did not know what exactly he said or promised without my knowledge and approval. In line with Bell $(1999,25)$ and Lønsmann $(2016,25-27)$, I thus became worried about a possible emplacement as a "consultant" in the foundry, which would imply that I no longer had ownership of my research project, and that I would instead be implementing an agenda of the temporary employment agency and, perhaps, the foundry's management. After all, the senior recruiter had clearly indicated an agenda to me by expressing his hopes about changing people's mindsets and making them "future-proof". An official research project with a label of Maastricht University would possibly help him implement this agenda. In this way, I might even become complicit in the broader development of labour market liberalisation and its associated decrease of job security (see, e.g., Peck, Theodore, and Ward 2005).

Hence, if I wanted to continue my plan of getting access to the foundry, I had to make sure to 'take back control' and start a negotiation with the foundry's management on behalf of myself. Fortunately, as time progressed, several situations arose that provided me an opportunity to do 


\section{2 - Power Dynamics at Work}

this. To begin with, after the senior recruiter had talked with the foundry's management, he contacted me to say that they wanted to set up a meeting in the foundry. I agreed with the proposed time and place, and started to do various preparations to affect my emplacement during the scheduled meeting. First of all, I made sure that I would stress my independent position as a researcher, and my affiliation with Maastricht University, as opposed to the temporary employment agency. Concerning non-verbal signs, I thought about making sure that I would literally position myself with some spatial distance from the senior recruiter during the meeting, for example by sitting at the opposite ends of a table. Due to the affordances of my body, I also felt that I had to make an extra effort to not be misplaced as someone's junior partner. I was only 29 years old, and people often thought that I looked even five to ten years younger than that. Hence, I decided to try to signify 'authoritativeness' by following a formal dress code and maintaining a straight body posture.

When I entered an office of the metal foundry on the day of the meeting, it turned out that some luck was on my side. The senior recruiter had called to say that he would be late, which gave me an opportunity to introduce myself and my research project independently from him. The meeting turned out to be with the foundry's Human Resource (HR) managers, and not with the directors, which could be interpreted as a sign that the directors did not consider the meeting a top priority. Furthermore, when I entered the office, I noticed that all HR managers spoke Limburgish, and I decided to do so as well. While this probably was a habitual rather than a deliberate choice, the effect of this choice should not be underestimated. On the one hand, standard Dutch would have been more in line with my attempt to position myself with a sense of authoritativeness. Speaking Limburgish, on the other hand, is typically associated with informality, solidarity, and local and/or regional identity among those who speak it (see, e.g., Cornips 2020b; Thissen 2018). Hence, as a linguistic affordance, speaking Limburgish might have helped to establish some goodwill and cooperativeness during the meeting.

When I introduced myself, I decided to fall back on the history that had motivated me to apply for my PhD position in the first place. I told the HR managers how cross-border contacts in the Meuse-Rhine border area used to be more intensive than today, and how people could rely on mutually intelligible language varieties such as Limburgish. I then told them how local and regional politicians and bureaucrats were aiming for a more integrated cross-border labour market these days, but that it was unclear 
how much language had become an obstacle by now, and how people from different sides of the border communicated with each other at work. I said that Maastricht University had employed me as a researcher to investigate this issue for four whole years, and that I was now looking for workplaces to execute this research project. I also told them that people from several institutions I had visited had mentioned the metal foundry as an interesting and relevant case to look at.

One of the HR managers responded that I had come to the right workplace indeed, although many other languages than German were used in the foundry's production departments as well. I said that those would only make my research more interesting. Overall, the atmosphere was light and informal. The HR managers seemed surprised about the interest in their company, and they laughed and joked regularly. For example, one manager mentioned how I would be able to have lunch or dinner with my parents more often again if I came to work in the foundry - a joke that was arguably enabled by the affordances of my young looks. My slim and younglooking body, combined with the facts that I spoke Limburgish and joined in some of their laughter, possibly also emplaced me as rather harmless, which may partly explain why they did not appear to have a problem with letting me in as a researcher. After clearing up that I would not hide my researcher-identity to anyone, that I would not force anyone to participate, and that I would make sure to anonymise all participants in my publications, my access seemed secured. I also said that I would anonymise the company's name, but that I would not be able to guarantee that readers could find out about its identity in another way. The head of the HR department told me that I could just mention the company's name if I wanted to, and that they were open to criticisms.

In the end, we arranged that the HR managers from the metal foundry together with the HR management from my faculty at Maastricht University would draw up a contract to take care of issues related to insurances and workplace safety. As an affordance, this contract gave me an opportunity to formally seal my independence as a researcher. It made clear that, even though I would do some production work as part of my research, this work would be "unpaid", while I would "continue to receive my monthly salary from Maastricht University". Furthermore, it made clear that Maastricht University would "continue to have authority" over me as an employee, that the authority of the foundry and/or the temporary employment agency would be "limited to guaranteeing the safety" of me and other workers, and that only I would have authority over "the research 


\section{4 - Power Dynamics at Work}

findings and the interpretation of these findings". In brief, my concerns regarding independent research seemed to be taken care of. The next challenge was how to get access to work practices in the metal foundry.

\begin{tabular}{|c|c|c|c|c|c|c|}
\hline & $\begin{array}{l}\text { Core } \\
\text { Shooting }\end{array}$ & Melting & Casting & Finishing & $\begin{array}{l}\text { Non- } \\
\text { production }\end{array}$ & Total \\
\hline Dutch & $\begin{array}{l}48(55 \%) \\
28 \text { perm } \\
20 \text { temp }\end{array}$ & $\begin{array}{l}18(\mathbf{6 9 \% )} \\
15 \text { perm } \\
3 \text { temp }\end{array}$ & $\begin{array}{l}33(45 \%) \\
19 \text { perm } \\
14 \text { temp }\end{array}$ & $\begin{array}{l}72(48 \%) \\
46 \text { perm } \\
26 \text { temp }\end{array}$ & $\begin{array}{l}159(100 \%) \\
148 \text { perm } \\
11 \text { temp }\end{array}$ & $\begin{array}{l}330(67 \%) \\
256 \text { perm } \\
74 \text { temp }\end{array}$ \\
\hline German & $\begin{array}{l}17(20 \%) \\
4 \text { perm } \\
13 \text { temp }\end{array}$ & $\begin{array}{l}7(27 \%) \\
4 \text { perm } \\
3 \text { temp }\end{array}$ & $\begin{array}{l}27(37 \%) \\
19 \text { perm } \\
8 \text { temp }\end{array}$ & $\begin{array}{l}38(25 \%) \\
6 \text { perm } \\
32 \text { temp }\end{array}$ & $\begin{array}{l}0 \text { (0\%) } \\
0 \text { perm } \\
0 \text { temp }\end{array}$ & $\begin{array}{l}89(\mathbf{1 8 \% )} \\
33 \text { perm } \\
56 \text { temp }\end{array}$ \\
\hline Polish & $\begin{array}{l}11(13 \%) \\
1 \text { perm } \\
10 \text { temp }\end{array}$ & $\begin{array}{l}0(0 \%) \\
O \text { perm } \\
\text { O temp }\end{array}$ & $\begin{array}{l}4(6 \%) \\
0 \text { perm } \\
4 \text { temp }\end{array}$ & $\begin{array}{l}16(11 \%) \\
\text { O perm } \\
16 \text { temp }\end{array}$ & $\begin{array}{l}0(0 \%) \\
0 \text { perm } \\
0 \text { temp }\end{array}$ & $\begin{array}{l}31(6 \%) \\
1 \text { perm } \\
30 \text { temp }\end{array}$ \\
\hline Other & $\begin{array}{l}11(13 \%) \\
\text { O perm } \\
11 \text { temp }\end{array}$ & $\begin{array}{l}1(4 \%) \\
1 \text { perm } \\
0 \text { temp }\end{array}$ & $\begin{array}{l}9(12 \%) \\
\text { O perm } \\
9 \text { temp }\end{array}$ & $\begin{array}{l}24(16 \%) \\
8 \text { perm } \\
16 \text { temp }\end{array}$ & $\begin{array}{l}1 \text { (1\%) } \\
1 \text { perm } \\
0 \text { temp }\end{array}$ & $\begin{array}{l}46(9 \%) \\
10 \text { perm } \\
36 \text { temp }\end{array}$ \\
\hline Total & $\begin{array}{l}87(\mathbf{1 0 0} \%) \\
33 \text { perm } \\
54 \text { temp }\end{array}$ & $\begin{array}{l}26(100 \%) \\
20 \text { perm } \\
6 \text { temp }\end{array}$ & $\begin{array}{l}73(\mathbf{1 0 0 \% )}) \\
38 \text { perm } \\
35 \text { temp }\end{array}$ & $\begin{array}{l}150(100 \%) \\
60 \text { perm } \\
90 \text { temp }\end{array}$ & $\begin{array}{l}160(100 \%) \\
149 \text { perm } \\
11 \text { temp }\end{array}$ & $\begin{array}{l}496(100 \%) \\
300 \text { perm } \\
196 \text { temp }\end{array}$ \\
\hline
\end{tabular}

Table 3. The number of permanent (perm) and temporary (temp) workers in the foundry in August 2017, divided by department and citizenship. The category "non-production" includes, among others, HR managers, Information Technology (IT) staff, and engineers. The categories "Dutch", "German", and "Polish" may include first-generation migrants who have obtained Dutch/German/Polish citizenship at some point in their life. ${ }^{3}$

\subsection{Getting access to production work practices}

In total, there were four production departments in the metal foundry, which have been introduced in the first chapter (section 1.1). To understand both the current and the next section, some familiarity with these departments is crucial. Therefore, I have shared the general data

\footnotetext{
${ }^{3}$ The figures presented are the sum of the data about all agency workers in the foundry in August 2017, which I have received as an anonymised Microsoft Excel file from one of the agency's recruiters, and the data about the metal foundry's employees, which I have collected through email communication with an HR manager from the foundry. As the HR manager filled in some gaps in the data from August 2017 with data from 2018, minor differences might exist between the actual figures and the figures presented here.
} 
about the workers' characteristics once more (table 3), and I will now also briefly repeat the description of the work practices in each production department. To begin with, there was the Core Shooting Department, where sand cores were produced to mould metal. Secondly, there was the Melting Department, where the metal was melted. Thirdly, there was the Casting Department, where the molten metal was moulded using the sand cores. And finally, there was the Finishing Department, where the metal products, after hardening, were sawn, ground, blasted, welded, and qualitychecked, among other actions.

Each production department had three teams, which alternately worked in different shifts, namely an early shift (from 06.00 to 14.00), a late shift (from 14.00 to 22.00), and a night shift (from 22.00 to 06.00). New production workers were always assigned to work in one particular team in one of the production departments, and they would typically stay there as long as they worked in the foundry. During my fieldwork in 2017, the foundry had nearly 500 workers, and nearly 350 of them were production workers. Table 3 shows the spread of the workers over the different departments. Furthermore, the table shows that temporary workers and workers from particular citizenship categories were not spread evenly among the different departments, and the same goes for the spread of permanent contracts among workers from different citizenship categories.

While discussing the practical organisation of my fieldwork with the foundry's HR managers, they suggested that I would work one week in each team of the three largest production departments (i.e., the Core Shooting, the Casting, and the Finishing Department). In this way, I could spend a total of nine weeks to get a broad overview of those departments where language diversity apparently was significant. Furthermore, the HR managers suggested that I would also work different shifts. I agreed with them that these were great ideas, while adding that ethnographers typically spend a bit more time with just one group of people in order to let both sides get comfortable, and to notice the subtle details of human behaviour. The managers accepted this emplacement as a knowledgeable person regarding ethnographic fieldwork, and we agreed that after the initial nine weeks, I would be free to spend several additional weeks with a particular work team of my choice. Besides that, we agreed that I would also spend one single work shift in the Melting Department (i.e., the smallest production department, with seemingly little language diversity). In total, my fieldwork was to last fifteen weeks, from 3 July to 15 October 2017. 
One distinctive feature of the metal foundry was that all its production workers were male. Although I was familiar with the typical, traditional associations of blue-collar production work with masculinity (see, e.g., Baxter and Wallace 2009; Bell 1999), I had not seen such a consistently gendered workplace before, perhaps apart from the bakery where I had worked as a teenager. Even in the metal factory where I had briefly worked in 2013, there were some female production workers (who, admittedly, had been assigned to do the physically less demanding work, regardless of their strength). Possibly, this difference was related to the fact that production workers in the foundry (as opposed to the workers in the factory, and similar to workers in the bakery) regularly had to work night shifts. According to a labour recruiter from the temporary employment agency, whom I interviewed (in Limburgish) on 27 September 2017, women were usually not willing to work different shifts. She speculated that this might be because most women would not feel comfortable being in a maledominated workplace at night. In this regard, the sexist discourse typically associated with male-dominated workplaces (see, e.g., Bell 1999, 28) might have played a role as well, and I indeed observed some examples of this in the foundry's production departments, as female bodies passing through these departments were often sexually commented upon.

The foundry's production departments had not always been $100 \%$ male, however. As I learnt during my conversations with labour recruiters, HR managers, and (senior) production workers, a small number of women had worked in the Core Shooting Department before. The fact that this was the only production department with a separate female toilet still recalled that past situation, like a fossil in the foundry's landscape. Furthermore, the fact that these women had worked in the Core Shooting Department, as opposed to any of the other production departments, was probably no coincidence. Among labour recruiters, HR managers, and production workers, it was common sense that the 'lightest' production work was done in the Core Shooting Department. Therefore, new production workers with a body type like mine (young-looking and slim) were often assigned to work in this department. While discussing the practical organisation of my fieldwork, the HR managers also suggested that I would start my fieldwork by doing the supposedly 'lightest' work in the Core Shooting Department, and end with the supposedly 'heaviest' work in the Finishing Department. Judging the affordances of my body, they seemed to find the idea of me starting in the Finishing Department instead rather amusing. 
Slightly intimidated by imaginations of a 'heavy' department, I went along with the suggested order. In retrospect, however, I realise that I never really found out what the supposed 'heaviness' of the Finishing Department was exactly based on. After I had spent nine weeks in the three largest production departments, and two weeks doing other types of datagathering, I still spent four additional weeks with one team in the Finishing Department. All in all, the work there did not stand out as exceptionally 'heavy' to me. When it comes to lifting, there was not much of a difference between the departments, and people often used hoists to lift the heaviest materials. When it comes to endurance, I found the Casting Department the 'heaviest', as people typically had to follow the speed dictations of a conveyor belt there. Regarding other bodily sensations, the Core Shooting Department was often filled with a sharp smell from the ingredients used to produce sand cores, which made working there 'heavier' in this respect. Perhaps one thing that made the Finishing Department stand out as 'heavier' was its somewhat more 'chaotic' nature, as it was the largest department both in terms of surface and number of workers, and the most diverse department in terms of work activities and types of tools and machines. A small number of people also worked with relatively dangerous tools such as saws there. Thus, it might have been the relative technical expertise required to work in this department, which has traditionally been associated with masculinity (Wacjman 2010, 144), that made people think of it as 'heavy'. In addition, an explanation might be found in the 'heaviness' associated with the material that people primarily worked with (i.e., metal), as opposed to the sand from the Core Shooting Department.

Nevertheless, I still did get an impression of the work practices of each work team in each production department during my fieldwork, following the order suggested by the HR department. Before starting in a new team, one HR manager always informed the team manager about my arrival. This was typically also the person that I would first go and talk with at the beginning of a new working week. During such conversations, team managers usually indicated that they did not really know what to do with me. Despite my young looks, they seemed insecure about the emplacement of our hierarchical relation, as several team managers asked me whether it would be okay for them to give me any work assignment. I always answered that they could, but that did not make much of a difference in the end. From their perspective, it was rather unpractical that I would only stay one week in most teams, and that I often did not work full eight-hours shifts. Instead, I typically worked four to six hours per shift in order to leave 


\section{8 - Power Dynamics at Work}

some time for writing fieldnotes and transcriptions. Clearly, this did not make me stand out as a useful worker that would be worth investing in. Therefore, team managers usually told me that I could just go and look around at their department, and see if there was anyone who wanted and needed my help.

In the Core Shooting and the Finishing Department, this actually turned out to be a quite ideal situation for my research. In both departments, people typically worked alone or in pairs with a particular machine. Thus, in case I would have been treated like any other worker, I would never have got the opportunity to observe two other people working together with a machine, as one of them would always have been me. Instead, I was now free to judge which situation seemed interesting, and offer my help as an additional second or third 'pair of hands'. Overall, as I was interested in language diversity, I tried to observe a diverse range of possible (socio)linguistic situations at work. Fortunately, it was not hard to find different situations, as the people working together at a machine often did not share a common first language. Furthermore, I also regularly joined people who were working alone, as this typically offered a good opportunity for combining my participation with situational conversations. Throughout my fieldwork, it never happened that someone turned down my offer to help.

In the Casting Department, the situation was less ideal for my research. As mentioned previously, people in this department typically worked at a conveyor belt. As a result of (or as afforded by) such work activities, I could not freely come and participate whenever I wanted to, and situational conversations were hardly possible. In fact, during the time that I worked in the Casting Department, there were several moments that I did not have much to do and felt rather awkward and useless. In response to such moments, I often went to ask the team managers whether I could go and make myself useful somewhere. The managers' uncertainty about the emplacement of our hierarchical relation possibly was an advantage for me in such situations, because they seemed to find it difficult to say "no" if I showed an interest in doing a certain task. As I aimed for an experience that somewhat approached that of other workers, however, I usually let them decide where I could make myself useful at any given moment.

The consequence of this approach was that the team managers usually let me do some work tasks at the largest of the two conveyor belts in the Casting Department. The reason for that probably was that the other, 
smaller conveyor belt was known as a more 'heavy' and 'risky' workstation. Hence, young-looking and slim people like me were typically not assigned to work there. In this way, the emplacement of my body probably influenced the kind of data that I was able to get access to. Somewhat unsatisfied with this situation, I still decided to express my wish to work at the smaller conveyor belt once during the very last night of my fieldwork. Even though the team manager did not seem enthusiastic about my request, he decided to cooperate. He did not inform the other four workers at the smaller belt about my arrival, however, or ask them whether it was okay for me to join them. When I approached the workers, I did not ask if they were okay with my participation either, but I did ask each of them individually whether it was fine for me to make a video recording. They all said that was okay, so I managed to collect relevant data that night (which I analyse and discuss in chapter 5). Yet, all in all, this approach to accessing work practices did make me feel more like an 'intruder' (an undesirable emplacement), which confirmed to me that it was probably better that I had gone along with the team managers' suggestions most of the time.

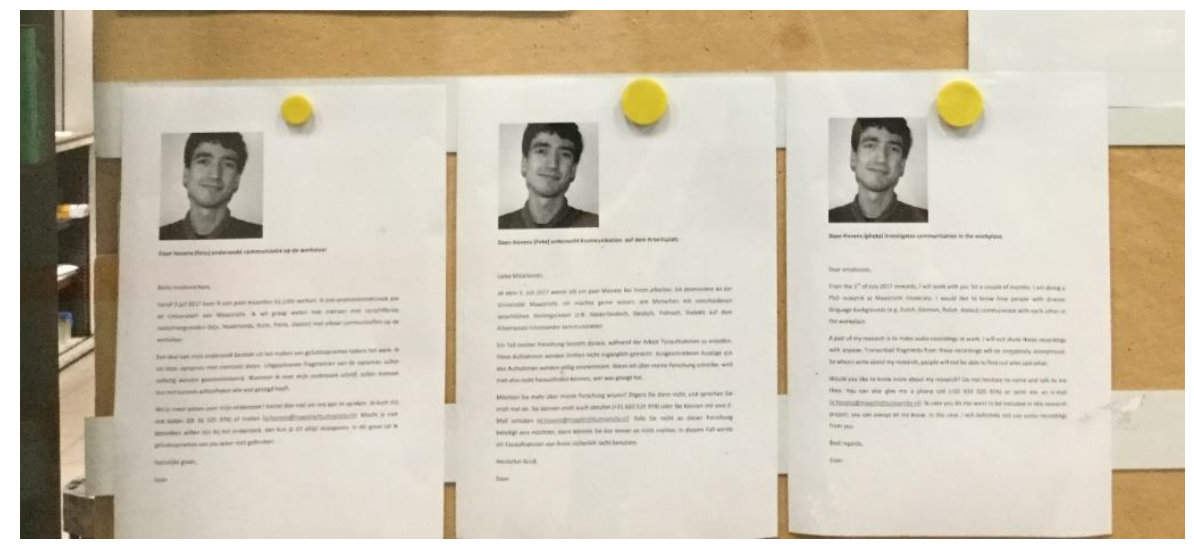

Figure 3. Impression of my fieldwork announcement in three languages (Dutch, German, English) on a noticeboard in the foundry's Core Shooting Department. 


\section{0 - Power Dynamics at Work}

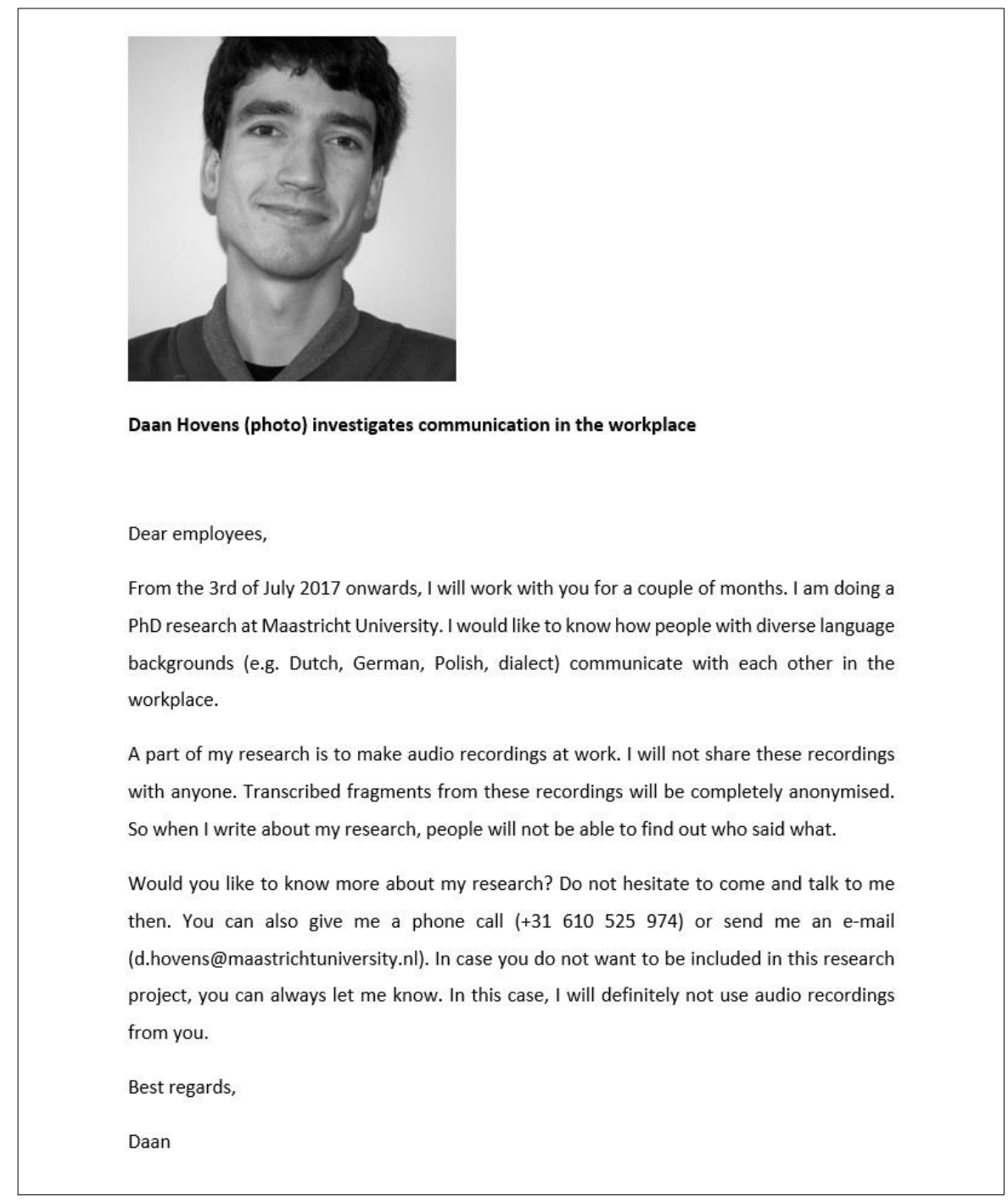

Figure 4. English version of my fieldwork announcement for production workers in the metal foundry. The announcement only mentions audio recordings, because I initially thought about working with implicit consent in the case of audio recordings, and explicit consent in the case of video recordings. In the end, however, I worked with explicit consent for both. 


\subsection{Getting access to workplace discourse and informed consent}

Before starting my fieldwork in the foundry, I made sure to get a formal approval from the Ethics Review Committee Inner City Faculties in Maastricht (hereafter: ERCIC). In order to live up to certain ethical standards, I decided to work with implicit consent. Obtaining explicit consent from every single foundry worker was deemed impossible due to the large size of the workforce, the high turnover rates among the workers, and my methodological procedure of regularly changing work teams. Therefore, I decided to make use of a written announcement instead (figures 3 and 4). The HR management sent a digital copy of this announcement to all team managers, and when I first entered the production departments, I saw that they had already put it on the noticeboards that could be found there. In this way, my announcement was positioned among other messages for production workers, and since these other messages typically came from the foundry's management, it might have affected my emplacement as well, by giving people the impression that I was sent by the management.

As the HR management had told me that being able to speak either Dutch or German or English was required to work in the foundry's production department, I decided to write the announcement in those three languages. I also included a photograph of myself, such that it would be easier for people to identify me. By using three languages, my announcement differed from most messages from the foundry's management, which were typically written in Dutch only. On the other hand, my announcement followed the established practices from the temporary employment agency that worked for the foundry. When people from this agency published a written announcement on a noticeboard, they would typically use the same languages as I did, and they would also present them in the same order (i.e., first Dutch, then German, then English). Thus, by following this established hierarchical emplacement of the three languages, I avoided that production workers and managers would perceive my announcement as a controversial language-political statement, which might have made it harder for me to do my fieldwork. At the same time, I became somewhat complicit in the reproduction of a particular language ideology in this way, by presenting Dutch as the most legitimate (written) language on the foundry's territory, German as the second most legitimate option, and English as the least legitimate option of the three, albeit still more legitimate than the languages that I did not use at all, such as Polish or Limburgish. 


\section{2 - Power Dynamics at Work}

Interestingly, as part of the written announcements (figure 4), I also explicitly listed a number of languages, and I again put Dutch first and German second. However, as I was specifically listing "language backgrounds", which may be interpreted as "first languages", and as I did not expect to meet people with English as a first language, I did not include English in this list. Instead, I mentioned Polish third and "dialect" fourth, reflecting the first languages that I expected to come across most frequently. The reason for writing "dialect" rather than "Limburgish" was that I wanted to cover the possibility that there also might be people in the foundry speaking a local language variety from North Rhine-Westphalia. Furthermore, the reason for writing "dialect" rather than "local language variety", as is more common in the field of sociolinguistics nowadays, was that I wanted to write down a word that many workers themselves would probably use as well. Still, by using the word "dialect", with its possible connotations of being inferior to standard(ised) languages (see Van Rooy 2020), and by putting this word at the end of the list, I positioned it at the bottom of the hierarchy of mentioned varieties. This decision did not appear to be controversial, however, and I did not receive any comments about it. If anything, people might have been surprised to read the word "dialect" in my announcement at all, because the use of (spoken) Limburgish was something that people typically did not think of in relation to language diversity in the foundry, as I noticed throughout my fieldwork.

After my fieldwork had started, I quite soon found out that many production workers did not check the announcements on the noticeboard very carefully. Moreover, I noticed that the ability to understand either Dutch or German or English differed greatly among them. For example, some workers with a Syrian refugee background hardly seemed to understand any German or English, and since their recent arrival in the Netherlands, they had only learnt little Dutch. Therefore, I made it a habit to personally introduce myself to every single worker when I started working in a new team. Typically, during such interactions, the worker and I would introduce ourselves with our first names and decide which language we would speak with each other. Afterwards, I would ask the worker if he had seen my written announcement. Usually, this was not the case. Hence, I typically presented myself in a way that was similar to the structure of this announcement (figure 4): I would first tell him that I am a researcher from Maastricht University; I would then tell him that my research is about how people communicate with each other in linguistically diverse workplaces; I would continue by saying that my research involves making audio 
recordings of this communication; and I would conclude by saying that people could always say "no" to being recorded, that I would not share any recordings with the foundry's management or the temporary employment agency, and that I would never start recording anyone unannounced.

This last statement (that I would never start recording anyone unannounced) was not included in my written announcement, and it was not a requirement from ERCIC either. Still, I decided to add this rule to the ethical guidelines of my fieldwork, partly because it could help me gain people's trust within the relatively short period of time that I could spent with most of them, and partly because I felt that I sometimes needed to double-check that certain people (such as the abovementioned Syrian refugees) had really understood what I was doing. The moment before I intended to start making an audio recording presented a good opportunity for such a double-check, as I could show and point at the recording equipment in these situations. In this way, before having analysed any recordings of workplace interactions, I already became well aware of the merits of combining verbal and non-verbal communication.

In total, I made 66 audio recordings of workplace interactions during my fieldwork, which equalled more or less 74 hours of data (table 4). Most people had no problem with me recording them. In fact, it only happened twice that someone said that he did not want to cooperate. Despite this general cooperativeness, it was quite a challenge to capture people's talk on audio most of the time, due to the affordances of the work environment (which was characterised by loud sounds from tools and machines). Moreover, within this loud environment, talk was often fragmented and full of deictic words (see also Söderlundh, Kahlin, and Weidner 2020, 108). Hence, it soon became clear to me that I really had to be present if I wanted to be able to make sense of these recordings (which enabled no linguistic analysis otherwise), and that I could not wait too long with writing down relevant notes and/or making a transcription even if I was present, as the recordings would otherwise still become incomprehensible to me. Thus, being present turned out to be essential for this type of linguistic data-gathering. 
44 - Power Dynamics at Work

\begin{tabular}{|c|c|c|c|c|c|}
\hline & $\begin{array}{l}\text { Core } \\
\text { Shooting }\end{array}$ & Casting & Finishing & $\begin{array}{l}\text { Other / } \\
\text { general }\end{array}$ & Total \\
\hline $\begin{array}{l}\text { Period(s) of } \\
\text { observation } \\
\text { and } \\
\text { participation }\end{array}$ & $\begin{array}{l}\text { Three } \\
\text { weeks } \\
\text { in July }\end{array}$ & $\begin{array}{l}\text { Three } \\
\text { weeks, } \\
\text { mostly in } \\
\text { July and } \\
\text { September }\end{array}$ & $\begin{array}{l}\text { Seven } \\
\text { weeks } \\
\text { in August, } \\
\text { September, } \\
\text { and October }\end{array}$ & $\begin{array}{l}\text { Entire } \\
\text { period }\end{array}$ & $\begin{array}{l}3 \text { July - } \\
15 \\
\text { October } \\
2017\end{array}$ \\
\hline $\begin{array}{l}\text { Audio } \\
\text { recordings of } \\
\text { workplace } \\
\text { interactions }\end{array}$ & 24 hours & 6 hours & 35 hours & 9 hours & 74 hours \\
\hline $\begin{array}{l}\text { Video } \\
\text { recordings of } \\
\text { workplace } \\
\text { interactions }\end{array}$ & 0 hours & 5 hours & 1.5 hours & 0 hours & 6.5 hours \\
\hline $\begin{array}{l}\text { Semi- } \\
\text { structured } \\
\text { interviews } \\
\text { (audio) }\end{array}$ & 0 hours & 0 hours & 0 hours & $\begin{array}{l}11.5 \\
\text { hours }\end{array}$ & $\begin{array}{l}11.5 \\
\text { hours }\end{array}$ \\
\hline $\begin{array}{l}\text { Photographs } \\
\text { of texts, } \\
\text { signs, and } \\
\text { symbols }\end{array}$ & 28 photos & 19 photos & 60 photos & $\begin{array}{l}32 \\
\text { photos }\end{array}$ & $\begin{array}{l}139 \\
\text { photos }\end{array}$ \\
\hline Fieldnotes & \pm 20 pages & \pm 20 pages & \pm 70 pages & $\begin{array}{l} \pm 40 \\
\text { pages }\end{array}$ & $\begin{array}{l} \pm 150 \\
\text { pages }\end{array}$ \\
\hline
\end{tabular}

Table 4. Overview of the fieldwork data gathered in each production department. Situational conversations are included in the audio- and videorecorded workplace interactions and the fieldnotes. Other relevant sources (such as the website of the foundry, newspaper articles about the foundry, statistical data about employees, etc.) are not included in this overview. The number of recorded hours are roughly rounded. The number of fieldnote pages are rough calculations, as some are written in a sketchy, 'shorthand-like' style. 
Being present also proved important for carrying the audiorecording equipment. Inspired by Holmes and Stubbe $(2015,22)$, I once asked another worker to carry the equipment instead of me. Even though he agreed, my request seemed to make him feel uncomfortable and selfconscious, possibly because it was unclear why exactly I had asked him rather than someone else. My main reason for asking him was my expectation that he might be the person most willing to cooperate at that moment. Partly due to his own academic background, this worker had shown some interest in my research project, and he had indicated some familiarity with the social sciences. Moreover, earlier that week, he had enthusiastically introduced me to some of his work tasks. Hence, I thought that he might not mind helping me with my research. Despite the fact that he agreed to cooperate indeed, however, it seemed like I had misjudged how comfortable he would feel doing so. One possible explanation for this is that he did not speak Dutch. Instead, he spoke Polish as his first, and German and English as his second languages. Therefore, he might have felt that I was specifically asking him because he did not live up to certain sociolinguistic norms of a 'Dutch' work environment. After all, this would arguably be in line with the language ideology that I had implicitly reproduced through my written fieldwork announcement. In any case, after this incident, I decided not to ask other people to carry the recording equipment for me anymore. Instead, I always carried it myself - specifically, in the pocket of my work shirt, which enabled the best possible recordings of spoken language within the given circumstances.

With regard to video recordings, I followed a similar procedure as with the audio recordings by always asking people for explicit consent first. In total, I made four video recordings of workplace interactions, which equalled more or less 6.5 hours of data (table 4). Due to the affordances of this material (enabling me to analyse visual information), my participation in the video-recorded practices was not as important as with the audiorecordings, although it still helped me gather extra insights about specific situational circumstances. During my fieldwork, I did not meet anyone who did not want to be video-recorded. Some people double-checked that I would really anonymise the recordings afterwards (which I confirmed I would), but overall, they did not seem to have a problem with being filmed. At the same time, however, I noticed that people regularly showed that they were aware of the presence of the camera (a rather small, 'smart' device on a tripod), for example, by pointing at it, or by verbally referring to 


\section{6 - Power Dynamics at Work}

it. The affordances of the camera (which could capture both audio and visual data), as opposed to the audio-recording device, thus appeared to make a difference for how much people seemed to feel 'exposed', and for the degree in which their behaviour was noticeably influenced by the presence of a recording device (which also became an active participant in this way). In other words, making audio and video recordings each came with their own specific effects on the qualities of my data.

Apart from audio and video recordings, I also gathered data through the experience of participating in production work practices, and by talking with people while doing so (i.e., situational conversations). As mentioned in the previous section, it was never a problem to get access to such data in the Core Shooting and the Finishing Department, as people were typically quite open to accepting my presence as a researcher there. My additional second or third 'pair of hands' could help make their work 'lighter' (e.g., by letting me carry certain materials), and I think that many also simply liked chatting with someone, particularly if they would have been working alone otherwise. Furthermore, the fact that I looked rather young might have been an advantage in this respect, as this might have contributed to my emplacement as a rather unthreatening person. I did not deliberately use the ambiguous status of a PhD candidate by presenting myself as a student (see also Lønsmann 2016, 27), and I always corrected people who said that I was one, because I felt that it should not downplay the research project that I was asking them to cooperate with. To many workers, however, the idea of a researcher participating in production work practices seemed rather foreign. Therefore, they often tried to put me into a category that they were more familiar with (see also Hawkins 2010, 259; Van de Weerd 2020, 59-60), and due to the affordances of my young looks and my connection to a university, this category often tended to be 'student' or 'intern' (i.e., someone doing a project for school).

Finally, language choice also seemed to matter for the emplacement of me and my relation with a given person in a given situation, and this probably influenced the data that I gathered as well. A clear example of this was a group of senior production workers with a permanent contract, who had worked in the foundry for many years already, and who spoke Dutch and Limburgish as their first languages. Two labour recruiters from the temporary employment agency, whom I talked with shortly before the start of my fieldwork, referred to this group with the Dutch words "oude garde" ("old guard"). According to them, these workers could be very critical about new developments in the foundry, and 
they said that it might be a challenge for me as a researcher to get socially accepted by them. In the end, however, I did not experience such problems. Rather than a target of criticism, several members of the old guard tried to treat me as a messenger whom they could voice their opinions to. They would typically do so in Limburgish, and my choice to speak Limburgish as well (with its connotations of informality and solidarity) might thus have contributed to this emplacement as a person whom they could entrust their thoughts to. Besides that, their permanent contract, as an affordance, probably enabled some more 'daring' behaviour from their side without having to worry about immediate consequences such as losing their job. One member of the old guard even told me that he did not care about being anonymised in my publications, as he would confidently stand up for his points of view.

Other language choices than Limburgish probably mattered as well. As a general guideline, I always tried to accommodate as much as my individual language skills, combined with the emerging spatial affordances, enabled me to do. Thus, with people who spoke Dutch, but not Limburgish (such as the previously mentioned Syrian refugees), I would speak Dutch. Furthermore, with people who spoke neither Dutch nor Limburgish (such as many workers with a German or Polish background), I would speak either German or English. If I had spoken Dutch or Limburgish to them instead, I might have given the impression that I was testing their language skills, or that I was trying to implement a Dutch- or a Limburgish-only language policy. By speaking German or English, I tried to avoid such a 'displacement' by showing that I cared about including them linguistically. Nonetheless, the most outspoken, elaborate, and critical points of view that I came across during my fieldwork typically came from members of the old guard. One possible reason for this is that other workers might not have had such outspoken, elaborate, or critical views, or that they might have felt less entitled to hold such views, as the foundry was positioned on Dutch nationstate territory. Another possible reason might be the relatively limited amount of time that I spent with most workers. If I had spent more time with them, we have might have gradually developed a stronger relationship of trust, as a consequence of which they might have shared more outspoken, elaborate, or critical opinions with me. Thus, it is no coincidence that the views of the old guard feature more prominently in this dissertation, even though I have tried to balance different perspectives overall. 


\subsection{Getting access to academic audiences}

When my fieldwork in the metal foundry was finished, there were just over three years of my PhD trajectory left. All in all, I spent the main part of this time on writing three journal articles, which are included as empirical chapters in this dissertation. In order to get access to academic journals, I had to try to position my linguistic-ethnographic observations and analyses within existing scholarly debates, and use a language that fellow researchers could relate to. Ideally, this scholarly language would also help me consider my own observations from different perspectives, and notice things that I had not noticed before. In other words, the general aim of 'using' theory, as I learnt over these years, was not to 'add' a framework to the descriptions of my data, but to improve these descriptions such that they would become more insightful in and of themselves (Latour 2005, 147).

Prior to the start of my fieldwork, the theoretical concept that I had primarily familiarised myself with was community of practice (Lave and Wenger 1991; Wenger 1998), specifically the way that this concept had been used in sociolinguistic workplace studies (e.g., Holmes and Stubbe 2015). Therefore, as afforded by this concept, my fieldworker eyes and ears were especially sensitive for words and gestures that different workers regardless of their individual language backgrounds- used when communicating with each other. By paying attention to such shared communicative resources, I initially expected that I would be able to argue that a community of practice existed or, more likely, that different communities of practices existed within the foundry. Furthermore, I believed that I would be able to discuss in this way why certain words and gestures had ended up in the shared communicative repertoire of one particular community, and not in others. In line with the sociolinguistic history of the Meuse-Rhine border area that had fascinated me so much, I even imagined a possible implication of my research already, with a historical period of divergence between (individual) linguistic repertoires of people from the Dutch and the German part of the border area now being followed by processes of linguistic convergence in cross-border workplaces such as the metal foundry, somewhat reminiscent of historical cases such as the one studied by my colleague Pecht (2021).

To a limited degree, these initial expectations were indeed fulfilled. In the Casting Department, where people typically worked at conveyor belts, work practices clearly enabled some group dynamics that resulted in 
the use of particular 'in-group' communicative resources. An example of this was "jalla jalla", which means something like "hurry up" in Arabic, and which some people in the Casting Department jokingly used to tell each other to work faster. Yet, on the other hand, in the Core Shooting and the Finishing Department, where people typically worked alone or in pairs, work practices did not really enable such group dynamics, and the number of 'in-group' words and gestures that I could identify there was very limited. Furthermore, the work breaks in the foundry did not really change this overall impression either. An interesting tendency was that workers who could speak German (including people with a non-German first language, such as Dutch, Greek, or Limburgish) would often form one or several groups during such breaks, while people who could not speak or understand this common lingua franca would usually form different groups. However, even within the German language-based 'work break communities', I could hardly identify any 'in-group' words, gestures, phrases, or even grammatical features that different people with different first languages frequently used when talking with each other, and that could serve as a means to distinguish these communities.

Already during, but especially after my fieldwork, these general observations (as affordances) caused some theoretical struggles. Because a concept such as community of practice, as discussed above, should help to improve descriptions rather than force them into a particular framework, I was wondering whether I had to abandon the concept entirely, whether I could write a journal article about not being able to identify a community of practice in the foundry, or whether there were important aspects of either the theoretical concept or my observations that I had possibly not considered so far.

Gradually, while reading, writing, giving presentations, and receiving feedback, I found the latter to be most accurate. Indeed, my focus on 'micro-linguistic' features such as words and gestures had been quite narrow, and I realised that a more flexible approach to the concept community of practice could still help me produce insightful descriptions of both social and linguistic observations in the foundry. The old guard (see previous section), for example, could be distinguished as a community of practice on the basis of certain opinions about and representations of the foundry's historical development over time. Furthermore, the fact that some groups of workers used German as a lingua franca made them a community of practice already in and of themselves, regardless of any micro-linguistic features, and at least some members of these German- 


\section{0 - Power Dynamics at Work}

speaking 'in-groups' (which also included several members of the old guard) liked to draw a distinction between those who could speak either Dutch or Limburgish or German (and who could, therefore, supposedly 'be more easily communicated with') and those who could neither speak German nor Dutch nor Limburgish (i.e., some of the more recently recruited labour migrants from Poland and elsewhere).

In the end, the most significant influence on my use of the concept community of practice came from a rather unexpected corner of the academic world: posthumanist theory (Latour 2005; Pennycook 2018). As follows from the previous paragraphs, a focus on spoken-language-based communities of practice would have had to rely primarily on fieldwork data gathered in the Casting Department, during work breaks, and during situational conversations. The largest part of my fieldwork data, however, was gathered during work practices in the Core Shooting and (particularly) the Finishing Department (table 4). Therefore, I felt that I needed a way to capture what I had observed and experienced in these two departments in a meaningful and insightful way, such that I would not go and ignore all this data simply because it did not fit into a theoretical framework. One common feature of both departments was the prominent role of machines, and posthumanist theory seemed to offer a promise that these machines could be studied in some sort of 'linguistic' way. Intrigued by this possibility, and encouraged by one of my supervisors and several colleagues from my research department at Maastricht University, I started reading about posthumanism, while executing several thought experiments in order to test whether a posthumanist approach could indeed help me improve my descriptions.

A first breakthrough occurred after two colleagues had suggested me to read a particular text by Latour (1992). In this book chapter, Latour argues that "mundane" artifacts should not be overlooked in sociological studies that try to explain people's behaviour. An example he provides is a car that makes it practically impossible to drive without wearing a seat belt (Latour 1992, 225-227). This example resonated very well with what I had observed in the metal foundry, as there were many machines there that more or less forced people to behave in particular 'safe' ways. When I gave a presentation about these rough ideas during a (self-organised) seminar at the University of Copenhagen in December 2018 (as enabled by my academic network and research budget), one attending scholar (Janus Spindler Møller) asked me why I did not include these machines as members of a community of practice, for example as experts sharing 
resources with newcomers. This was the second breakthrough that I needed for my thinking, and after which I crossed what later turned out to be a point of no return from posthumanism. Apparently, if I just broadened my ideas about who or what could be included as a potential participant in emerging interactions and community-formations, I could notice particular dimensions of the observed and analysed power dynamics that I might have missed otherwise, such as the importance of knowing how to interact with a particular machine for becoming an 'in-group' member, and the challenges that certain machines posed to non-Dutch readers trying to become such members.

\subsection{Getting access to professional audiences}

Apart from improving my descriptions and getting access to academic journals, I also considered several ways that my research project could have a positive societal impact. In general, of course, good descriptions and a positive impact could not really be separated. Any intention for impact starts with an understanding of reality after all, and if this understanding is poor, the impact will probably be poor as well. Basically, the main question I tried to answer was what the possible societal implications of my descriptions could be, and how these descriptions could be 'translated' for interested stakeholders, such as company managers, employees, and labour union representatives.

As discussed previously, the general aim of my research institute ITEM was to overcome challenges related to cross-border cooperation and mobility. In relation to this, I started to think of the metal foundry as a "laboratory of European integration" (see Knippenberg 2004 and section 1.4). Indeed, many major news topics in the European Union came together in this work environment, including economic crises and recoveries, labour migration from East to West, refugees from Syria, and resistance to such migration from 'local' populations. In a way, the metal foundry was 'Europe on steroids', or, to phrase it more academically, a critical case for whether different people in Europe could live and work together. Hence, any insight about how to deal with, say, resisting 'local' populations (such as the previously mentioned old guard) could be valuable for (work)places beyond the metal foundry as well, even when they were not one-on-one the same, and this could certainly help overcome challenges related to cross-border mobility. 


\section{2 - Power Dynamics at Work}

One remaining question was how to reach specific audiences with such insights. At the moment of writing this chapter, this is still an ongoing project, which has suffered a few setbacks due to the COVID-19 pandemic. In March 2020, for example, my supervisors and I planned to organise a conference for different societal stakeholders at Statistics Netherlands, during which we would exchange academic and professional perspectives on the topic of language diversity in blue-collar workplaces. Unfortunately, this turned out to be one of the very first events from Maastricht University that was cancelled due to the mentioned pandemic, and so far, we have not set a new date for the event yet. Furthermore, during this cancelled event, the senior labour recruiter from the temporary employment agency was one of the invited speakers. His previously discussed interest in my research project had not yet disappeared, and we had agreed that I would tell him about my findings once I had finished my dissertation. As an indirect consequence of the pandemic, however, the senior labour recruiter decided to quit his job, and I have not had any contact with him or anyone else from the agency anymore since then.

The metal foundry has had many personnel changes as well since the end of my fieldwork (although mostly unrelated to COVID-19), but two $\mathrm{HR}$ managers have worked there during most of my PhD trajectory. Once my journal articles were accepted for publication with minor revisions (which has happened twice so far), I sent a draft to both of them in order to let them know what was about to appear online, and to give them a chance to check the photographs for any competition-sensitive information, as we had agreed upon earlier. In both cases, the HR managers did not respond. Whenever I asked for additional information about the metal foundry (such as statistical employee data), however, they always answered and sent me what I wanted. I still plan to meet with them once after my dissertation and the pandemic are both finished. In the meantime, I have also maintained email contact with two production workers from the foundry, namely one older $(>40)$ production worker from Limburg, and one younger $(<40)$ production worker from Central or Eastern Europe. These contacts did not significantly impact my dissertation either, but they did occasionally provide me with additional information (such as an explanation of a technical term), and I also shared my journal articles with one of them after publication. 
Methodological Reflections - 53

\subsection{Conclusion and discussion}

This chapter has discussed the emergence of my PhD dissertation, with a particular focus on my positionalities, or emplacements, as a researcher. Specifically, it has discussed why my dissertation focuses on specific research data and theoretical concepts, how I have got access to these data, how I have gained certain theoretical insights over time, and which ethical choices I have made during these processes. In this final section, I further reflect upon four findings.

The first finding concerns my curiosity as a researcher, which has turned out to emerge from a balanced combination of familiarity and unfamiliarity. It was my familiarity with Limburg (specifically NorthLimburg) and 'Limburgishness' that made me feel that I might learn something through my research project that concerns me and my life. At the same time, this project has been very much guided by things that I was unfamiliar with, and that were somehow surprising to me. It was my surprising realisation that I had managed to live an almost 'German-free' life within walking distance of the Dutch-German border for eighteen years that started my fascination with cross-border issues in the Meuse-Rhine border area; it was my surprising realisation that I had never really associated cross-border labour commuting in this area with labour migrants from Poland that made me want to find a workplace with both Germanand Polish-speaking workers; and it was my surprising realisation that I had never known that machines could be studied in a 'linguistic' way that made me want to learn more about posthumanism. Thus, the data and concepts that have taken centre stage in this dissertation cannot be separated from my specific biographical emplacements as a researcher. A different researcher (say, a Polish-speaking researcher from Germany with a different study background) would probably have been surprised by other things and, hence, written a quite different dissertation, which can be taken as a strong argument for the promotion of a diversity of backgrounds among researchers.

The second finding concerns my relative freedom to follow my curiosity as a researcher, which has enabled the abovementioned effects on my dissertation, and which can never be taken as a given. At the beginning of section 2.2 , I wrote that PhD candidates in the Netherlands are typically treated as employees rather than students. One aspect of this is that I had a salary and a research budget, which, as affordances, enabled me to focus on my research project (rather than, say, a part-time job) and visit many 


\section{4 - Power Dynamics at Work}

conferences, and to resist the potential temptation of becoming a consultant. On the other hand, the social construct of being employed also comes with an expectation that someone does something in exchange for money, and the PhD vacancy that I applied for already included a general outline of my research project. Therefore, at the beginning of my PhD trajectory, I quite behaved like an "employee" in the sense that I followed my supervisors' instructions to find a workplace to do linguisticethnographic fieldwork right away, even though I was not sure whether that was the best possible approach. Ever since I started looking for this workplace, however, my supervisors left me quite free to explore my own way through this research project. I am aware that all of this was a luxurious emplacement in the sense that not everyone is as free and autonomous as I was as a researcher, but I also want to stress that "luxurious" does not mean "superfluous" here, as I believe that every society can benefit from free and autonomous explorations by artists, journalists, researchers, writers, and other people, as they can help us reconsider habitual ways of doing things.

The third finding is a somewhat relativising statement about the previous finding, as this chapter has also shown the significant influence of broad social identity categories such as (primarily) age, gender, and language on the data that I was able to get access to during my fieldwork. To begin with, age and gender mattered as a specific number (29) and as one out of two sex categories (male), as these social constructs probably helped me get access to the production departments of the metal foundry (a male-dominated work environment, where nobody was under 18 years old to my knowledge), and as they helped me execute my fieldwork there without being sexually harassed (which, due to the affordances of such 'data', might have made me write a very different kind of dissertation). At least as important, however, was the significance of age and gender in the sense of how my body was perceived during my interactions with different human and non-human actants. My body looked quite young and slim, which possibly contributed to an emplacement as a rather unthreatening person, and which might have helped when asking for people's cooperation with my research. At the same time, however, this body also contributed to an emplacement as not very 'fit' to do the supposedly 'heavy' production work in the foundry, as this work tended to be associated with seemingly 'stronger' bodies. As a consequence, I gathered my data from the different production departments in a specific order (which, as a butterfly effect, probably influenced these data in all kinds of ways), and I faced several 
difficulties when trying to gather data at an apparently 'heavy' and 'risky' conveyor belt.

When it comes to language, the chapter has highlighted several advantages of being able to speak Limburgish (a linguistic affordance). Partly due to the political status of Limburgish as a regional minority language, and its common conceptualisation as a group of dialects (Cornips 2013), this finding may not be self-evident. To begin with, being able to speak Limburgish probably contributed to my emplacement as a suitable candidate for this PhD project. After being hired, the same ability probably helped to establish relations of goodwill and cooperativeness with different managers and labour recruiters, which, in turn, possibly helped me to get access to the foundry. Furthermore, once I had started executing my fieldwork there, my ability to speak Limburgish probably also helped to establish some relations of goodwill and trust with other Limburgishspeaking production workers, who might have more openly shared certain views and experiences with me as a consequence. Thus, my Limburgish speaking skills have probably helped me gather a lot of data for this dissertation, which partly compensated for certain constraints that I faced, such as my inability to speak certain languages (e.g., Polish), and the limited amount of time I spent with most workers. A possible political implication of this finding is that it should not be considered 'useless' or 'irrational' in case someone wishes to learn Limburgish as a second language, or in case parents wish to raise their children in Limburgish. Hence, I believe that the societal infrastructure of Limburg should afford people to learn or teach Limburgish in case they wish to do so. At present, however, there are hardly any options for this, and preschools, despite good intentions, have even been observed to discourage speaking Limburgish at home (Cornips 2020b), so there is still much to be gained in this respect.

The fourth finding concerns the theoretical approach taken in this chapter, and how this has enabled (or afforded) me to improve the descriptions of my research-methodological processes. Partly due to the path dependency constructed by the other, previously written chapters of this dissertation, I have experimented with a posthumanist approach while producing these descriptions. Primarily, this chapter has explored the concepts affordance (Gibson 2015) and emplacement (Canagarajah 2018). As evidenced by my frequent use of these words, both are widely applicable. More importantly, however, this frequent use confirms the idea that a researcher's positionality is not fixed, but a transient outcome of a complex, situated interaction between the researcher and various other 


\section{6 - Power Dynamics at Work}

'forces' at work (see also Bell 1999; Hawkins 2010; Lønsmann 2016). The affordances of me and my environment have simultaneously enabled and constrained, or at least encouraged and discouraged me to access certain research data and theoretical insights for my dissertation. Thus, in the end, this dissertation has turned out to be the result of several interactive processes of emplacement which are enabled and disabled, encouraged and discouraged by these affordances.

Finally, I am well aware of the fact that I have not been able to highlight every possible influence on the research data and the theoretical concepts that I have used. For example: I have not discussed the technologies that afforded me to make my audio and video recordings, or the machines that have contributed to my emplacement as a 'masculine' person (or not) in certain situations; I have not discussed the significance of 'time' in the sense that doing fieldwork during summer time in a period of economic growth probably meant that I came across more labour migrants (as labour is generally more scarce during such periods) than I might have during other periods; I have not discussed how I originally thought about doing fieldwork in two different workplaces (one on the Dutch, and one on the German side of the border), and how I abandoned this idea in the end due to time constraints and the richness of my already gathered fieldwork data in the foundry; I have not discussed an adjustment to the order in which I participated in the different departments (due to specific practical constraints, such as a sick leave), which entailed that my three working weeks in the Casting Department were scattered over my fieldwork period (table 4); and I have not discussed how some practical wisdoms or skills from my previous journalistic activities might have affected the fieldwork data I was able to gather, or how much I felt that doing research as an ethnographer was actually different from doing research as a journalist.

Most of all, however, these limitations highlight the significance of another affordance, which is the word limit of any text. Even though this chapter has enabled me to use more words than any journal article I have written so far, there are always limitations to how far an author can go. When it comes to the current chapter, I think that point has come right now. 
Language Policy and Linguistic Landscaping - 57

\section{Language Policy and Linguistic Landscaping ${ }^{4}$}

\subsection{Introduction}

This article is a linguistic-ethnographic study of language policy in a metal foundry in the Dutch province of Limburg, located within the DutchGerman borderland. Blue-collar production workers, including migrant workers, commute to the foundry from various places of residence in the Netherlands and Germany. Here, they encounter diverse spoken languages, including Dutch, English, German, and local varieties from Limburg (known as "Limburgish"; see Cornips 2013), as well as Arabic, Polish, Russian, and Turkish, among others.

The article tracks the historical emergence of this diverse (socio)linguistic constellation, as well as the language-political responses from the foundry's management over time, and explores the dissatisfaction with these developments among a group of senior production workers from Limburg, who typically spoke Dutch and Limburgish as their first languages. It shows that, although the management tried to place Dutch-speaking workers in the foundry's sociolinguistic norm centre (Pietikäinen and KellyHolmes 2013), many senior production workers from Limburg experienced the changes as a process of peripheralisation, and as a loss of workplace dignity (Lucas 2011). More specifically, I argue that a metaphorical way of understanding language policy as linguistic landscaping helps to describe and explain these findings.

In doing so, I draw on previous research about language policy in blue-collar workplaces, where the term blue-collar refers to workers in places as diverse as construction sites (e.g., Theodoropoulou 2019), fishprocessing plants (e.g., Holm et al. 2019), and cleaning companies (e.g., Gonçalves and Schluter 2017; Holm et al. 2019). In this body of research, much (but not all) blue-collar work is also described as involving a temporary basis and low social status (Lønsmann and Kraft 2017, 138). In addition, blue-collar work is typically regarded as physically demanding. With regard to language practices, many authors have observed that people in blue-collar workplaces often use other languages than the official or majority language of the nation-state in which they are working (Dijkstra, Coler, and Redeker 2020; Goldstein 1997; Gonçalves and Schluter 2017;

\footnotetext{
${ }^{4}$ This chapter has been published in the journal Language Policy (Hovens 2021).
} 
Holm et al. 2019; Hiss 2017; Hovens 2020; Kraft 2019; Piller and Lising 2014; Theodoropoulou 2019). Besides this, the ability to use English as a lingua franca cannot be taken for granted here (see, e.g., Lønsmann 2014).

Occasionally, employers may explicitly prefer to recruit blue-collar workers who speak a particular migrant or minority language, due for example to certain stereotypes about a particular group, or the dependency this may create on a bilingual manager as a broker (Gonçalves and Schluter 2017). More commonly, however, studies show that the recruitment of migrant and/or minority workers occurs when there are not enough 'local' and/or majority workers who are willing to do certain blue-collar jobs, at least not for the wages provided (Duchêne 2011; Hiss 2017; Holm et al. 2019; Kraft 2019; Piller and Lising 2014). Furthermore, these studies show that for upward mobility in the company and the wider labour market, some degree of proficiency in the state's official or majority language(s), possibly in addition to English, is often required.

Several authors have pointed out that opportunities for blue-collar migrant workers to learn such 'valuable' languages, both inside and outside the workplace, are often limited, while the responsibility to learn these languages is often placed on them as individuals rather than on any institution (Holm et al. 2019; Kraft 2019; Piller and Lising 2014). Hiss (2017, 708) argues that linguistically assimilating migrant labour might be against a company's economic interests, as maintaining strong connections to their places of origins can facilitate the return of migrant labour if and when they are no longer needed. Duchêne (2011) further underlines the exploitative nature of companies profiting from migrant workers' multilingual skills (e.g., for translation services) without rewarding them. Nation-state ideology typically serves as a way to legitimise such sociolinguistic inequalities (Holm et al. 2019; Piller and Lising 2014). Other means of legitimation may be safety concerns (Kraft 2019; 2020b) and evaluations of job interviews (Roberts 2013).

This article adds to these existing perspectives by focusing not on migrant workers, but on 'local' workers who are supposed to profit from existing sociolinguistic inequalities by being placed in the norm centre. The 'local' workers I spoke with, however, did not seem to believe that they were profiting at all. The article discusses why this was the case, and how the complex position of these workers can be described. In this way, the article contributes to the development of rich and nuanced perspectives on language policy and power in blue-collar work environments. 
The article starts with a theoretical framework, which centres around the terms language policy and linguistic landscape. Afterwards, I present the broader historical-sociolinguistic situatedness of the MeuseRhine borderland where the foundry is located. I then briefly discuss my linguistic-ethnographic fieldwork data and methods. This is followed by an extensive presentation of these data, which leads to the final conclusion and discussion of the findings.

\subsection{Theory: Language policy as linguistic landscaping}

In recent decades, the field of language policy studies has developed from being primarily concerned with language planning activities on the level of the nation-state, towards being increasingly interested in de facto language policies and practices that emerge in daily, situated interactions in, e.g., schools and workplaces (Tollefson and Pérez-Milans 2018, 7-8). An influential contribution has come from Spolsky $(2004,5)$, who added language practices and language ideologies to language planning as the three defining components of language policy. Shohamy $(2006,54)$ further added the component language policy mechanisms to this framework, highlighting the means through which ideologies are reproduced and practices emerge in daily interactions. Johnson (2013, 7-9), on the other hand, argued that it is unhelpful to conflate the notions of policy, ideology, and practice, and proposed instead to limit the definition of language policy to language policy mechanisms only.

More or less simultaneously, the field of linguistic landscape studies has developed from being primarily concerned with large quantitative explorations of the presence of certain language varieties on written signs in the public spaces of an entire nation or city, towards being increasingly interested in ethnographic explorations of how people interact with diverse semiotic signs in specific smaller-scale spaces such as a neighbourhood or a street (Shohamy 2019). Inspired by the work of Scollon and Scollon (2003), Blommaert $(2013,32-33)$ argued that a linguistic landscape should be understood as a historically, discursively organised space that typically provides certain norms for people who interact in it. Building upon posthumanist perspectives such as actor-network theory (Latour 2005), Pennycook $(2019,177-178)$ continued this line of thought and presented the notions of agency and language as distributed among the human and 
non-human actants (such as objects, smells, and space itself) that constitute the linguistic landscape (or, in his words, the semiotic assemblage).

The simultaneous broadening of the two fields has made authors ask similar questions: "What isn't language policy?" (Johnson 2013, 9); "So, is everything linguistic landscape?" (Shohamy 2019, 80). While I agree with Johnson (2013) that it is helpful to define language policy more precisely as policy mechanisms, it is probably fine to leave the idea of a linguistic landscape as open and flexible as it currently is. The main reason for this is that, while the field of language policy studies is about a specific research topic (language policy), the linguistic landscape field has not so much evolved around a specific topic, concept, or theory, but more around a perspective or metaphor that guides particular ways of collecting and organising research data. It is about seeing the world in a spatially and historically organised way, and about noticing the various actants that interact to produce this organisation. In principle, this perspective can be combined with many different research topics, concepts, and theories.

In this article, I explore the value of combining the linguistic landscape metaphor with Johnson's (2013) conceptualisation of language policy. This implies that I do not consider a linguistic landscape as one out of several language policy mechanisms (Shohamy 2006; 2015). Instead, I suggest that all language policy mechanisms can be regarded as different forms of linguistic landscaping in a concrete physical, as well as discursively constructed space. It is possible, for example, to regard policies about who can enter a nation, a school, or a workplace as acts of linguistic landscaping that may influence who can be (considered) part of the landscape (and who cannot). Similarly, it is possible to regard language education policies as acts of linguistic landscaping that may influence which linguistic resources become (considered as) part of the landscape. Furthermore, a wide range of other mechanisms that may impact "the structure, function, use, or acquisition of languages" (Johnson 2013, 9), such as the (re)production of policy texts, discourses, and written signs, can be regarded as acts of linguistic landscaping as well.

Imagining language policy metaphorically as linguistic landscaping has several advantages. First of all, by using a verb instead of a noun, the metaphor helps to imagine language policy as a constantly ongoing construction process or power struggle. Secondly, the metaphor helps to imagine that this construction process does not start from scratch, but that each policy agent (over and over again) faces an already shaped landscape, 
which the agent may affect by doing certain interventions (i.e., linguistic landscaping). Yet completely reshaping an existing landscape might be too ambitious, and various actants in the landscape might resist change. This relates to the third advantage, which is that the metaphor helps to imagine different, historically formed layers of the landscape (e.g., different language ideologies), which can still be influential today. Fourthly, the metaphor helps to imagine the landscape as (partly) overlapping with and connecting to other landscapes, and mobile organisms and artifacts might move in and out. Finally, the metaphor helps to imagine complex hierarchical relations in a multidimensional landscape, beyond binary oppositions such as here and there, self and other, or centre and periphery (see also Brambilla 2015, 22).

In the next sections, I explore how this metaphorical way of imagining language policy can be applied in a metal foundry and the Meuse-Rhine borderland.

\subsection{Linguistic landscaping in the Meuse-Rhine borderland}

The Meuse-Rhine border landscape in this article roughly refers to the Dutch province of Limburg and the German Rhine-Ruhr metropolitan region (which is part of the German state North Rhine-Westphalia; figure 5). The political border that divides this area in a Dutch and a German part is relatively young. It was created around the year 1815, after the end of the Napoleonic Wars (Engelbrecht 1997). As I shall show this event was followed by significant language-political developments. 


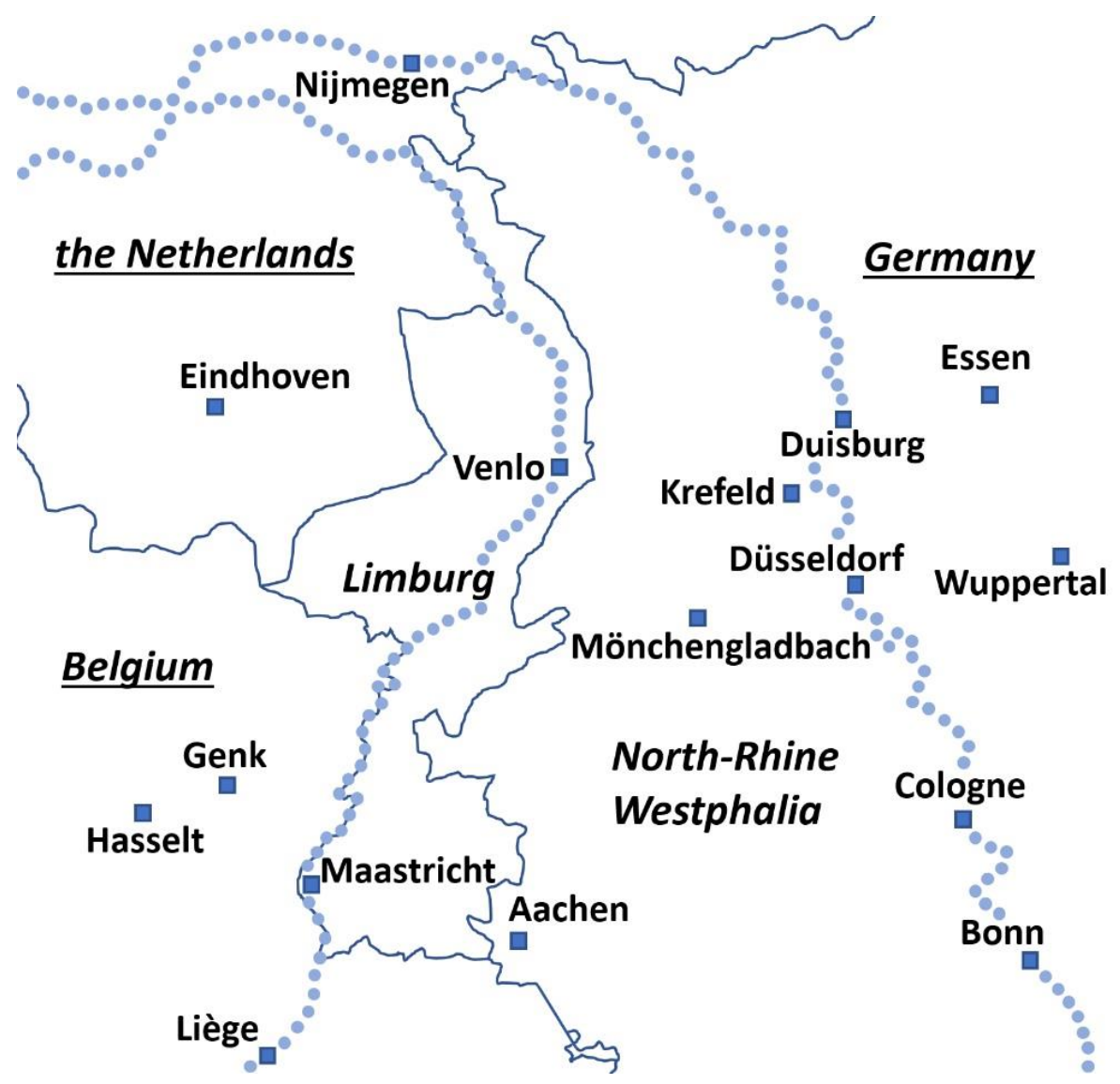

Figure 5. Map showing the Meuse-Rhine borderland. The dotted line on the left represents the Meuse river flowing through the Dutch province of Limburg. The dotted line on the right represents the Rhine river flowing through the German state North-Rhine Westphalia (map created by author).

At the time that the border was created, the Meuse-Rhine border landscape was characterised by the West-Germanic dialect continuum: language varieties from towns that were geographically closer to each other were typically more similar than varieties from towns that were further away, regardless of the newly constructed Dutch-German border (Cornelissen 2015, 57-59; Giesbers 2008, 4-7). Furthermore, the use of standard Dutch, standard German, French, and Latin in different societal 
domains (such as the government, schools, and the church) did not follow the newly constructed territorial division either (Jacobs 2008).

After the creation of the border, diverse acts of linguistic landscaping aimed to establish standard Dutch as the official language in many domains on the Dutch side of the border, and standard German on the German side. An example of this is the spread of state-subsidised school textbooks in standard Dutch for German-speaking communities in Limburg (Jacobs 2008, 121). Furthermore, diverse policy acts have discouraged mobility between the Dutch and the German part of the border landscape since the second half of the 19th century, including the introduction of a passport obligation for all foreigners staying in Germany during World War I (Korres 2006, 134). The decreasing cross-border mobility that followed went hand in hand with decreasing cross-border contacts, as Giesbers $(2008,63)$ has shown with regard to the relative share of Dutch-German marriages in five Dutch and five German towns in the Meuse-Rhine borderland, which strongly decreased between 1850 and 2000 .

The decrease in cross-border contacts may partly explain why traditional local varieties from the Dutch and the German part of the Meuse-Rhine border landscape have diverged linguistically from each other: the West-Germanic dialect continuum is now considered "broken" (Cajot 1996; Cornelissen 1995; Giesbers 2008). In most places on the German side of the border, traditional local varieties have even become nearly extinct (Cornelissen 2008; 2015; Giesbers 2008). This is partly due to the heavy industrialisation and the following migration of people who did not speak these varieties to the coal-rich areas of the Rhine-Ruhr region, which has resulted in the emergence of regional varieties (e.g., Ruhrdeutsch) that are relatively close to standard German, while they also have certain characteristics of both traditional and new migrant varieties (Cornelissen 2015, 131).

In the coal-rich south-eastern part of the Dutch province of Limburg, a similar sociolinguistic development has occurred on a smaller scale (Cornips 2003). Overall, however, traditional local varieties (known as "Limburgish") are still spoken by many people in the Dutch province of Limburg today, and they are often considered important markers of people's local and regional identities and solidarities (Cornips 2013; Cornips and Knotter 2016; Driessen 2006; Thissen 2018). Cornips and Knotter (2016, 163) describe the historical construction of Limburgish identity in the nineteenth and twentieth century as a process of "negative integration" or 
"integration through differentiation" in the Dutch nation-state, with which they mean that Limburgish identity emerged as an oppositional identity to the rest of the Dutch nation, while at the same time, 'being Limburgish' implied 'being Dutch' as well. This implication seems obvious to many people nowadays, even though Limburg was home to several separatistminded individuals and movements up until World War II (Pabst 1992).

Today, many local and regional politicians, bureaucrats, and entrepreneurs in Limburg would like to get rid of certain (socio)linguistic traces that the linguistic landscaping efforts of the past have left, as they are obstacles for the political-economic ambition to create a cross-border labour market in the Meuse-Rhine borderland. The observed decreased interest in learning German among Dutch pupils (Duitsland Instituut Amsterdam 2018) has become a particular concern in this respect. In 2017, various politicians, bureaucrats, and entrepreneurs from Dutch-German and Dutch-Belgian border areas (including Limburg) formed the "Actieteam Grensoverschrijdende Economie en Arbeid" ("Action Group Cross-Border Economy and Labour"). In a report that this group presented to the Dutch government on 30 January 2017, it wrote the following (in Dutch) concerning language (Actieteam Grensoverschrijdende Economie en Arbeid 2017, 34):

Het actieteam stelt vast dat een gebrekkige kennis van het Duits een van de belangrijkste belemmeringen is bij het werken over de grens. De daling van het aantal leerlingen dat Duits op school volgt, is daarom een zorgelijke ontwikkeling. Schoolinstellingen, ouders en leerlingen moeten zich meer bewust zijn van het belang van kennis van de buurtaal en cultuur.

The action team observes that insufficient knowledge of the German language is one of the most important obstacles when it comes to working across the border. For this reason, the decreasing number of pupils who learn German at school is a worrying development. Educational institutions, parents, and pupils should be more aware of the importance of knowing the neighbour language and culture.

The use of the words "neighbour language and culture" confirms that nation-state discourses are deeply sedimented in the Meuse-Rhine border landscape, even among the members of this supposedly 'cross-borderminded' group. Apparently, from the presented Dutch border-regional 
perspective, the German language and culture are not part of an implicitly assumed 'self', but of a discursively constructed 'national neighbour'. Furthermore, the example shows that the economic urgency to promote the German language on the Dutch side of the border may be stronger than the urgency to promote Dutch on the German side.

The alarming discourse about the decreasing number of pupils learning the German "neighbour language", and its economic consequences, has entered regional news media in Limburg as well (see, e.g., Pollux 2019). Through such a stress on economic arguments, this discourse matches well with what Heller and Duchêne (2012) call language in late capitalism. In this ongoing era, the authors write, "'pride' no longer works as well as the sole trope of nation-state legitimization; rather, the state's ability to facilitate the growth of the new economy depends on its ability to legitimize the discourse of "profit'" (Heller and Duchêne 2012, 10). In the case of Limburg, the political challenge might be to legitimise the spread of German (and, possibly, other languages), as this seems economically profitable. However, a discourse of profit might lead to tensions with established, sedimented discourses of pride, for example, if students or employees in Limburg are told to speak German to help boost the regional economy, but their national pride stops them from doing so. In the remaining sections, I discuss how tensions between pride and profit play out in practice in a metal foundry in Limburg.

\subsection{Methodology and data}

My linguistic-ethnographic fieldwork in the production departments of the metal foundry lasted from 3 July to 15 October 2017. During this period, I participated in various work practices as an additional worker (e.g., by helping people lift heavy materials). At the end, I made 74 hours of audio recordings and 6.5 hours of video recordings of workplace interactions; I audio-recorded 11.5 hours of interviews with (former) workers and managers, as well as labour recruiters; I took 139 photographs of diverse signs, texts, and symbols; I wrote approximately 150 pages of fieldnotes, and I collected a wide range of other data.

This article is primarily based on the audio-recorded interviews and my fieldnotes. Furthermore, I have drawn extensively on different historical sources from and about the metal foundry, including: a book about the foundry's history and its founding father's biography, which his son 
published in 2018; one critical article about the foundry from a local labour party magazine from 1985; and a magazine that the foundry published to commemorate its anniversary in 2005. Combined with the interviews, these sources have helped me to reconstruct the company's history. Despite their immense value for my research, however, I have not included them in my reference list, in an attempt to protect the company's privacy. Although the foundry's management has allowed me to mention the company's name, I have decided not to do so, as this helps me to write more freely.

It was not possible for me to get explicit consent from every single employee before my fieldwork started. The foundry had around 500 employees, the turnover rate among them was high, and I regularly changed work teams in order to get a broad overview of the production process. Therefore, as approved by the Ethics Review Committee Inner City Faculties in Maastricht, I decided to work with implicit consent by hanging up a written announcement in Dutch, German, and English, as every production worker was supposed to understand at least one of these languages. Before making any recording, however, I still asked for people's explicit consent.

While doing interviews for my fieldwork, I had to consider which language(s) to use. With people who spoke Dutch and Limburgish as a first language (like me), I would usually speak Limburgish, as I felt that this established a more informal atmosphere. With people who did not speak Dutch or Limburgish, I would speak German or English (which I both speak as a second language). If I had spoken Dutch or Limburgish to them instead, I might have given the impression that I was testing their language skills, or that I was trying to implement a Dutch- or a Limburgish-only language policy. By speaking German or English, I tried to avoid this impression and to establish an informal atmosphere in these situations as well.

Finally, shortly before the start of my fieldwork (on 12 June 2017), two recruiters from a temporary employment agency that worked for the foundry warned me (in Limburgish) about a particularly vocal group of production workers, which they referred to with the Dutch words "oude garde" (and which I hereafter also refer to as the "old guard"). They told me that these senior workers from Limburg could be very critical about new developments in the foundry, and that it might be a challenge for me as a researcher to get socially accepted by them. In the end, I did not experience such problems, however. Rather than a target of criticism, several members of the old guard treated me as a potential messenger whom they could 
voice their opinions to. They would typically do so in Limburgish, so my choice to speak Limburgish might have helped this social situation to emerge. In the following sections, I discuss some of these opinions in more detail.

\subsection{Linguistic landscaping through labour recruitment practices}

The founding father's biography highlights the unprivileged labour-class environment of a small industrial town in Limburg in which he grew up. In 1945, after the end of World War II, he was in his early twenties. When he looked at the traces from the war in the Meuse-Rhine border landscape, his attention was caught by copper grenade bodies. He started to melt and mold them in a former goat stable at his parental house, and so the metal foundry was founded. Gradually, he built up a customer base, and by the time he retired in 1985, the foundry had more than 200 employees and an annual revenue of more than $\mathbf{3 0}$ million Dutch guilders (approximately 15 million euros).

Finding enough employees for the foundry had been a challenge from the start. The founding father's way of dealing with this was simple but effective: he offered people a higher salary than other nearby industrial workplaces. Apparently, he did not believe that this would ruin his business, as has been observed in managerial discourse in other cases (e.g., Hiss 2017, 701). In 1955, he was even convicted in court for paying his employees more than the legal maximum wage (a post-war policy that was supposed to stimulate exports from the Netherlands). In this way, the foundry built up a reputation as a workplace where people could earn relatively much money, as long as they were willing to deal with its demanding and somewhat eccentric managers (i.e., the founding father and 
one of his friends)..$^{5}$ The founding father prided himself in being a hard worker, and he expected the same from his employees. He still participated in production work practices sometimes, and he did not shy away from criticising employees who did not perform well in his view. At the same time, he rewarded what he perceived as hard work, for example, by giving people a free crate of beer. Employees with whom he had a good relation could get interest-free loans from him as well.

According to a critical article about the metal foundry from 1985, published in a magazine from a local labour party (in Dutch), only few of the foundry's employees were labour union members. The same article observed that the foundry did not employ any "foreigners". This was considered surprising, as many industrial companies in the Netherlands and Germany had recruited so-called "Gastarbeiter" ("guest labour") around the 1960s, which were labour migrants from Italy, Morocco, Spain, and Turkey (among other countries). As confirmed by his son during a (Limburgish) interview that I had with him on 18 October 2017, the founding father chose not to recruit any foreign labour during those years, as he managed to attract enough local labour due to the comparably high wages he offered. According to the labour party publication, not recruiting foreign workers was a "principle choice" from him, as they would cause "trouble". According to his son, he did so out of a concern for "communication problems". Whatever might be the reason, practically all of the foundry's employees from its early days until the 1980s were from the Dutch province of Limburg, and the dominant spoken language in the foundry was Limburgish.

When the founding father retired in 1985, his son succeeded him. The son had studied foundry engineering in the German Ruhr area, and had already worked in the foundry for more than 10 years before taking over his father's position. Under his management, the company continued to grow,

\footnotetext{
5 Several senior production workers from Limburg mentioned the "high wages" reputation that the foundry used to have to me, including one worker whom I spoke with (in Limburgish) on 14 August 2017, one worker whom I spoke with (in Limburgish) on 28 August 2017, one worker whom I spoke with (in Limburgish) on 5 September 2017, and one worker whom I spoke with (in Limburgish) on 3 October 2017. The description "demanding and somewhat eccentric managers" is based on the founding father's biography, a Dutch article from a local labour party magazine from 1985 (see next paragraph), and two different (Limburgish) conversations that I had with elderly people who lived nearby the foundry (but who never worked there), which took place around the start of my fieldwork in July 2017.
} 
and during the second half of the 1990s, the number of employees surpassed 400 . The offered wages were now no longer sufficient to recruit Dutch- and Limburgish-speaking labour only. For the first time, the foundry's production departments opened up for German-speaking crossborder commuters, and for labour migrants who had originally come to the Netherlands as Gastarbeiter, and who had learnt (some) Dutch as a second language since then.

The requirement that migrant workers had to speak Dutch seemed to be applied strictly at least in certain cases. For example, one production worker with a migrant background, whom I spoke with (in Dutch) on 30 August 2017, told me that he was turned down when he first applied for a job in the foundry in the 1990s, because his Dutch was deemed not good enough. Concerning cross-border commuters, some spoken German seemed to be tolerated, although one production worker from Germany who could speak Dutch, German, and a local variety told me on 12 September 2017 (using this local variety) that when he was recruited by the foundry in the late 1990s, the managers had explicitly told him that he was expected to speak Dutch, not German, at work.

That the recruitment of non-Dutch-speaking workers was a delicate issue, is shown by an article from a magazine that the foundry published in 2005. In this magazine, which appeared in Dutch, two Human Resource managers (hereafter: HR managers) wrote that "'foreigners' ought to master the Dutch language sufficiently", because the mastery of this language would be "essential" when employees had to read written work instructions. Furthermore, they wrote that due to "the past", some workers would not or only insufficiently master the Dutch language. Therefore, the foundry had started to offer an annual Dutch language course, and the HR managers underlined that the company considered it very important that "employees take this course very seriously and finish it with a noticeable result". This discourse of linguistic assimilation matches well with the discourse on migrant integration that became prominent in the Dutch political landscape in the early 2000s (see, e.g., Entzinger 2014).

Finally, the global financial crisis of 2007-2008 led to a turning point in the company's history. Around the turn of 2008-2009, the demand for the foundry's products (i.e., metal components of trucks, luxury cars, and central heating boilers) dropped sharply. In February 2009, the founding father's son went with early retirement. A new Chief Executive Officer (hereafter: CEO) was appointed by the foundry's main shareholder. He was 
from the Dutch province of North Brabant and he spoke Dutch, but not Limburgish. Furthermore, he had no ties to the founding father and no previous working experience in the foundry. He was, as he wrote in the preface of the book about the company's history (in Dutch), a "beroepsmanager" ("manager by profession"). One of the first things that the new management did after taking office was to lay off more than 100 employees, which allegedly saved the foundry from bankruptcy.

Ever since this crisis, as the foundry's Chief Financial Officer (hereafter: CFO) explained to me (in Limburgish) in an interview on 4 December 2017, the management had become cautious with handing out new permanent contracts. By using temporary labour from employment agencies instead (Dutch: uitzendkrachten), the company could adapt more easily to (sudden) changes in the demand for its products. During my fieldwork in 2017, when the economy was blooming again, 196 out of 496 workers in the foundry (i.e., 40\%) were temporary workers. Most of the temporary staff worked in the production departments. Here, 185 out of 336 workers (i.e., 55\%) were temporary workers. At the end of my fieldwork, partly in response to criticisms from production workers about the lack of job security, the management decided to give 14 temporary workers a permanent contract.

The increased reliance on temporary labour from employment agencies meant a dramatic change for the foundry's linguistic landscape, especially during times of economic growth. The reason for this is that many temporary production workers who were recruited through employment agencies did not speak Dutch or Limburgish. Table 5 shows the number of production workers and other workers (such as salespeople) in the foundry in August 2017, divided by citizenship. The categories Dutch, German, and Polish may include first-generation migrants who have obtained Dutch/German/Polish citizenship at some point in their life. In the following section, I discuss the acts of linguistic landscaping that emerged in the foundry in response to the increased language diversity. 
Language Policy and Linguistic Landscaping - 71

\begin{tabular}{|l|l|l|l|}
\hline Citizenship & $\begin{array}{l}\text { Production } \\
\text { workers }\end{array}$ & Other workers & Total \\
\hline Dutch & $171(51 \%)$ & $159(99 \%)$ & $330(67 \%)$ \\
\hline German & $89(27 \%)$ & $0(0 \%)$ & $89(18 \%)$ \\
\hline Polish & $31(9 \%)$ & $0(0 \%)$ & $31(6 \%)$ \\
\hline Other & $45(13 \%)$ & $1(1 \%)$ & $46(9 \%)$ \\
\hline Total & $\underline{36(100 \%)}$ & $\underline{160(100 \%)}$ & $\underline{496(100 \%)}$ \\
\hline
\end{tabular}

Table 5. The number of production workers and other workers (e.g., HR managers, salespeople, and engineers) in the metal foundry, divided by citizenship, in August 2017. ${ }^{6}$

\subsection{Linguistic landscaping and the construction of a 'Dutch' work environment}

The historical interest of the founding father's son is not just reflected by the book that he published about his father and the company. Under the son's management, the metal foundry was constructed as a place with a history, as the foundry's landscape was enriched with several commemoration stones, i.e., stones with engraved texts that commemorated the construction of a new wing of the foundry building, or the first official use of a new machine. Almost all of these texts were written in standard Dutch, following a somewhat standardised formulation: 'the first stone was placed by this specific person on this specific date'. An exception to this tendency is a commemoration stone that was placed on 19 February 1993 (figure 6). This was the Friday before the carnival celebration, an annual tradition that is often considered a symbol of Limburgish identity (see, e.g., Cornips and De Rooij 2015; Thissen 2018). Therefore, the text on this specific stone is in Limburgish.

\footnotetext{
${ }^{6}$ The figures presented are the sum of the data about all temporary workers in August 2017, which I have received as an anonymised Microsoft Excel file from one of the temporary employment agency's recruiters, and the data about the metal foundry's employees, which I have collected through email communication with an HR manager. As the HR manager filled in some gaps in the data from August 2017 with data from 2018, minor differences might exist between the actual figures and the figures presented here.
} 


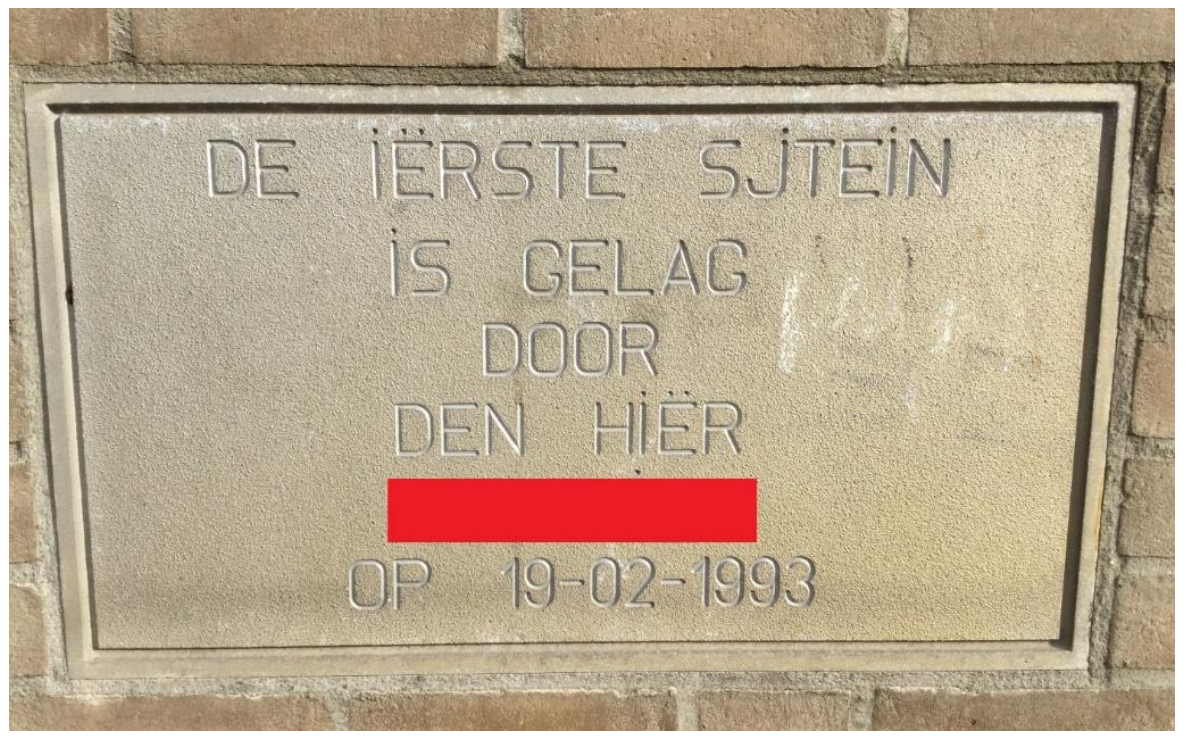

Figure 6. Commemoration stone with Limburgish text, reading: "The first stone was placed by Mr [name anonymised by author] on 19-02-1993".

The placements of commemoration stones are not just acts of historical landscaping, but also of linguistic landscaping. These acts reproduce a familiar pattern in the linguistic landscape of Limburg, where standard Dutch is often used to construct formal, institutional, and authoritative situations, while Limburgish is typically used to construct situations characterised by informality, solidarity, and local and/or regional identity (see, e.g., Cornips 2020; Thissen 2018). This pattern can be recognised in other ways as well. As discussed in the previous section, the dominant spoken language in the foundry until -at least- the 1980s was Limburgish. When it comes to written announcements and instructions, however, standard Dutch was used. Furthermore, standard Dutch -not Limburgish- was considered the language that "foreign" workers had to learn, as shown by the foundry's magazine from 2005 (see previous section).

During my fieldwork in 2017, spoken Limburgish was still used frequently among workers from the Dutch province of Limburg, but in many production work teams, Limburgish-speaking workers were not a numerical majority anymore. Arguably, German had become the most frequently spoken language in the production departments, as this was a lingua franca 
spoken and understood by practically all workers from Germany, by many workers from the Netherlands (excluding first-generation migrants who had learnt Dutch, but not German as a second language), and by several (but not all) workers from Central and Eastern Europe.

With regard to written announcements and instructions, standard Dutch was still the dominant language in the foundry's landscape. Furthermore, when one of the foundry's directors gave a formal presentation for production workers, as I observed on 12 July 2017, solely standard Dutch was used. Due to linguistic proximity, standard Dutch was possibly more understandable for German-speaking workers (particularly those who had worked in the foundry for a longer time) than for workers who spoke neither Dutch nor German nor Limburgish. Thus, production workers with limited knowledge of Dutch, German, and Limburgish were often linguistically excluded in the foundry.

Explicit explanations for the continued, exclusive use of written standard Dutch in the linguistic landscape were presented to me on 12 June, 3 July, and 7 August 2017, when I attended several guided tours and introductory presentations for potential or newly recruited production workers. While referring to written board announcements from the management, which were written in Dutch only, the tour guides or presenters told the participants that the management used 'Dutch only' because employees were expected to learn Dutch over time. The following quote (in German) from a tour guide (who spoke Dutch and Limburgish as his first languages, and German and English as his second languages) is an example of this:

Was Sie hier sehen, sind Publikationen von der Direktion, Abteilungsleiter, und so weiter, und so weiter. Das ist meistens auf niederländisch geschrieben. Warum? Weil die Direktion möchte ganz gerne, dass die Leute niederländisch lernen im Laufe der Zeit.

What you see here are publications from the management, head of department, and so on, and so forth. That is mostly written in Dutch. Why? Because the management would like it quite much when the people learn Dutch over time.

The tour guides and presenters did not explain how people were expected to learn Dutch, and they did not refer to the annual Dutch language courses that the foundry's management organised for certain production workers 
either. The implication thus seemed to be that learning Dutch was people's own responsibility.

Shortly before my first working day in the foundry (3 July 2017), I came across an explicit formulation of a language rule in the digital linguistic landscape of the foundry as well. The reason for this was that I had to take an online test to ensure that I was familiar with, among others, certain safety regulations. Possibly as a way to manage workplace safety in the linguistically diverse production departments (see also Kraft 2020b), the test was available in Dutch, English, and German. I decided to take the Dutch version. In this way, I encountered the following rule about language use:

Van iedere medewerker wordt verwacht dat hij/zij de Nederlandse taal (eventueel de Duitse taal) dusdanig beheerst dat de medewerker zich verstaanbaar kan maken. Ook collega's onderling worden geacht de Nederlandse taal te spreken.

From every employee it is expected that he/she masters the Dutch language (perhaps, the German language) sufficiently such that the employee can make him/herself understandable. Also colleagues among each other are expected to speak Dutch.

When I asked one of the labour recruiters who worked for the foundry about this rule during an interview in her office on 27 September 2017, she told me (in Limburgish) that it was outdated, and that they had forgotten to update it. The part that had to be changed, according to her, was that they had to write "the German or the English language" instead of just "the German language". She further added that since January 2017, the tight labour market had made the foundry's management accept the recruitment of people who did not speak Dutch or German, but who did speak English as a second language. The updated language rule could thus be characterised as a normative expectation from the management to speak Dutch at work, although German and English (and, implicitly, Limburgish) were more or less 'tolerated'.

While observing language practices in the foundry's landscape during my fieldwork in 2017, I noticed that 'tolerating' German and English could mean different things. For the foundry's management, as discussed previously, it clearly meant that only Dutch was used for written announcements and instructions, and for formal presentations, while German and English were 'tolerated' for informal, spoken communication 
at work. When labour recruiters from the temporary employment agency would write a general email or announcement for production workers, on the other hand, they would typically do so in three languages: Dutch, German, and English. The order can be taken as a reflection of the language hierarchy and the chronological order in which the languages became 'accepted' in the production departments. Besides this, the more multilingual practices from the labour recruiters can be taken as a reflection of the idea that German and English were 'tolerated' as long as someone had a temporary contract, but that the norm to speak Dutch became stricter in case someone became permanently employed.

Nonetheless, in daily work practices, many permanent workers would speak other languages (such as German, Limburgish, and English) as well. Hence, the placement of Dutch language signs, formal Dutch presentations, and explicit Dutch language norms in the foundry's landscape did not affect most actual speaking practices at work. Something similar can be said about the annual Dutch language courses that the foundry's management organised for certain, selected production workers (namely those who had shown an interest in learning Dutch and who were expected to stay in the foundry for at least the near future). As these courses did not include all non-Dutch-speaking workers, and as they only covered the beginners' level, they did not seem to make much difference for daily, informal language practices. According to the self-employed teacher, whom I spoke with (in Limburgish) on 22 November 2017, it was not realistic to expect that participants would be fluent in Dutch after finishing the course. Rather, she said, I should view the courses as an "encouragement" to invest in learning Dutch.

Put differently, the Dutch language courses could be considered another act of linguistic landscaping through its signification of which production workers were expected to accommodate linguistically, and which ones were supposed to be the sociolinguistic norm centre in the foundry's landscape. Hence, despite all the changes in the foundry's recruitment and informal language practices, the old guard (i.e., senior Dutch- and Limburgish-speaking production workers who had started working in the foundry under the management of the founding father or his son) could still be considered as (part of) the top of the company's sociolinguistic hierarchy. Even so, many of them were quite critical about the linguistic landscape that had emerged over time. In the next section, I discuss in more detail why this was the case. 
76 - Power Dynamics at Work

\subsection{Linguistic landscaping and the position of the "old guard"}

To understand the complex hierarchical position of the old guard in the metal foundry's landscape, it is useful to first consider why the foundry's management tried to place these workers in the company's sociolinguistic norm centre. Within the management, the CFO was considered ultimately responsible for labour recruitment practices and the related questions about language policy. During my (Limburgish) interview with the CFO, which took place in his office on 4 December 2017, he gave two reasons why the management preferred to have Dutch-speaking workers:

(...) um de doodsimpele rede det det in de communicatie met elkaar gemekkeliker is, en auk de binding met 't bedrief wat mekkeliker makt.

(...) for the very simple reason that this is easier during the communication with each other, and it also makes the bonding with the company somewhat easier.

Concerning the second reason, "bonding", the CFO elaborated:

De wöls toch gewoeën gaer det medewerkers zich [company name]medewerker veule en det ze ' $n$ good geveul hebbe beej 't bedrief, en 'n good geveul hebbe beej de collega's, eh, en det is netuurlik gemekkeliker as-se met äör kens communicere en as-ze met elkaar kenne communicere, eh, det kump de werksfeer ten goede, det kump daomei auk de kwaliteit ten goede (...)

After all, you would simply like that employees identify as
[company name]-employees, and that they have a good feeling
about the company, and a good feeling about the colleagues, eh,
and that is of course easier if you can communicate with them and
if they can communicate with each other, eh, that is beneficial for
the atmosphere at work, and in that way for the quality as well
(...)

Based on this interview, it appears that the management was quite concerned about processes of bonding among workers themselves, and between workers and the company, and it does not appear that the management was interested in destroying any solidarity between different ethnolinguistic groups of blue-collar workers (Hiss 2017, 708). At the same 
time, the interview shows that the management had a rather narrow perspective on what might lead to such bonding processes. From the CFO's point of view, it was self-evident that non-Dutch-speaking workers had to accommodate linguistically in order to facilitate communication and bonding processes in the foundry. Dutch-speaking workers (including the old guard) were not expected to contribute actively, and other possible bases for communication and bonding (such as English, German, Limburgish, Polish, or a mixture of languages) were not considered, which further confirms how deeply sedimented nation-state discourses had become over time.

As the management tried to place Dutch-speaking workers in the sociolinguistic norm centre, and as knowing Dutch would supposedly facilitate processes of bonding with the company, it might be expected that Dutch-speaking workers such as the old guard felt a relatively strong bond with the management. During my conversations with the members of the old guard, however, it turned out that the standard of bonding set by the foundry's founding father and his son was a difficult one to live up to. For example, one such member whom I talked with (in Limburgish) on 24 July 2017, told me how the former directors would regularly come and see how things were going in the production departments, and how they would shake hands with everyone after New Year's Eve. The same person, plus two other members whom I talked with (in Limburgish) on 14 August 2017, told me about an easter egg that production workers used to get from the management, a practice that apparently stopped recently. Furthermore, two more members of the old guard, whom I talked with (in Limburgish) on 11 September 2017, referred to the free crates of beer that people would occasionally receive from the former directors as a sign of appreciation for their hard work. Even the author of the critical article from the local labour party magazine from 1985 observed that the foundry's founding father was "highly regarded" by his employees.

Of course, salaries and employment conditions had changed over time as well. As discussed previously, the founding father had offered relatively high salaries, and had managed to attract almost exclusively Dutch- and Limburgish-speaking workers in this way. Allegedly, the foundry's salaries were still relatively high compared to other blue-collar workplaces in the Meuse-Rhine borderland in 2017, but not so high that many Dutch- and Limburgish-speaking workers could be convinced to come and work there. Furthermore, as discussed previously, the foundry was increasingly relying on temporary labour from employment agencies since 
the global financial crisis of 2007-2008 (when many of the old guard had been laid off), and the people who were recruited in this way often spoke neither Dutch nor Limburgish. For certain, the foundry's management still invested in certain rewards for its workers (such as free ice cream on a hot summer day), but in the eyes of the old guard, this was not enough.

For the members of the old guard I spoke with, it appeared that the acts of bonding, the salaries, the employment conditions, the lay-offs, and the recruitment of non-Dutch-speaking workers together constituted a holistic entity. As one member whom I talked with on 24 July 2017 told me, these things showed that people had less "respect" for production workers these days. One of the members I talked with on 14 August 2017 also said it was a lack of "respect" for production workers that explained why so many temporary workers with diverse language backgrounds were recruited these days. According to him, people did no longer recognise the "craftmanship" that was needed for their work. Therefore, they would think that high turnover rates and language diversity were no insurmountable obstacles for achieving satisfactory work results. In other words, many of the old guard seemed to feel that their dignity at work was threatened, i.e., their "inherent worth and value and/or being deserving of respect" (Lucas 2011, 354).

These observations have important theoretical implications. The experience of belonging to a sociolinguistic norm centre, as opposed to a periphery, may not be constituted by the question whether people in a constructed periphery follow the language norms of a constructed centre (see, e.g., Pietikäinen and Kelly-Holmes 2013, 9), or by the question whether people in this centre gain more material profits than people in the periphery (see, e.g., Kraft 2019), even though these things all matter. First and foremost, however, the experience of belonging to a sociolinguistic norm centre may be one of deserving and receiving respect from others (regardless of whether these others are actors from a centre or a periphery), and an experience of having inherent worth and value. Moreover, these observations imply that the linguistic landscape cannot be isolated from a broader semiotic landscape (or semiotic assemblage; Pennycook 2019), and that linguistic landscaping acts cannot be separated from other acts of landscaping (e.g., the act of placing easter eggs in the landscape), as these acts may all influence people's subjective experience of workplace dignity. 
For most members of the old guard, it was clear that the norm to speak or learn Dutch was and would not be followed much in practice in the production departments. Hence, the fact that the management continued reproducing this norm, and thus, continued reproducing a deeply sedimented nation-state discourse, was probably not beneficial for the management's credibility in the eyes of the old guard. Interestingly, despite the previously discussed, growing awareness of the importance of the German language for the economy of Limburg, the management did not try to legitimise the spread of German and other languages in the production departments through a discourse of profit (Heller and Duchêne 2012). In theory, for example, the management could have tried to argue that by allowing non-Dutch-speaking workers to enter these departments, the company could increase its production and make (more) profit, which might help the company (and the jobs it provided) to survive, and which might provide the management with more financial resources that could be invested in higher wages and more permanent contracts. In the end, the fact that the management did not produce such a discourse might have further contributed to the common feeling of peripheralisation among the old guard.

\subsection{Conclusion and discussion}

This article has explored the value of linguistic landscaping as a metaphor for describing the historically emerged language diversity and language policy mechanisms in the production departments of a metal foundry in the Dutch province of Limburg, and for explaining the dissatisfaction among the "old guard" (i.e., senior Dutch- and Limburgish-speaking production workers) with the emerged diversity and mechanisms. In this final section, I discuss three advantages of applying this metaphor.

The first advantage is the idea that a landscape has various, historically formed layers. Understanding the old guard's dissatisfaction requires taking into account these layers. To begin with, the foundry as a case shows how deeply sedimented the layer of Dutch nation-state ideology has become in Limburg over time. Within the global colonial landscape, this ideology legitimised the relative privilege of people who were considered part of the Dutch nation (as was indicated, among others, by Dutch being their first language). On top of this national-ideological layer, the foundry's founding father had built a layer of relatively 


\section{0 - Power Dynamics at Work}

exceptional privilege for Dutch- and Limburgish-speaking people who came to work in his company, and whom he offered relatively high wages. In this way, he had even managed to recruit practically no non-Dutch-speaking workers. During my fieldwork in 2017, there were still many production workers in the foundry who had started working there under the management of the founding father or his son. This old guard had seen how things were different in the past, and hence, they did not accept the idea that the company could not help but rely on production workers from temporary employment agencies, who often did not speak Dutch.

The second advantage of linguistic landscaping as a metaphor is the idea that landscapes can (partly) overlap or connect with other landscapes. During my fieldwork, it became clear that the old guard's dissatisfaction concerned more than just the fact that the share of Dutch- and Limburgishspeaking workers had decreased over time. What they apparently appreciated about the founding father, was not just the high wages he offered and the fact that he did not employ non-Dutch-speaking workers (even though these things certainly mattered), but also his regular presence in the production departments, his regular interactions with production workers, and his regular signs of understanding and appreciating people's work. The fact that the founding father seemed proud of his own labour class background, and that he spoke Limburgish (i.e., the language of informality, solidarity, and local and/or regional identity) should not be underestimated in this respect. In short, the acts of linguistic landscaping were part of a broader practice of semiotic landscaping, which constructed a work environment in which the old guard felt they had a dignified position (Lucas 2011). This further implies that the arrival of non-Dutch-speaking production workers in the foundry's linguistic landscape can only partly explain the old guard's dissatisfaction in 2017, and that a broader repertoire or assemblage (Pennycook 2019) should be taken into account to understand why they felt that the company did not represent them anymore.

The third advantage of linguistic landscaping as a metaphor is the idea that diverse and complex hierarchical relations can exist in a multidimensional landscape (Brambilla 2015). The linguistic landscaping acts of the foundry's management clearly aimed at placing Dutch-speaking workers (such as the old guard) in the company's sociolinguistic norm centre. However, considering the observation that many production workers (including the old guard themselves) did not speak Dutch at work, and considering the abovementioned argument that the foundry's linguistic 
landscape was part of a broader semiotic landscape, it becomes clear that is too much of a simplification to present Dutch-speaking workers as the foundry's centre, and non-Dutch-speaking workers as its periphery. Above all, this article has shown that inequality and exploitation are not necessarily given 'facts' that can be objectively detected or measured by a researcher, but subjective experiences based on various acts of linguistic and semiotic landscaping. Apparently, the old guard did not feel that they belonged to the company's periphery under the management of the founding father and his son, but they had started feeling so by 2017. From a linguistic-ethnographic perspective, it is valuable to understand why they experienced this change, and which acts of linguistic and semiotic landscaping have contributed to this experience of change.

The findings discussed here have several implications. For researchers, the article is an invitation to further explore the potential of the linguistic landscape metaphor, and to pay more attention to the complex human experience (rather than just the detection) of inequality and exploitation. For managers, the article may serve as a source of inspiration for how to "bond" or establish relations of solidarity with employees such as the old guard. And last but not least, for employees such as the old guard themselves, the article may serve as a reminder that given constructions and subjective experiences in a particular time and space can never be taken for granted, as they are vulnerable to change over time. Hence, if possible, it may be best to become not too dependent on them. 
82 - Power Dynamics at Work 
Workplace Learning through Human-Machine Interaction - 83

\section{Workplace Learning through Human-Machine Interaction ${ }^{7}$}

\subsection{Introduction}

Practices, or "those repeated social and material acts that have gained sufficient stability over time to reproduce themselves" (Pennycook 2018, 53), play an important role in any work environment. Work practices may have positive or negative consequences for areas such as productivity, workplace safety, and job satisfaction. The concept community of practice is typically used to refer to a group of people who have developed particular practices during a shared history of mutual engagement (Wenger 1998, 83; King 2014). This means that these practices are not based on some preexisting script that, in this case, employees have brought to their workplace. Instead, these practices are jointly negotiated over time and on the whole, it is hard to imagine that much work can be done without them.

The aim of this article is to explore how jointly negotiated work practices can emerge in a contemporary blue-collar work environment that seems far from ideal for this to happen, namely a production department of a metal foundry in the Dutch province of Limburg, less than three kilometres from the Dutch-German border. In this work environment, opportunities for human-human interaction are limited due to mechanisation, as a consequence of which many employees work with particular machines, either alone or in pairs. Moreover, these machines produce a lot of sound, which further limits the opportunities for human-human interaction. Besides this, when human-human interaction occurs, employees are often confronted with language diversity and the transience of work relations, both of which could impact the joint negotiation of work practices (Mortensen 2017). The languages spoken in the metal foundry include Dutch, German, and local varieties from Limburg (known as "Limburgish"; see Cornips 2013), as well as Arabic, Polish, Russian, and Turkish, among others. The individual language repertoires of employees who work in pairs often do not overlap much.

Although mechanisation frustrates processes of jointly negotiating work practices (i.e., workplace learning) in the foundry, the article shows that it also enables various forms of workplace learning, which emerge

\footnotetext{
${ }^{7}$ This chapter has been published in the Journal of Linguistic Anthropology (Hovens 2020).
} 


\section{4 - Power Dynamics at Work}

through human-machine interaction. By analysing a critical case, during which the challenges of transience, language diversity, and limited opportunities for human-human interaction come together, the article shows how human-machine interaction can help to overcome some challenges, while others still remain. ${ }^{8}$ The main participant in the case study is a temporary employee from Poland who needs to learn how to work with a particular machine. At first, he receives some help from a more experienced employee from the Netherlands. They have no shared history yet, and the overlap in their individual language repertoires is limited. Later, the employee from Poland is left to work with the machine on his own. Applying a posthumanist framework (Latour 2005; Pennycook 2018), the article discusses the employee's workplace learning process, and the diverse functions of human-machine interaction that emerge during this process.

The article starts with a literature review about existing linguistic-ethnographic research in blue-collar work environments. The methodological background of the study (including its ethical considerations) is then elaborated upon. The subsequent sections focus on the theoretical framework and the empirical material as the basis for the final discussion about the implications of the study for our understanding of language, workplace learning, and mechanisation in contemporary blue-collar work environments.

\subsection{Language and workplace learning in blue-collar work environments}

Transience and language diversity characterise many contemporary blue-collar work environments. Lønsmann and Kraft $(2017,138)$ define blue-collar workers as labourers in the primary sector (e.g., agriculture) and the secondary sector (e.g., manufacturing), whose jobs are "often, but not always, temporary, and low-status." Furthermore, many studies of blue-collar workplaces highlight language diversity as a prominent theme (e.g., Goldstein 1997; Handford and Matous 2015; Kleifgen 2013; Kraft 2017; Piller and Lising 2014; Sunaoshi 2005; Theodoropoulou 2019; Tutt et

\footnotetext{
${ }^{8}$ Since the publication of this journal article in 2020, the theoretical perspectives of the PhD dissertation have been further developed. While language diversity is introduced as a "challenge" in this article, I took a slightly different position in the introduction of the dissertation in chapter 1.1.
} 
al. 2013), although there are well-known exceptions to this tendency (e.g., Daly et al. 2004; Holmes and Marra 2002; Holmes and Woodhams 2013).

Several studies that focus on language diversity in blue-collar work environments show that employees with similar ethnolinguistic backgrounds tend to work together in groups there, and that they often speak a different language at work than the country's official or majority language (Goldstein 1997; Kleifgen 2013; Piller and Lising 2014). Kleifgen $(2013,162)$ points out that "an open policy regarding self-selected teams and multiple-language use" can positively affect processes of workplace learning in such settings. However, in work environments where learning typically depends on interactions between employees whose individual language repertoires do not overlap much, communication may still be a challenge.

In a study of a manufacturing company in the United States, Sunaoshi (2005) found that higher-ranking workers from Japan had difficulties using English in their interactions with lower-ranking workers from the United States. Despite such difficulties, the study found that interactions became more effective once workers had spent more time with each other (Sunaoshi 2005, 192-193). Similar observations have been made on construction sites in the United Kingdom (Tutt et al. 2013) and Qatar (Theodoropoulou 2019), where workers with diverse language backgrounds developed a shared repertoire over time. These findings suggest that language diversity can become less of a challenge when workers spend some time together and, thus, develop particular ways of interacting.

On the other hand, these findings also suggest that jointly negotiated work practices may not be as likely to emerge in an environment that is not only characterized by language diversity, but also by transience. On a construction site in Hong Kong, Handford and Matous (2015, 95-96) found that time pressure, combined with the importance of safety, could explain why the construction workers spent little effort on interpersonal accommodation, particularly on the side of full-time employees from Japan towards contracted employees from Hong Kong. Another explanation is that these employees possibly did not see much value in spending time on creating goodwill, as their work relations would be short-lived (Handford and Matous 2015, 96). Thus, transience may not only pose a challenge to workplace learning due to a lack of time, but also due to a lack of motivation. 
One strategy that people, whose individual language repertoires do not overlap much, may use when they need to interact, is to employ certain multilingual modes (see Backus et al. 2013), such as a lingua franca (Hülmbauer, Böhringer, and Seidlhofer 2008), receptive multilingualism (Ten Thije and Zeevaert 2007), code-switching or code-mixing (Muysken 2000), languaging (Jørgensen and Varga 2011), and translation or interpretation (see, e.g., Kraft 2020a). One additional strategy to deal with both linguistic and auditory challenges is to rely on non-verbal communicative modes. Various studies of blue-collar workplaces have, in fact, highlighted the important role of non-verbal modes such as gestures, objects, sounds, gaze, and body positioning (Gherardi and Nicolini 2002; Kleifgen 2013; Sunaoshi 2005; Theodoropoulou 2019; Tutt et al. 2013).

Nonetheless, in a study of workplace learning on a construction site in Italy, Gherardi and Nicolini (2002, 206-208) found that verbal resources played an important role in the construction of memorable events, as the situated use of certain words (e.g., "always", "never", "you should", "well done") helped newcomers to memorise specific situations in specific ways, and to develop a sense of how to see and feel in this environment. This indicates that situated combinations of verbal and non-verbal modes might be essential for the development of a professional vision (Goodwin 1994).

Apart from the human employment of multilingual modes, translation, interpretation, and non-verbal communicative modes, human-machine interaction can also play an important role in mechanised work environments. In a study of workplace learning in a circuit board manufacturing plant in the United States, Kleifgen $(2013,61-63)$ observed how a machine produced rhythmic sounds that experienced employees could interpret as indications of a robotic arm managing or failing to pick a socket. This is how the machine became an active participant in the situated interactions and learning processes at work. The active role of machines has also been explored by Suchman (2007), who argues that machines cannot be as effective as experienced human tutors in situated learning processes, as they typically miss the circumstantial and interactional details that human-human interaction routinely relies upon (Suchman 2007, 182-183). Human-machine interaction alone may not overcome the potential challenges posed by language diversity, in other words.

Finally, language diversity may pose a challenge to workplace learning in relation to written communication. Written texts -or literacy 
artifacts (Barton and Hamilton 2005)- play an important role in many daily interactions in the workplace. In such institutional settings, texts are often thought to exercise power and control over work practices, but as pointed out by Ueno (2000) and Kleifgen (2013), they need to be recontextualized and (re)appropriated in order to become meaningful in situated interactions. Therefore, an inability to make sense of a written text may frustrate such (re)appropriations, as Lønsmann (2014, 100-101) found with regard to blue-collar workers in a multinational company in Denmark, who had problems understanding English signs, computer messages, and emails.

\subsection{Methodology}

This article focuses on one audio-recorded case, in which diverse circumstances that may challenge workplace learning (limited opportunities for human-human interaction, transient work relations, language diversity) come together. By analysing this critical case, the article explores the question whether and, if so, how jointly negotiated work practices can emerge under these combined circumstances. Furthermore, the selected case can be considered typical in the sense that it reveals the functions that human-machine interaction can fulfil during such processes. If human-machine interaction helps to overcome the already mentioned challenges for workplace learning in this case, it can probably fulfil important functions in less challenging learning situations as well.

The selected case was recorded during a 3.5-month period of ethnographic fieldwork in the metal foundry, which took place between 3 July and 15 October 2017. During this time, I participated in various work practices in almost every foundry production department as an additional worker, for example, by helping people lift heavy products. My participation in these practices implied that I worked different shifts, including night shifts. In total, I made 74 hours of audio recordings and 6.5 hours of video recordings of workplace interactions; I audio-recorded 11.5 hours of interviews; I took 139 photographs; I wrote approximately 150 pages of fieldnotes; and I collected a wide range of other data. The current article's case study is based on one audio recording, two photographs, and my fieldnotes.

As other researchers in blue-collar work environments have noticed as well (e.g., Holmes and Woodhams 2013, 280-281), the sound levels in the foundry posed a challenge to making good-quality audio recordings. 


\section{8 - Power Dynamics at Work}

Moreover, I found that employees' talk during work practices was often fragmented and full of deictic words, which made it impossible to interpret the recordings in case I was not present. Therefore, I am clearly present as a participant in the audio-recorded interactions, and I typically carried the recording equipment in the pocket of my work shirt. In the remaining sections of this article, I will further reflect upon the impact of my presence. As I wanted to find out how employees talked with each other, I decided that I could not act as their interpreter.

Due to the size of the foundry (which had around 500 employees during my fieldwork), the transience of the workforce, and my procedure of regularly changing work teams, it was impossible to get explicit consent from every employee before my fieldwork started. Therefore, I worked with implicit consent by hanging up a written announcement in three languages (Dutch, English, and German) in the workplace. The Ethics Review Committee Inner City Faculties in Maastricht has officially approved this research practice. Nevertheless, I still asked for people's explicit consent before recording them.

Finally, although I made observations in every single production department during my fieldwork, it is no coincidence that this article focuses on a case from the Finishing Department in particular. Work practices that made up the foundry production process were clustered into four departments: the Core Shooting Department (where sand cores were produced to mould the metal); the Melting Department (where metal was melted); the Casting Department (where the molten metal was moulded using the sand cores); and the Finishing Department (where the metal products, after hardening, were sawn, ground, blasted, welded, and quality-checked, among other actions). Among these four departments, the Core Shooting Department and the Finishing Department had the highest percentage of temporary workers (both around 60\%), and the diversity of spoken languages in these departments was relatively high as well. In the next section, I introduce the Finishing Department in more detail.

\subsection{Transience and language diversity in the Finishing Department}

The main participant of this article's case study is VIN, a younger $(>30)$ man from Poland. When I met VIN in the metal foundry, he had lived in the Netherlands for almost a year. During this time, he had worked in three different places (consecutively) through a temporary employment agency 
(hereafter: agency). The foundry was his third workplace, and VIN had worked there for about two months when we met. As the current section shows, VIN can be considered a typical example of the foundry's historically developed labour recruitment practices.

Like other employees, VIN was assigned to work in one particular production department where he would usually stay as long as he worked in the foundry. In VIN's case, this was the Finishing Department. Counting 150 employees at the time of my fieldwork, who worked in three different eight-hour shifts, this was the largest production department. At the time, there were 88 temporary employment agency workers (hereafter: agency workers) like VIN in the Finishing Department, making 59\% of the staff. ${ }^{9}$

Most agency workers in the Finishing Department (66-70 workers, or $75-80 \%$ ), including VIN, had a so-called "stage A contract" (Dutch: "fase A-contract") in August 2017. "Stage A" means that an employee had been working via an agency for less than 78 weeks (uitzendbureau.nl 2018). During this stage, he could do hourly work for an unlimited number of employers through the agency, but neither the employer nor the agency had to guarantee any number of working hours (uitzendbureau.nl 2018). The remaining 18-22 agency workers (20-25\%) had a "stage B contract", which means that they had worked via an agency for more than 78 weeks, and were now working on the basis of temporary contracts from this agency (uitzendbureau.nl 2018).

During my fieldwork in 2017, the economy was doing very well and the demand for the foundry's products was very high. In contrast, following the global financial crisis of 2007-2008, the foundry narrowly escaped bankruptcy and had to lay off more than 100 employees. Since then, the foundry's management had been cautious with handing out new permanent contracts, as the CFO explained to me in an interview. ${ }^{10}$ Using agency workers instead, the foundry was able to adapt more easily to

\footnotetext{
9 I have received the data about the agency workers directly from one of the agency's recruiters as an anonymized Microsoft Excel file. I have gathered the data about the metal foundry workers through email communication with an HR manager from the foundry. As the HR manager filled in some gaps in the data from 2017 with data from 2018, there might be small differences between the actual figures and the data presented here.

${ }^{10}$ The (Limburgish) interview with the CFO took place in the CFO's office on December 4, 2017.
} 
(sudden) changes in the demand for its products, which primarily included metal components of trucks, luxury cars, and central heating boilers.

When the economy was blooming again as in 2017, the foundry had a hard time finding enough agency workers to keep up with the rising demand for its products. Therefore, the agency that worked for the foundry had started looking for labour beyond the Dutch border, which was facilitated by the European Union's free movement of people. Consequently, people like VIN gained an opportunity to work in the foundry.

In the Finishing Department, people with Dutch citizenship (including first-generation migrants who had obtained Dutch citizenship) made up less than half (48\%) of the workforce, although they were still the largest national group. People with German citizenship were the second largest group (25\%), which can be explained by the foundry's proximity to the Dutch-German border. The third largest group (11\%) consisted of people with Polish citizenship, including VIN, which is in line with the observation that there are many labour migrants from Poland who work for agencies in the Netherlands (Berkhout, Bisschop, and Volkerink 2014). The remaining workers (16\%) included citizens from EU countries like Greece, Hungary, and the Czech Republic, as well as citizens from non-EU countries like Morocco, Syria, and Turkey.

Furthermore, in the Finishing Department, most employees with Dutch citizenship (67\%) worked on permanent contracts from the foundry, while most employees with German citizenship (84\%), Polish citizenship $(100 \%)$, and others (67\%) worked for an agency. The reasons for these differences are partly historical. As many older employees and one former CEO explained to me, most production workers up until, approximately, the 1990s could speak Dutch. ${ }^{11}$ Ever since that time, the need for more labour gradually opened up the production departments for, first, German-speaking employees and, since January 2017, employees who

\footnotetext{
${ }^{11}$ Among the older workers to tell me about this development were an employee from Limburg whom I spoke to (in Limburgish) during a work shift in the Casting Department on July 24, 2017, an employee from Limburg whom I spoke to (in Limburgish) during a work shift in the Finishing Department on August 28, 2017, and an employee from Germany whom I spoke to (in Limburgish) during a work shift in the Finishing Department on September 26, 2017. The (Limburgish) interview with the former CEO took place in the former CEO's home on October 18, 2017.
} 
Workplace Learning through Human-Machine Interaction - 91

spoke neither Dutch nor German (but, in most cases, some English). Recently recruited employees, especially since the financial crisis of 20072008 , tended to work for agencies.

VIN started work for the foundry in mid-2017. Apart from his first language, Polish, I mostly heard him speak English in the workplace. He did not speak Dutch or German, although he occasionally blended in a German word in an otherwise English sentence. That newcomers like VIN did not (or did hardly) speak Dutch or German was considered a problem by many of the older, Dutch and German-speaking employees, who often felt uncomfortable speaking English. VIN, on the other hand, told me (in English) that he did not consider language diversity a problem, as long as his coworkers showed him what to do: "it is about how to show me how make it -dat-dat-dat- I can do that". I will explore how VIN did, indeed, manage to develop some relevant expertise during a work shift in the Finishing Department, but first I will explain my theoretical approach to the joint negotiation of work practices.

\subsection{A posthumanist approach to workplace learning in the Finishing Department}

What distinguishes practices from other repeated social and material acts is that they "have gained sufficient stability over time to reproduce themselves" (Pennycook 2018, 53). Communities of practice (Lave and Wenger 1991; Wenger 1998) is a well-known framework that helps to describe how specific acts gain such stability, as it offers a set of technical terms or tools that can capture the joint negotiation of particular practices over time. In the current section, I discuss how this framework can be applied in VIN's work environment, the Finishing Department.

Following Wenger $(1998,73)$, a community of practice consists of participants who engage with each other due to a joint enterprise, and who build up a shared repertoire while doing so. Joint enterprises that I observed in the Finishing Department included specific work practices such as the sawing, grinding, blasting, welding, and quality-checking of hardened metal products. Specialized employees always did the welding tasks, and these welders did not do other tasks. Other employees could be assigned to do any of the remaining tasks, either alone or in pairs, and which task they 


\section{2 - Power Dynamics at Work}

did could vary per work shift. Therefore, I consider all employees in the Finishing Department who were participating in any of the remaining tasks as potential members of one community of practice. The overarching, joint enterprise of this community would be to finish the production process of particular metal products.

In order to achieve the different purposes of their joint enterprise, employees in the Finishing Department worked with reifications (Wenger 1998, 58-61) as diverse as tools, words, machines, and printed work instructions. According to Wenger $(1998,61)$, reifications typically create shortcuts for the participants of a joint enterprise, which can help certain actions to take less effort and become more effective. The introduction of hoists in the Finishing Department, for example, had probably once made it easier to lift heavy products. Similarly, the introduction of the commonly used, English abbreviation "FD" had probably once made it easier to refer to this department.

Wenger $(1998,88)$ further underlines that reifications are "open to reinterpretation and to multiple interpretations." At the same time, Latour (1992, 225-227) and Holland et al. (1998, 60-63) have pointed out that reifications -which they call artifacts- can encourage and discourage certain ways of use by certain participants. In other words, reifications afford (Gibson 2015, 119-120) certain meanings or practices. The hoists in the Finishing Department, for example, were attached to rails in the ceiling, which afforded employees with diverse body types to lift heavy products in specific areas of the workplace, and not in others. Similarly, the abbreviation "FD" afforded quick communication between employees with diverse language repertoires at particular moments in particular areas of the foundry, depending on the sound level. If intentionality is not assumed to be a requirement for agency, as in actor-network theory (Latour 2005) and posthumanist applied linguistics (Pennycook 2018), these observations problematise the distinction between participants and reifications (hereafter: artifacts) in a community of practice.

Problematising the distinction between participants and artifacts has implications for the shared repertoire of a community of practice as well. Wenger $(1998,84)$ argues that a community's shared repertoire should not be thought of as a container of "literally shared meaning" between all members of a community of practice, but as "a resource for the negotiation of meaning" between these members. Considering that the 
artifacts that make up such a "resource" play an active role as participants in the negotiation of meaning or practices, however, the community's shared repertoire may be better thought of as a spatial repertoire (Pennycook 2018, 47-51). This spatial repertoire consists of all interacting participants-and-artifacts then -in other words, all actants (Latour 2005, 53-55)- during the pursuit of a joint enterprise in a particular time and space.

Problematising the distinction between participants and artifacts does not preclude any differences between different types of actants. According to Wenger $(1998,88)$, participants and artifacts act as "distinct forms of memory and distinct forms of forgetting". Although a distinction between participants and artifacts on the basis of memory may be problematic as well, it is plausible that the accumulation of memories of past experiences matters for the degree in which actants participate in the practices of a community. Therefore, I keep the distinction between masters and apprentices (hereafter: experts and newcomers), which Lave and Wenger $(1991,56)$ have constructed to make a relative distinction between different actants in a community of practice based on their degree of participation.

In the Finishing Department, certain experienced employees (experts) were able to do any of the non-welding tasks, while others could only do some of them. Newcomers were usually not able to do any of these tasks on their own yet, as they lacked the expertise to interact with human co-workers and non-human artifacts in a meaningful way for the pursuit of their joint enterprise. Lave and Wenger (1991) have shown how such newcomers typically start their involvement in a community's practices through "legitimate peripheral participation" by doing simple aspects of a task, and how their involvement becomes more complex as they gradually move towards "full participation" in the community's practices. Wenger (1998, 99-101) underlines how newcomers typically depend on mutual engagement with more experienced human co-workers (i.e., experts), which would explain why it is important that these experts consider the participation of newcomers legitimate. In the next sections, I discuss how this framework can be applied to the work situation which VIN, a newcomer to the Finishing Department, found himself in upon our first meeting. 


\subsection{Human-machine interaction as a means to distinguish newcomers from experts}

Initially, it was a challenge for me to distinguish newcomers from experts in the Finishing Department. As may be expected in an industrial work environment, the department's joint enterprise was Taylorised, i.e., segmented into "standardized, repeatable tasks in order to maximize efficient production" (Urciuoli and LaDousa 2013, 177). Moreover, many work tasks were delegated to machines (mechanisation) and employees' work largely consisted of enabling these machines to do such tasks (e.g., by feeding them certain materials).

However, during the delegation of tasks, I noticed that human expertise was still considered relevant here. This task delegation was done at the start of a work shift by a team manager, who had an overview of the available labour and the particular needs of a given moment. As discussed in the previous section, welding tasks were only done by specialised welders (human experts). Other production workers were assigned to do the remaining tasks, which mostly involved interactions with a particular machine. Such machines were usually operated by one or two employees, which means that production workers typically worked alone or in pairs. During my fieldwork, the question whether an employee was considered capable of working alone with a machine turned out to be an important indicator of whether he was still considered a newcomer.

In the Finishing Department, where many employees had temporary contracts and diverse language backgrounds, team managers did not seem to take language skills into account when they asked two people to work together, as I frequently saw people working together who did not share a lot of language resources. Two team managers from this department whom I spoke to about my observation, confirmed that they did not take language skills into account. ${ }^{12}$ Considering that many of the more experienced workers were older men from the Netherlands or Germany, unlike many newcomers, I could see the challenge for the managers to find 'linguistic matches'. As a consequence, mutual

\footnotetext{
12 The (Limburgish) conversation with the first team manager from the Finishing Department took place during a work shift on August 25, 2017. The (Limburgish) conversation with the second (interim) team manager from the Finishing Department took place during a work shift on August 28, 2017.
} 
Workplace Learning through Human-Machine Interaction - 95

engagement between newcomers and experts often constituted a challenge.

The current article's case study is an example of such a challenging situation. When VIN and I met for the first time, he was assigned to work with a blasting machine. This artifact was introduced to the spatial repertoire of the Finishing Department's community of practice, because it could help clean metal products by blasting a special kind of sand. VIN was not familiar with this artifact yet, so he still had to figure out how to interact with it. He was accompanied by a more experienced worker (a human expert) who could show him how to do this. This was PER, an older, permanent contract worker from Limburg, the Netherlands, who had worked in the metal foundry for over 20 years. After 2.5 hours, PER would leave the workplace and VIN would have to be able to work with the blasting machine on his own then, which implies that he had to develop a certain degree of expertise in a short period of time.

The main task of people working with the blasting machine was to hang metal products on hooks, which would go through a blasting cabin like a 'merry-go-round'. After this 'ride', the workers had to take the products off the hooks again and remove any remaining sand from them, for example by putting the products on a vibrating table. Afterwards, the workers had to check the products for possible flaws. They would do this partly with their naked eye, and partly by using certain tools. Possible flaws would be marked with a crayon. Finally, 'flawless' products were placed on a pallet, while 'flawed' products were placed on another pallet. A forklift truck would come and bring the 'flawless' products to the next stage of the production process, while the 'flawed' products were brought to a welder.

The quality check clearly involved some degree of human expertise. To facilitate this task, the spatial repertoire was usually enriched with written work instructions (a literacy artifact) that made clear what to pay attention to when checking the quality of a particular product type. These instructions were always written in Dutch only, and they were always accompanied with photos and illustrations. Despite the latter, a newcomer without any knowledge of Dutch would probably not be able to understand the instructions, as they often contained specific explanations such as "hier mag een braam van max. $2 \mathrm{~mm}$ blijven staan" ("a burr of max. $2 \mathrm{~mm}$ may remain here"). Literacy artifacts like this required some human expertise before they could afford a meaningful interaction with an employee for the pursuit of a joint enterprise in the Finishing Department, in other words. 
96 - Power Dynamics at Work

When I met VIN and PER at the blasting machine, PER told me that someone else would afterwards perform a quality check this time. Possibly, this explains why VIN was thought to be able to work alone later that day. If you want to perform a quality check, PER told me in Limburgish, "den mos-se wete was-se "nt doon bös" ("then you have to know what you are doing"). Since VIN was not involved in the quality-check practice this way, he did not develop his expertise in this respect, which could have turned him into a fuller participant in the work practices with the blasting machine. He did, however, need to develop his expertise with regard to the interactions with the blasting machine. At the start of the work shift, it was this expertise that distinguished PER from VIN, and VIN's learning process can be considered a means to enable the blasting machine to perform its cleaning task.

Yet, PER did not seem particularly motivated to support this cause, because he did not expect VIN to stay very long in the foundry anyway-or, in his words: "euver twieje-en-'n-half oor bön ik weg, morge steit dae heej nimmer" ("in two-and-a-half hours I am gone, tomorrow he is not here anymore"). Moreover, PER did not agree with his employer's policy to recruit migrant workers like VIN, as "hae ken auk Nederlanders pakke, we hebbe namelijk viefhonderddoezend werkloze" ("he could also take Dutch people, we have five-hundred-thousand jobless people after all"). For PER, not investing in VIN's learning process was a way to resist this policy, and he did not consider VIN's role as a newcomer in the foundry legitimate, in other words.

Furthermore, this refusal to invest in VIN's learning process might have been a way for PER to maintain the distinction between himself as an expert, and VIN as a newcomer. It is possible to understand PER's apparent desire to underline this expert identity against the background of Taylorisation (which could make employees more easily replaceable by others), the idea that permanent workers like PER might get laid off during a crisis (as happened after the financial crisis of 2007-2008), and the idea that blue-collar jobs are often considered "low-status" (Lønsmann and Kraft 2017, 138). Moreover, PER's reluctance confirms the idea that transience may not only pose a challenge to workplace learning due to a lack of time, but also due to a lack of motivation to invest in the learning process of newcomers. Despite his apparent reluctance, however, the next section shows how PER still helped VIN to develop his expertise in human-machine interaction during the analysed work shift. 
Workplace Learning through Human-Machine Interaction - 97

\subsection{Human-machine interaction as a communicative mode}

The case examined in this article shows what can happen when various obstacles, which challenge the development of jointly negotiated work practices, come together during one event. The current section focuses on the interactions between PER and VIN and explores the question whether and how this mutual engagement contributed to the development of jointly negotiated work practices, which primarily involved interacting with a blasting machine (a non-human artifact).

The first obstacle concerns the limited overlap between PER and VIN's individual language repertoires. As discussed earlier, I only heard VIN speak Polish (his first language) and English (his second language) in the foundry, although he occasionally blended in a German word in an otherwise English sentence. I heard PER speak Dutch and Limburgish (his first languages), as well as German and English (his second languages). In theory, this meant that they could employ the communicative mode of English as a lingua franca, but PER told me that he had hardly spoken any English since secondary school. Similar to most other, older production workers from Limburg I met in the foundry, he preferred using German over English with his colleagues.

The second obstacle concerns the transience of the work relation between PER and VIN. They had never worked together before, so they could not rely on memories of any jointly negotiated work or communication practices from the past. The third obstacle concerns the limited opportunities for human-human interaction, as PER had to leave the workplace after 2.5 hours, and VIN would have to be able to work with the blasting machine on his own then.

Moreover, PER's unwillingness to spend much time and effort on VIN's learning process can be considered another obstacle. The same is valid for the impact of my presence on the analysed event. Without being present, I would not have been able to make sense of the audio-recorded interactions between PER and VIN. At the same time, my presence meant that I became part of these interactions. As the current section shows, this probably frustrated the mutual engagement between PER and VIN.

When I first met PER and VIN, I introduced myself and my research project and asked for their permission to make an audio recording. To 


\section{8 - Power Dynamics at Work}

ensure that I was being understood and to establish an informal, nonthreatening atmosphere, I decided to use Limburgish when I talked with PER. As I could not do something similar by speaking Polish with VIN, I decided to use English when I talked with him. Hence, my introductory talks with PER and VIN were more or less separate conversations: one in a monolingual Limburgish mode, and one in an English lingua franca mode. However, based on some of PER's utterances I could tell that he overheard and understood some content from the English conversation between VIN and me. VIN did not seem to understand the Limburgish conversation between PER and me.

My introductory conversation with PER took quite a bit longer than the one with VIN. PER shared many opinions about the foundry with me during this conversation, which I possibly allowed or even encouraged him to do by verbally acknowledging that I was listening to him (e.g., by saying "jao-jao", which means "yeah-yeah" in Limburgish). I have discussed some of these opinions, such as PER's view on the recruitment of labour migrants, in the previous section. Clearly, conversations like these were useful for me to develop an understanding of the environment that I found myself in.

At the same time, my initial decisions had a noticeable effect on the interactions that I became part of. When PER spoke to me, he would use Limburgish. When VIN spoke to me, he would use English. Furthermore, PER continued to share many opinions about the foundry with me, which is an investment in mutual engagement that he might have spent differently without my presence. Moreover, as PER noticed that I did not mind speaking English with VIN, he tried to use me as an interpreter once.

Extract 2 shows the interactions between PER and VIN that occurred after PER asked me to interpret for him, which I politely refused. Before asking me, he had just explained to me (in Limburgish) how the situation at the blasting machine was rather exceptional at that moment. Of the five hooks that were going through the blasting machine, four had to remain empty. The reason was that one particular type of product had to be blasted as fast as possible, because another employee urgently needed it. Unfortunately, there was only one hook that matched this product type. To speed up the process, the team manager had asked PER to only use this hook for now, and to leave the other four empty. As the blasting time could be adjusted for each individual hook (via the machine's control panel), the blasting time for each empty hook could be reduced to the minimum (three 
seconds). The amount of 'wasted time' would then be reduced to a minimum as well.

Due to this exceptional situation, VIN could develop new expertise that would turn him into a fuller participant in the work practices. As long as PER and VIN were working together, PER could adjust the blasting time himself - which he also did. Once he would leave, however, VIN had to perform this task on his own, but explaining how to do this was a challenge for PER. Therefore, after telling me how difficult it would be for him to explain everything in English, PER asked me if I could explain the task to VIN. After I refused, PER made an effort himself, as extract 2 shows.

\section{Extract 2}

Italics $=$ original transcription

$\underline{\text { Bold italics underlined }}=$ original transcription (associated with Dutch)

* Bold italics underlined with asterisks ${ }^{*}=$ original transcription (associated with Limburgish)

Bold italics $=$ English translation

\begin{tabular}{|c|c|c|}
\hline Participant & Verbal transcription & Other interactions \\
\hline 01 PER: & $\begin{array}{l}\text { do you have see what I have done? (.) do } \\
\text { you have see what I have done? } \\
\text { e:h what (is) }\end{array}$ & \\
\hline 03 PER: & $\begin{array}{l}\text { [clock] you } \frac{\text { zet }}{\text { set }} \text { the clock } a(x x x) \text { e:h on } \\
\text { three seconds (.1) four times (.1) on one } \\
\text { (.) on eh }\left(^{*} \frac{\left.d r e e j^{*}\right)}{\text { three }}\right. \\
\text { a big one (.) three minutes (.1) on } \\
\text { (.) and four times (.) three seconds (.7) } \\
\text { ja? (.1) one minute (.1) two minutes (.1) } \\
\text { yes? }\end{array}$ & $\begin{array}{l}\text { PER shows VIN } \\
\text { how to adjust the } \\
\text { blasting time, } \\
\text { using a relay } \\
\text { Above the relay, } \\
\text { there is a plate } \\
\text { with the Dutch } \\
\text { words "relais } \\
\text { straaltijd" ("relay }\end{array}$ \\
\hline
\end{tabular}


100 - Power Dynamics at Work

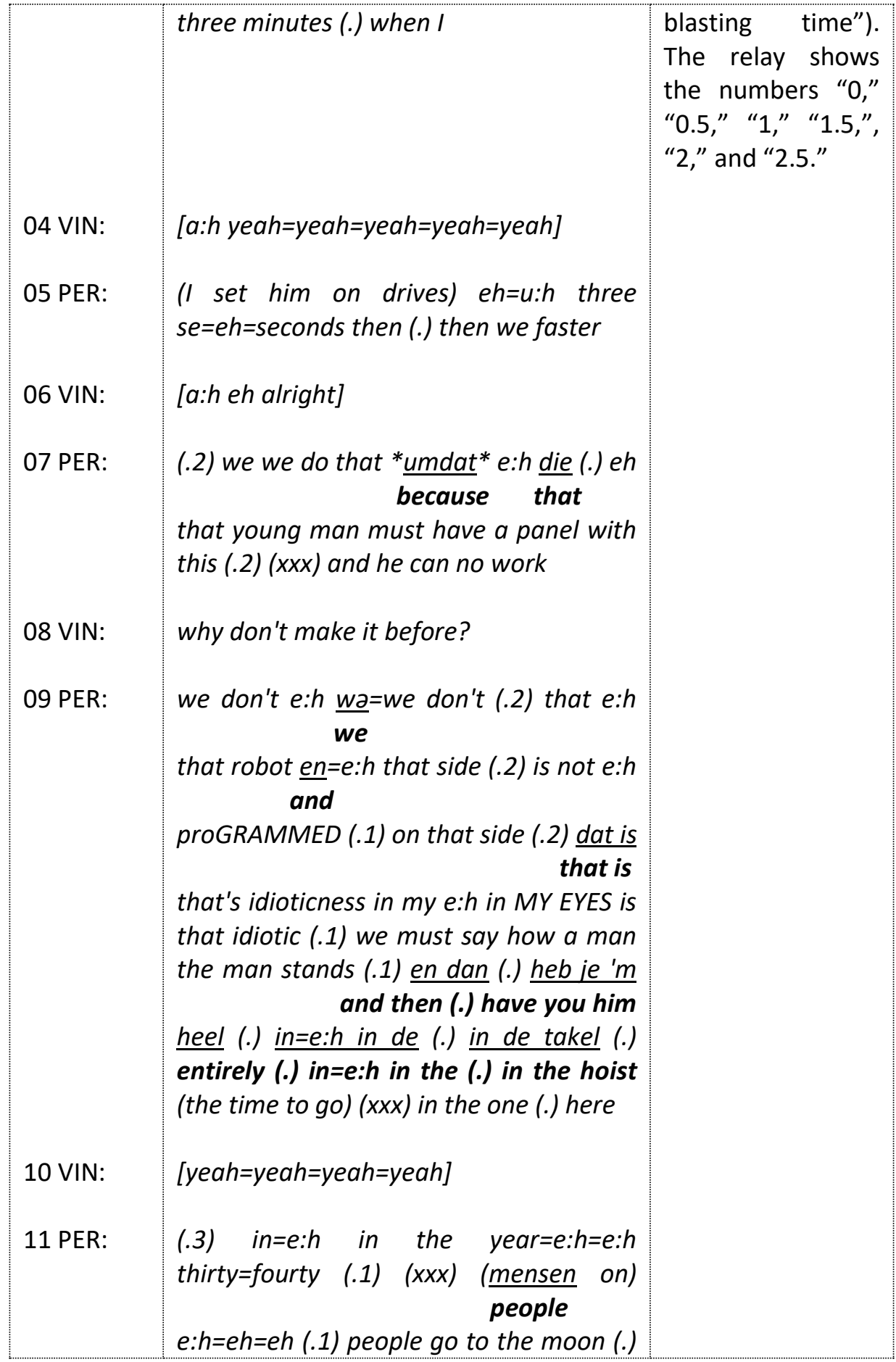


Workplace Learning through Human-Machine Interaction - 101

$\left[\begin{array}{l}\text { *en weej werke weej werke nog op die } \\ \text { manier* }^{*} \\ \text { and we work we work still in this way }\end{array}\right]$

Considering PER's reluctance to spend any effort on VIN's learning process and his modest appraisal of his own English speaking skills, it is rather surprising that he still decided to enrich the spatial repertoire with English language resources when explaining the practice of adjusting the blasting time to VIN. Typical of the communicative mode of English as a lingua franca, he combined these English resources with other verbal and nonverbal resources. Examples of verbal resources that he used are the Limburgish words "dreej" ("three", in line 3) and "umdat" ("because", in line 7), and the Dutch phrase "en dan heb je ' $m$ heel in de takel" ("and then you have him entirely in the hoist", line 9). In line 11, PER completely switched to a Limburgish mode again, when saying "en weej werke nog op die manier" ("and we still work in this way"). With regard to non-verbal communicative modes, PER performed the adjustment of the blasting time for VIN (line 3), while the relay (a literacy artifact in the spatial repertoire) afforded meaning-making through the numbers that it showed.

PER's opening question ("do you have see what I have done?" in line 1) immediately constructed PER as the more resourceful expert (who did something that VIN apparently needed to pay attention to), while it constructed VIN as the less resourceful newcomer. This way, the purpose or discourse type (Redder 2008, 140) of the interaction -instruction- was immediately established as well. Besides that, this question might have helped to turn the situation into a memorable event (Gherardi and Nicolini 2002, 206-208). Considering the purpose, line 3 is of central importance. After all, this is where PER gave the instruction that was supposed to teach VIN how to adjust the blasting time. Moreover, line 4 ("a:h yeah=yeah=yeah=yeah=yeah") indicates that VIN understood the explanation, which means that the purpose seemed to be achieved.

Whether VIN really knew how to adjust the blasting time by himself remained unclear as long as PER was still with him, because PER did not let VIN try to do the adjustment himself. When after 2.5 hours PER left the workplace, I stayed behind with VIN for approximately two more hours. During this time, it was confirmed to me that VIN had, indeed, understood PER's explanation, as he showed that he was able to adjust the blasting 
time by himself. He also knew which times to set the machine to. Thus, VIN had become a fuller participant in the work practices with the blasting machine.

However, PER could not know for certain whether VIN had actually understood his explanation. When PER was about to leave the workplace, this realisation urged him to check once more whether VIN would be able to perform the given tasks on his own. This second interaction between PER and VIN (see extract 1 in chapter 1 ) was similar to the first one (extract 2) in several ways. Again, the interaction started with PER asking a question ("do you know how the system works?"), which immediately constructed PER as the expert and VIN as the newcomer. And again, PER gave a verbal explanation in English while at the same time performing the human-machine interaction, but he still did not let VIN try to perform this interaction by himself. Apart from these two interactions, PER and VIN hardly talked with each other at all.

Finally, PER's switch from English as a lingua franca to a monolingual Limburgish mode (line 11) is worth some consideration. It is unlikely that PER would have made such a full switch without my presence, which raises the question who was the main addressee in line 9 and line 11: VIN or me?

Although I underlined in my self-introduction that I worked independently from the foundry's and the agency's management, it is possible that PER suspected that my observations would reach his employer. Concerning the observation that PER did not let VIN try to perform the human-machine interaction by himself, this leads to at least three possible interpretations. First, PER might simply not have thought about letting VIN try himself. Second, PER might have wanted to maintain some power distance between himself (the expert) and VIN by not letting VIN handle the machine. Third, PER's attempt to instruct VIN might not have been very genuine, and extract 2 might primarily have been a way for PER to show me how difficult it was to achieve a work-related purpose with an English-speaking agency worker like VIN. Possibly, PER thought that I might report such a finding to his employer afterwards.

No matter what PER's intention was, however, and despite all the odds, the purpose of PER's instruction was still achieved. By observing PER's human-machine interaction while listening to PER's English utterances, and through the affordances of the control panel, VIN managed to figure out 
Workplace Learning through Human-Machine Interaction - 103

how he could adjust the blasting time by himself. Whether VIN performed this task exactly in the way envisioned by PER in the end is irrelevant. VIN's potential influence on this task -his agency- is exactly what made it a jointly negotiated work practice, and although the total amount of jointly negotiated practices was minimal, this practice still contributed to the development of VIN's expertise, or professional vision (Goodwin 1994), with regard to the interactions with the blasting machine.

\subsection{Human-machine interaction as a joint negotiation of work practices}

Whereas the previous sections explored the function of human-machine interaction as a valuable outcome of jointly negotiating work practices, and the function of human-machine interaction as an additional resource for human-human interaction during the negotiation process, the current section centres its attention on human-machine interaction as a joint negotiation process in itself. Specifically, the section focuses on the interactions between VIN and the blasting machine that occurred after PER had left the workplace.

Although VIN had learnt how to adjust the blasting time by himself, this did not mean that everything went well. In fact, approximately 15 minutes after PER had left, VIN and I were already confronted with a problem. All of a sudden, the blasting machine stopped working, and neither of us understood why this had happened. Fortunately, the machine 'spoke' to us about the apparent problem by enriching the spatial repertoire with a Dutch message that it displayed on a screen: a literacy artifact (figure 7). The only difficulty was that we did not understand this message, which was "ongeoorloofde doorloop laadplaats" ("illegal passage of loading-point"). 


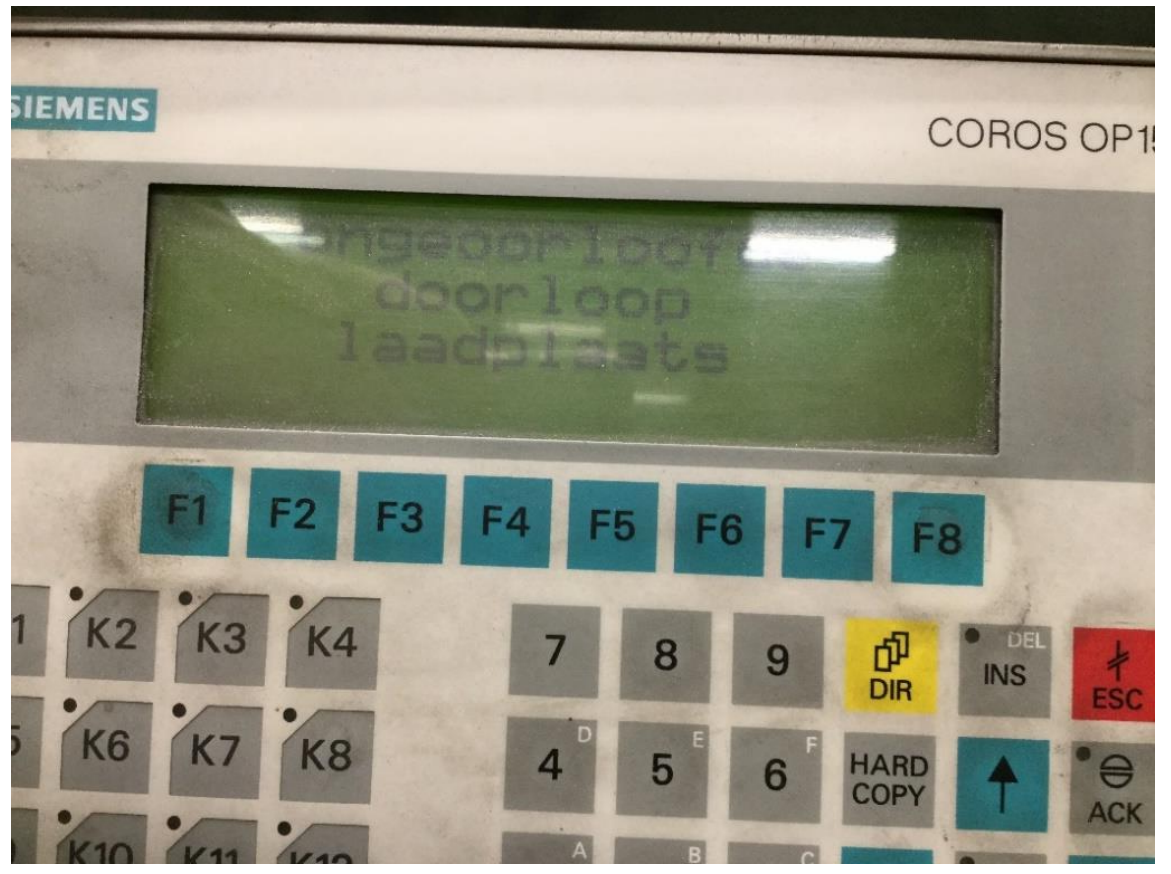

Figure 7. The blasting machine 'speaking' Dutch through a displayed message, and English through various buttons in the bottom right corner of the photograph.

VIN's first reaction upon noticing that we had a seemingly unsolvable problem, was to go find the team manager (an older worker from Limburg who also spoke a bit of English). PER was not an option, since he had left the foundry. VIN was not able to find the team manager, however. Therefore, he turned to another colleague -a younger Polish-speaking agency worker-but he could not help us.

Shortly afterwards, another older worker from the Netherlands approached our workstation. Without saying a word, he walked towards the blasting machine and pressed the start button. The machine started working again. Once VIN and I realised what had happened, we laughed about this simple solution and continued our work. In the presence of his Polish-speaking colleague, VIN also expressed his relief to the machine in 
Polish by saying "zapierdala, zapierdala, bierz to kurwa" ("it works fucking well, it works fucking well, take this, fuck"). ${ }^{13}$

After this incident, we did not encounter any problems anymore. Although the older worker from the Netherlands had not explained anything, it became clear to me that someone must have stood or walked somewhere where we were not supposed to stand or walk, and that an automatic safety measure must have turned off the machine. The words "ongeoorloofde doorloop laadplaats" made sense to me now, and as the safety measure was not activated anymore during the remaining 90 minutes I spent with VIN, I assumed that he had understood the main point as well.

The blasting machine's influence on where VIN and I could stand and walk during the work practices reminds me of Latour's (1992) argument that the role of "mundane" artifacts should not be overlooked in sociological studies that try to explain people's behaviour. Moreover, the way in which the blasting machine influenced our behaviour can be understood in terms of communicative modes as well. In fact, the machine employed both a monolingual Dutch mode by displaying a Dutch message on a screen, and a non-verbal communicative mode by turning itself off. The combination of these modes had the purpose of instructing us that we were doing something that, apparently, was unsafe. In the end, we both seemed to understand that we were not supposed to stand/walk in certain areas. Thus, apart from an artifact that afforded certain ways of being used, the blasting machine functioned as a non-human expert in relation to both our workplace learning processes.

In terms of affordances, the written texts on and around various buttons - mostly in Dutch, but occasionally in English- informed employees which buttons they should press in which situations. Interestingly, the emergency stop button had an English text ("emergency stop") around it, and it showed a clearly visible, symbolic indication of its function as well, as the button was bright red while being placed against a bright yellow background (figure 8 ). The button that employees needed to press to restart the machine, on the other hand, only had a Dutch text on top of it ("start stralen", which means "start blasting"), and its non-verbal indication was arguably less clear, as it was one out of several buttons that could lit up

\footnotetext{
13 I do not understand Polish myself. The credits for this translation go to Justyna Piotrowska and Zofia Sagnowska.
} 
a warm yellow light once the blasting process had started (this button is highlighted by me through a red circle in figure 8). Apparently, the blasting machine (as a literacy artifact in the spatial repertoire of the Finishing Department's community of practice) afforded the development of safe work practices more than it afforded the development of expertise (in human-machine interaction) in case an employee could not read Dutch.

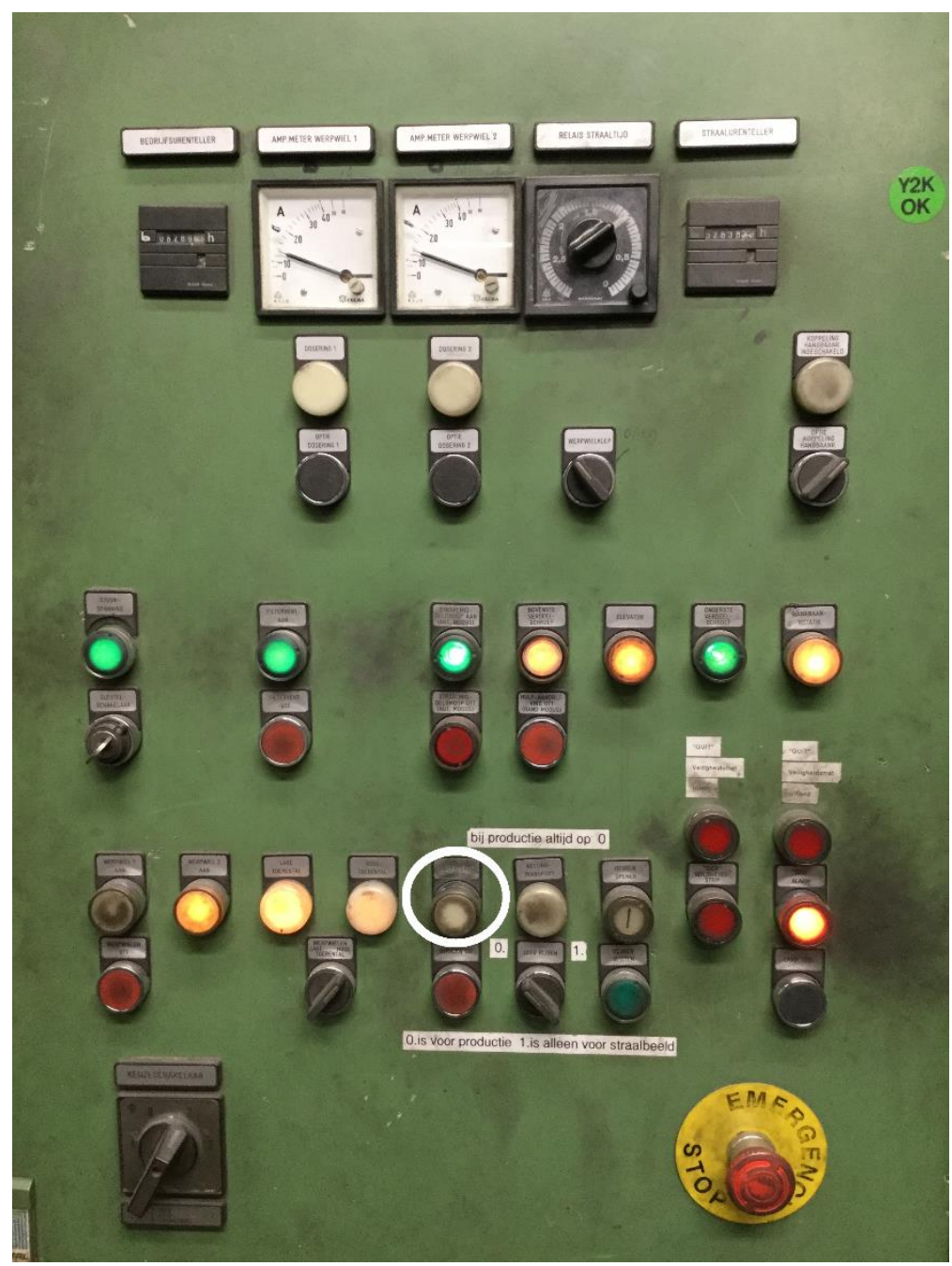

Figure 8. The control panel of the blasting machine. The "emergency stop" button is in the bottom right corner. I have circled the "start stralen" button. 
Workplace Learning through Human-Machine Interaction - 107

Despite the important role played by the blasting machine as a nonhuman expert, the role of the older, non-speaking employee from the Netherlands should not be overlooked either. If this person would not have intervened by pressing the start button (a basic human-machine interaction), VIN and I might not have realised what caused the blasting machine to stop working, and what we could have done to start the machine again. The purpose of the instruction that the blasting machine had started to construct was achieved in the end thanks to the affordances of this man's intervention. In this way, the human, non-speaking expert played an important role in both VIN's and my workplace learning process too.

Yet, why did this human, non-speaking expert not share any verbal explanations with us? By only relying on a non-verbal mode (pressing the start button), he could not know whether we understood why the blasting machine had turned itself off. Possibly, he considered this self-evident, as the machine displayed a message that explained the reason after all. Another possibility is that he, like PER, did not want to spend any effort on the learning process of two newcomers who might not stay in the foundry for long, and who might not speak the same language(s) as he did.

However, the purpose of the blasting machine's instruction was achieved nonetheless. Furthermore, it is possible to see VIN's and my actions, the machine's reactions, and the subsequent reactions from the human participants as a continuous negotiation process that led to a jointly negotiated work practice. Although the machine set certain apparent boundaries to the negotiated work practice, the exact outcome of these negotiations was not predetermined, and in theory, VIN or I could have tried to bypass these boundaries. Moreover, VIN's Polish utterances towards the blasting machine ("take this, fuck") show that he constructed the interactions with this machine as a type of negotiation process (a power struggle) as well. Together with the practice of adjusting the blasting time, this development of a work practice contributed to the process of VIN becoming a fuller participant in the Finishing Department's community of practice during the analysed work shift. 
108 - Power Dynamics at Work

\subsection{Conclusion and discussion}

The previous sections have shown how jointly negotiated work practices emerged in the Finishing Department of a metal foundry in the Dutch-German borderland - a blue-collar work environment characterised by transience, language diversity, and limited opportunities for mutual engagement between human co-workers. This final section discusses three findings.

The first finding is that human-machine interaction functioned as an effective, additional non-verbal communicative mode between a human newcomer (VIN) and a human expert (PER) whose individual language repertoires did not overlap much. In fact, they did not need to enrich the spatial repertoire with many verbal resources to achieve the purpose of the observed work instruction. This purpose was to teach VIN how to perform a specific task, and VIN's ability to observe and hypothesise could be considered at least as important for the achievement of this purpose as his individual language repertoire. In the analysed case, the full potential of human-machine interaction as a communicative mode was not reached, however, as PER did not let VIN try to perform the interactions with the machine by himself. Furthermore, the study did not find very strong evidence for the achievement of other possible purposes of the work instruction, such as making VIN understand why things had to be done in a certain way, or establishing harmonious relations between colleagues at work.

The second finding is that human-machine interaction could partly compensate for the absence of human-human interaction in the workplace. In line with Latour (1992), I observed how a machine functioned as an expert in the Finishing Department's community of practice, by guiding and facilitating VIN's learning process after PER had left the workplace. At the same time, the interactions between VIN and the machine were not sufficient to manage his learning process entirely, and the observed verbal utterances of VIN towards the machine ("take this, fuck") indicate that the machine's instruction failed to establish a harmonious relation between the human and the non-human co-worker as well. One reason for this was the minimal adaptation of the machine (as a literacy artifact in the community's spatial repertoire) to the language diversity in this work environment. Even for a newcomer who could read Dutch, however, it may not have been possible to interact with the machine in a productive way without any intervention from a human expert, as my personal experience has shown. 
In line with Suchman (2007), it is possible to explain this finding with the circumstantial details that the human expert had access to, as opposed to the machine.

The third finding is that human-machine interaction could not compensate for the challenges posed to workplace learning by transience. Arguably, the often-temporary work relations between human newcomers and human experts in the Finishing Department constituted the largest obstacle for workplace learning. To begin with, this is because newcomers did not have much time to build up memories that could help them become fuller participants in the department's work practices. Perhaps more importantly, however, this article has shown how transience can demotivate human experts to invest much effort in the learning process of newcomers. Possibly, this helps explain why the full potential of human-machine interaction as a communicative mode was not reached in the interaction between PER and VIN, and why, in the interaction that occurred after PER had left, another human expert did not combine the communicative mode of human-machine interaction with any verbal resources.

Taken together, these two interactions underline once more the vital role of the newcomer's ability to observe and hypothesise. The importance of this is already amplified when the overlap between the individual language repertoires of a human newcomer and a human expert is limited (see above), but it becomes even greater when the expert worker is not motivated to invest much effort in the learning process of the newcomer. Therefore, it may not be surprising that the main participant in this case study (VIN) was well aware of what mattered for the success of his learning process, as he told me that he would be fine as long as someone showed him what to do. VIN was a newcomer from Poland who had worked in three different workplaces in the Netherlands in one year, and who may be considered an 'expert newcomer' for that reason. Unlike many expert workers from the Netherlands and Germany in the Finishing Department, he did not consider language diversity a problem. In the end, understanding why his perceptions differed so much from these other workers' might be key to understanding the deeper challenges for workplace learning in contemporary blue-collar work environments (of which this particular Finishing Department is but one example).

Finally, the findings of this study imply that under less challenging circumstances, with more opportunities for additional human-human 
110 - Power Dynamics at Work

interaction between motivated co-workers who have time to build up a shared history of mutual engagement, the potential of human-machine interaction for workplace learning processes will be greater than in the analysed case. Whereas it is of course possible to consider the mechanisation of work environments primarily as a potential replacement of human workers, this implication shows that it might be wiser to (re)consider mechanisation as a potential means to support these workers during the process of developing productive, safe, and satisfying work practices. 
Emerging Production Work Assemblages - 111

\section{Emerging Production Work Assemblages ${ }^{14}$}

\subsection{Introduction}

This article presents a linguistic ethnography of a multilingual metal foundry in the Dutch province of Limburg, a regional minority language area in the Dutch-German borderland. In many ways, Limburg resembles other minority language areas in high-income economies, which are characterised by a loss of particular sources of income such as mining and manufacturing, and an increasing reliance on alternative sources of income such as tourism (see Heller, Pujolar, and Duchêne 2014). The metal foundry is an exception to this, as it has managed to stay competitive over time. This article analyses two work situations in the foundry from 2017, to see how this competitiveness at least partly emerged through specific workplace interactions. Specifically, it analyses two cases of a breakdown in a production process (i.e., an interruption of speed), which posed a threat to the foundry's competitiveness and which specific participants tried to manage expeditiously.

The work interactions in the foundry constituted a nexus of diverse trajectories of people, artifacts, and practices (Scollon and Scollon 2007), each of which contributed to the foundry's competitiveness. Amongst them were a large number of temporary workers whom the foundry had started to rely on more and more since the global financial crisis of 2007-2008, when the company narrowly escaped bankruptcy and the management drew the conclusion that they had to be able to adapt more easily to (sudden) changes in the demand for the foundry's products (i.e., metal components of trucks, luxury cars, and central heating boilers, among others). Furthermore, there were many machines in the foundry, which could take over various human work tasks and help to increase the company's productivity. On top of that, much production work was characterised by Taylorism, that is, "the management practice of segmenting labor into standardized, repeatable tasks in order to maximize efficient production" (Urciuoli and LaDousa 2013, 177).

Especially when the economy was blooming as in 2017, the foundry had a hard time finding enough temporary production workers to meet the

\footnotetext{
14 This chapter has been submitted to an international, peer-reviewed academic journal.
} 


\section{2 - Power Dynamics at Work}

demand for its products. One potential source of labour might have been female workers, but according to a labour recruiter I talked with on 27 September 2017, it was very hard to find women who were willing to work different shifts in an otherwise all-male work environment. She suggested that this might be because most women would not feel comfortable being in a male-dominated workplace at night, a speculation that might be related to the sexist discourse typically associated with male-dominated workplaces (see, e.g., Bell 1999, 28). Hence, the foundry had started recruiting from beyond the Dutch border male labourers, who usually spoke other languages than Dutch and the regional minority language Limburgish. Indeed, I often observed people speaking other languages at work, such as German, English, Polish, Russian, Arabic, and Turkish, and the most frequently used lingua franca probably was German.

While language diversity, male dominance, job insecurity, mechanisation, and Taylorism are not necessarily new phenomena in bluecollar work environments (see, e.g., Hiss 2017; Pecht 2021), the metal foundry in 2017 presented a unique case for developing a more comprehensive and detailed understanding of how these phenomena all come together during specific micro-interactions in the workplace. Consequently, this article applies a posthumanist perspective (Latour 2005; Pennycook 2018), which particularly helps to capture the role of machines in the work interactions that I analysed. More specifically, the article uses the concept assemblage (French: agencement; Bennett 2010; Deleuze and Guattari 1980; Latour 2005), which helps to capture how the foundry's competitiveness emerged (or not) from specific temporary associations between different human and non-human actors (hereafter: actants; Latour 2005), including the machines mentioned above.

Assemblages have been defined as "ad hoc groupings of diverse elements", whose "ability to make something happen" is "distinct from the sum of the vital force of each materiality considered alone" (Bennett 2010, 23-24). A human-machine assemblage, for example, can make things happen that neither the human nor the machine can do alone. The metal foundry's competitiveness thus depends on both. If either the human or the machine breaks down, the production process will be interrupted. In this respect, on a smaller scale, the human and the machine can each be considered assemblages in and of themselves as well (Bennett 2010, 31), as particular parts of a human body may get tired or injured, and as particular parts of a machine may stop working. Similarly, on a larger scale, the human-machine assemblage can be considered part of a broader political- 
economic assemblage (such as capitalism) or a commodity chain (Latour 2005; Thurlow 2020).

In brief, this article analyses two cases of a breakdown in a production process, to better understand how a contemporary metal foundry in a high-income economy in Europe managed to stay competitive, while describing how both human and non-human actants such as machines contributed to this competitiveness. In the next section, I place this research in the broader field of blue-collar workplace studies in linguistic ethnography. Afterwards, I briefly introduce the background of the foundry, the linguistic-ethnographic fieldwork I have executed there, and the data I have gathered in this way. I then present the analysis of the two breakdown cases in detail, which is followed by a final conclusion and discussion section.

\subsection{Language and power in blue-collar work environments}

By focussing on how specific assemblages make concrete things happen, this article is broadly situated in a field of linguistic-ethnographic studies that have been concerned with the workings of power, defined as "acting with effect" (Watson 2016, 171). Linguistic-ethnographic studies of bluecollar work environments in particular have primarily focussed on three effects of power so far, namely: (1) the construction of linguistic capital, (2) the construction of in-groups, and (3) the construction of interpersonal (hereafter: inter-actant) workplace relations. Regarding such effects, these studies have typically underlined the agency (i.e., "the capacity to act with effect"; Watson 2016, 170) of particular language practices or discourse. In this section, I briefly introduce the three existing strands of research, which the current article further builds upon.

To begin with, many studies have discussed the construction of linguistic capital in blue-collar work environments (Duchêne 2011; Goldstein 1997; Gonçalves and Schluter 2017; Holm, O'Rourke, and Danson 2020; Kraft 2019; Kraft 2020b; Piller and Lising 2014). A general finding of these studies is that only particular communication skills are constructed as linguistic capital (e.g., English speaking skills), even though the authors have observed that many other skills are used in daily working practices as well. Despite that, speakers without the skills constructed as valuable capital (often migrant workers) usually have few opportunities to acquire this capital, either inside or outside the workplace. Thus, the constructions of 
linguistic capital often privilege certain workers over others, although the privileged workers may not necessarily experience this as such (Hovens 2021).

Secondly, many studies have discussed the (implicit or explicit) constructions of in-groups and out-groups by blue-collar workers (Baxter and Wallace 2009; Daly et al. 2004; Gherardi and Nicolini 2002; Holmes and Marra 2002; Holmes and Woodhams 2013; Hovens 2020; Lucas 2011). Most of these studies have analysed spoken-English discourse, and they have highlighted the use of out-group comparisons (Lucas 2011), out-group demonisation (Baxter and Wallace 2009), in-group swearing practices (Daly et al. 2004), in-group humour (Holmes and Marra 2002), in-group jargon and interactional norms (Holmes and Woodhams 2013), in-group senses of workplace safety (Gherardi and Nicolini 2002), and in-group humanmachine interactions (Hovens 2020) as discursive means to construct particular blue-collar in-groups, or communities of practice (Lave and Wenger 1991; Wenger 1998).

Thirdly, some studies have discussed the construction of situated, inter-actant workplace relations through spoken interactions in blue-collar work environments (Handford and Matous 2015; Holmes and Stubbe 2015; Holmes and Woodhams 2013; Kleifgen 2013). By giving direct and explicit orders to a factory worker, for example, a manager has been observed (re)producing a particular superior-subordinate relationship (Holmes and Stubbe 2015, 33). The situatedness of such constructions is underlined by analyses of problem-solving interactions at work. Specifically, these studies have argued that the time pressure of a given situation may partly explain why people do not use certain forms of politeness, or inter-actant accommodation, that they may otherwise employ in their talk (Handford and Matous 2015, 95-96; Kleifgen 2013, 74-98).

Overall, although there are some exceptions (Gherardi and Nicolini 2002; Hovens 2020; Kleifgen 2013), this overview of existing studies shows that non-human agency has generally not received much attention yet in this field. In other words, the dominant paradigm has been social constructionist rather than new materialist or posthumanist (Canagarajah 2020, 563-564). This article thus adds to existing perspectives by exploring the relation between language practices, non-human agency, and power, and by focussing on the construction of material products as an effect of power. Before starting this exploration, however, the next section first introduces the fieldwork data that the article builds upon. 


\begin{tabular}{|c|c|c|c|c|c|c|}
\hline & $\begin{array}{l}\text { Core } \\
\text { Shooting }\end{array}$ & Melting & Casting & Finishing & $\begin{array}{l}\text { Non- } \\
\text { production }\end{array}$ & Total \\
\hline Dutch & $\begin{array}{l}48(55 \%) \\
28 \text { perm } \\
20 \text { temp }\end{array}$ & $\begin{array}{l}18(69 \%) \\
15 \text { perm } \\
3 \text { temp }\end{array}$ & $\begin{array}{l}33(45 \%) \\
19 \text { perm } \\
14 \text { temp }\end{array}$ & $\begin{array}{l}72(48 \%) \\
46 \text { perm } \\
26 \text { temp }\end{array}$ & $\begin{array}{l}159(100 \%) \\
148 \text { perm } \\
11 \text { temp }\end{array}$ & $\begin{array}{l}330 \text { (67\%) } \\
256 \text { perm } \\
74 \text { temp }\end{array}$ \\
\hline German & $\begin{array}{l}17(20 \%) \\
4 \text { perm } \\
13 \text { temp }\end{array}$ & $\begin{array}{l}7(27 \%) \\
4 \text { perm } \\
3 \text { temp }\end{array}$ & $\begin{array}{l}27(37 \%) \\
19 \text { perm } \\
8 \text { temp }\end{array}$ & $\begin{array}{l}38(25 \%) \\
6 \text { perm } \\
32 \text { temp }\end{array}$ & $\begin{array}{l}0(\mathbf{0} \%) \\
0 \text { perm } \\
0 \text { temp }\end{array}$ & $\begin{array}{l}89(\mathbf{1 8 \%}) \\
33 \text { perm } \\
56 \text { temp }\end{array}$ \\
\hline Polish & $\begin{array}{l}11(13 \%) \\
1 \text { perm } \\
10 \text { temp }\end{array}$ & $\begin{array}{l}0(0 \%) \\
0 \text { perm } \\
0 \text { temp }\end{array}$ & $\begin{array}{l}4 \text { (6\%) } \\
0 \text { perm } \\
4 \text { temp }\end{array}$ & $\begin{array}{l}16(11 \%) \\
0 \text { perm } \\
16 \text { temp }\end{array}$ & $\begin{array}{l}0(0 \%) \\
0 \text { perm } \\
0 \text { temp }\end{array}$ & $\begin{array}{l}31(6 \%) \\
1 \text { perm } \\
30 \text { temp }\end{array}$ \\
\hline Other & $\begin{array}{l}11 \text { (13\%) } \\
0 \text { perm } \\
11 \text { temp }\end{array}$ & $\begin{array}{l}1 \text { ( } 4 \%) \\
1 \text { perm } \\
0 \text { temp }\end{array}$ & $\begin{array}{l}9 \text { (12\%) } \\
\text { O perm } \\
9 \text { temp }\end{array}$ & $\begin{array}{l}24(16 \%) \\
8 \text { perm } \\
16 \text { temp }\end{array}$ & $\begin{array}{l}1 \text { (1\%) } \\
1 \text { perm } \\
0 \text { temp }\end{array}$ & $\begin{array}{l}46(9 \%) \\
10 \text { perm } \\
36 \text { temp }\end{array}$ \\
\hline Total & $\begin{array}{l}87(\mathbf{1 0 0 \% )}) \\
33 \text { perm } \\
54 \text { temp }\end{array}$ & $\begin{array}{l}26(100 \%) \\
20 \text { perm } \\
6 \text { temp }\end{array}$ & $\begin{array}{l}73(100 \%) \\
38 \text { perm } \\
35 \text { temp }\end{array}$ & $\begin{array}{l}150(100 \%) \\
60 \text { perm } \\
90 \text { temp }\end{array}$ & $\begin{array}{l}160(100 \%) \\
149 \text { perm } \\
11 \text { temp }\end{array}$ & $\begin{array}{l}496(100 \%) \\
300 \text { perm } \\
196 \text { temp }\end{array}$ \\
\hline
\end{tabular}

Table 6. The number of permanent (perm) and temporary (temp) workers in the foundry in August 2017, divided by department and citizenship. The category "non-production" includes, among others, Human Resource (HR) managers, Information Technology (IT) staff, and engineers. The categories "Dutch", "German", and "Polish" may include first-generation migrants who have obtained Dutch/German/Polish citizenship at some point in their life. ${ }^{15}$

\subsection{Background, data, and methods}

The linguistic-ethnographic fieldwork I have executed in the production departments of the metal foundry took place between 3 July and 15 October 2017. In total, I have made 74 hours of audio recordings and 6.5 hours of video recordings of workplace interactions; I have audio-recorded 11.5 hours of interviews with (former) workers, managers, and labour recruiters; I have taken 139 photographs of diverse signs, texts, and symbols; I have written approximately 150 pages of fieldnotes, and I have

\footnotetext{
${ }^{15}$ The figures presented are the sum of the data about all agency workers in the foundry in August 2017, which I have received as an anonymised Microsoft Excel file from one of the agency's recruiters, and the data about the metal foundry's employees, which I have collected through email communication with an HR manager from the foundry. As the HR manager filled in some gaps in the data from August 2017 with data from 2018, minor differences might exist between the actual figures and the figures presented here.
} 
collected a wide range of other data. The current article is primarily based on one audio recording and one video recording.

Speaking languages other than Dutch, German, and Limburgish was a relatively new phenomenon in the foundry in 2017. Many older production workers from Limburg, who typically spoke Dutch and Limburgish as their first languages, considered this 'new' linguistic diversity problematic (Hovens 2021). The foundry's management considered it problematic as well, and it made various language-political attempts to construct a work environment in which mostly Dutch would be used, even though this aspiration was far away from the de facto language practices in the production departments (Hovens 2021).

The foundry's production workers were distributed over four different departments: the Core Shooting Department (where sand cores were produced to mould metal); the Melting Department (where the metal was melted); the Casting Department (where the molten metal was moulded using the sand cores); and the Finishing Department (where the metal products, after hardening, were sawn, ground, blasted, welded, and quality-checked, among other actions). Table 6 shows the number of permanent and temporary workers in each production department in August 2017, divided by citizenship. As a contrast, I have also included all non-production workers (such as engineers), indicating that it was specifically the production departments that had a relatively large share of temporary and non-Dutch workers. As discussed previously, all production workers were male.

The current article focuses on one work situation that was audiorecorded in the Core Shooting Department, and one work situation that was video-recorded in the Casting Department. Together with the Finishing Department (Hovens 2020), the Core Shooting Department stood out as an environment with a relatively large share of temporary workers (around $60 \%)$, and -related to that- a comparably large share of workers who spoke neither Dutch nor German nor Limburgish. In the Casting Department, on the other hand, almost half of the workers were temporary (48\%), and all workers in this department could speak at least Dutch or German (often in addition to other languages such as Limburgish and Turkish).

Another distinction between the Core Shooting and the Finishing Department on the one hand, and the Casting Department on the other hand, concerns the opportunities for human-human interaction during 
working hours. The Casting Department stood out as it enabled regular interactions involving more than two workers, because people typically worked in groups (of varying sizes) at a conveyor belt there, while people in the Core Shooting and the Finishing Department typically worked alone or in pairs with a particular machine (see also Hovens 2020).

The workers of each production department were divided into different teams, which alternated in different work shifts. During my fieldwork, I spent one week with most teams, and I also worked in different shifts (including night shifts). My participation in these teams implied that I helped out as an additional worker, for example, by helping people lift heavy materials. In the Core Shooting and the Finishing Department, I typically went to look for workers whom I could help myself. In the Casting Department, where the production work was organised around two conveyor belts, I often discussed with a team manager where I would go and help out during a particular shift.

Due to the size of the workforce, the high turnover rates, and my procedure of regularly changing teams, it was impossible to obtain explicit consent from every single worker before my fieldwork started. Therefore, I worked with implicit consent by hanging up a written announcement in three languages (Dutch, English, and German) in the workplace, as all production workers were supposed to understand at least one of these languages. The Ethics Review Committee Inner City Faculties in Maastricht has officially approved this research practice. Nevertheless, I always asked for people's explicit consent before making an audio or a video recording. Usually, people did not have a problem with being recorded on either audio or video, even though I noticed that they were typically quite aware of the presence of a video camera, which thus might have affected their behaviour. In the next sections, I discuss two recorded work situations in further detail.

\section{4 'Screwed': The breakdown of a work assemblage after non-human resistance}

The main participant in this section is BEN, a younger $(<30)$, temporary worker from Germany and possibly a second-generation Turkish migrant, who worked in the Core Shooting Department of the metal foundry. His first languages were German and Turkish, and I did not hear him speak any other language. When I met BEN in July 2017, he was still a relative 
newcomer in the foundry. During the work shift that I analyse in this section, BEN's team manager had assigned him to work alone with a machine for the first time. As in the Finishing Department (Hovens 2020), this could be considered an important transition point, as it showed that the manager no longer considered BEN a 'peripheral' newcomer who could only work together with other, more experienced colleagues (see Lave and Wenger 1991).

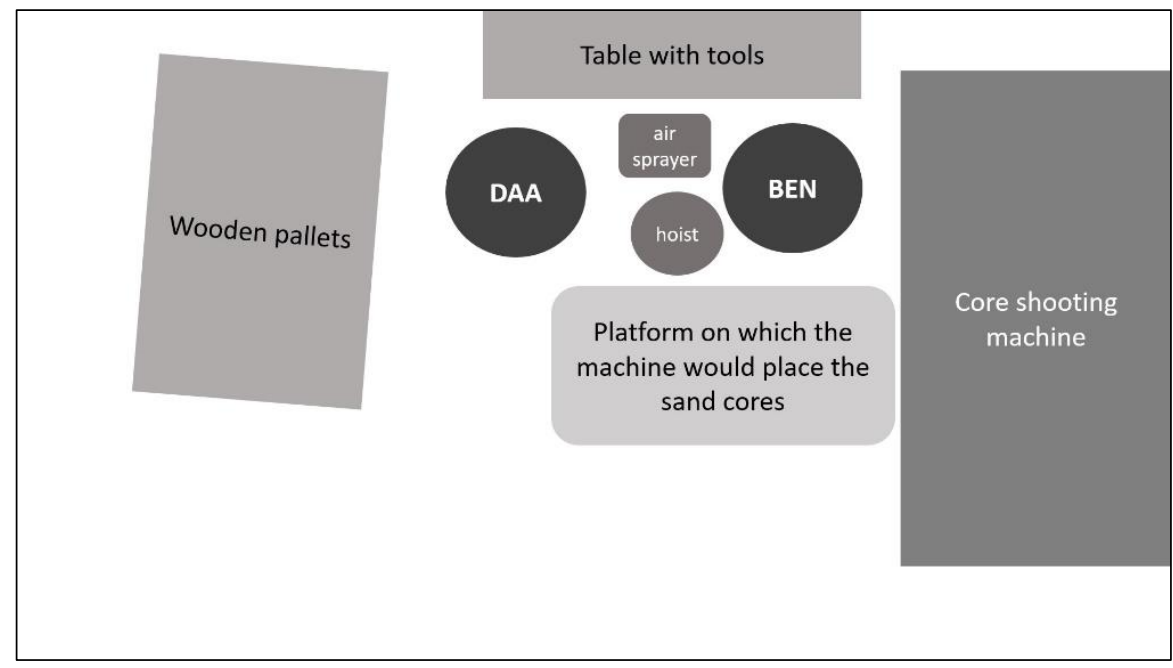

Figure 9. The spatial organisation of BEN's workstation. "DAA" refers to me, the author of this article (Daan Hovens). The sand waste containers were not in BEN's immediate surroundings and, hence, they do not appear on this map.

One primary task of production workers in this department was to lift sand cores from a platform. These cores were placed on this platform by a core shooting machine (figure 9). Depending on the characteristics of a particular core type (such as its weight), the workers would either lift them by hand or use a hoist. They then checked the cores for possible flaws, and they often had to do certain things with them, such as removing a burr, or gluing two elements together, while using specific tools that could be found on a table behind them. Afterwards, the workers placed the cores on a wooden pallet, except for the seriously flawed or broken ones, which they threw into a sand waste container. Furthermore, they regularly removed 
some loose, remaining sand from the cores, the pallets, and the work environment with a high-pressure air sprayer. Finally, a forklift truck would come and bring the pallets to the next stage of the production process (in the Casting Department). The same truck would also come and empty the sand waste containers every now and then.

When I saw BEN working alone for the first time, I already knew who he was. We had met earlier that week, I had introduced myself and my research project to him back then, and we had decided to speak German with each other. This time, I asked BEN if he would mind me making an audio recording while helping him with his work, for example by lifting the sand cores together. He said that was fine. The only issue was that, with or without my help, he did not manage to be very productive that evening. The machine was producing a lot of broken cores, and he did not understand why this was happening. Therefore, in the end, my help consisted for a large part of throwing broken cores in the sand waste container. BEN felt quite uneasy about the team manager's possible response to the pile of broken cores that emerged in this way, as he expressed to me in the following line:

o:h der chef wird das ja SEHEN (.) dem wird das nicht gefallen (.2) dem wird das GAR nicht gefallen (.3) im gegenteil der wird sich (gut aufregen)

o:h the chef will SEE that for sure (.) that will not please him (.2) that will not please him AT ALL (.3) on the contrary he will become (quite agitated)

About 45 minutes after I had joined BEN, the number of broken cores was becoming so big that he decided to stop the production process. Our work assemblage had thus broken down. Since BEN could not interpret any possible signs from the machine indicating what had caused the resistance of this non-human actant in our assemblage, he went to look for help from other, more experienced human workers who might be able to do the interpretation of the machine's signs for him.

The first person BEN asked was a younger $(<40)$ man from the Netherlands and possibly a first-generation Turkish migrant, who was working with a core shooting machine that was right next to 'ours', and who spoke Turkish as his first, and Dutch as his second language. He was a bit more experienced than BEN, but after they talked with each other in Turkish for a few minutes, it turned out that he could not help. Therefore, 
120 - Power Dynamics at Work

BEN went to ask another person. This was WIL, an older $(>40)$ labour migrant from Poland who had worked in the Core Shooting Department for several years already. WIL spoke Polish as his first, and German as his second language, which he regularly mixed with resources that are typically associated with Dutch. BEN and WIL thus spoke German as a lingua franca with each other. At least as important for the purpose of their communication, however, was the human-machine interaction that BEN performed in front of WIL by letting the machine produce one more sand core, so that WIL could observe this and hypothesise about the cause (see also Hovens 2020). WIL indeed managed to do an interpretation of the machine's utterances in this way, as extract 3 shows.

\section{Extract 3. Interpreting 'machine language'}

Italics = original transcription (associated with German)

Italics underlined $=$ original transcription (associated with Dutch)

Bold italics $=$ English translation

01 WIL: wo:W

WIL: wo:w

02 ((the core shooting machine makes a snapping sound))

03 WIL: wo:w (.) hab ihr nich GESEHEN?

WIL: wo:w (.) have you not SEEN?

$04 \quad$ ((5 seconds pause))

05 BEN: $\quad A: C H=s o=j a: h() j$.

BEN: A:H=like that=yeah (.) yes

06 WIL: er is undicht (.2) au=moet=eh (.) moet wat=eh (.) tuussen zijn

WIL: he is leaking (.2) au=must=eh (.) must something=eh (.) be in-between

07 BEN: oka:y? 
Emerging Production Work Assemblages - 121

\section{BEN: oka:y?}

WIL: e:h (.2) tuussen die onderkast (.) bovenkast (.) ist was zwischen

WIL: e:h (.2) between the lower box (.) upper box (.) is something in-between

09 BEN: a:h

BEN: $a: h$

10 WIL: vielleicht e:h (.2) ne kleine (ring) ein ( $x x x$ ) oder so was ( $x x x)$ a:h mub man anschauen

WIL: perhaps e:h (.2) a small (ring) a (xxx) or something like that (xxx) a:h one has to see

12 BEN: a:h=nee:h (.) kurz bevor ich auch noch fertig bin (.) kommt das ganze schrott (raus)

BEN: o:h=no:h (.) just before I am ready on top of all things (.) the entire scrap comes (out)

According to WIL's observations, the core shooting machine was leaking (line 6), and he thought this leakage was caused by something that had somehow got in-between the two boxes that the machine always pressed against each other during the core shooting process (line 8). WIL further speculated that this 'thing' might perhaps be a ring (line 10), but by adding the words "mub man anschauen"/"one has to see" (with the indefinite pronoun "man"/"one" instead of "ich"/"I" or "wir"/"we"), he also set a limit to his interpretation task and his responsibility to let a production work assemblage emerge again. BEN's response in line 12, on the other hand, indicates that BEN considered himself responsible. This discursive (re)production of their tasks and responsibilities in relation to the resisting machine appeared to be taken for granted, as these were not further explained or challenged during their interaction.

Shortly afterwards, WIL noticed what had been causing the leakage: a crushed screw. BEN asked how this screw could have ended up inbetween the boxes of the core shooting machine, but WIL said that he had 
no idea. BEN then asked whether he should go and get the team manager to look at the situation, and WIL replied that the manager would know what to do indeed. Thus, BEN went to get the team manager, even though he was still quite concerned about being blamed, as he expressed to me in the following line:

jetzt denkt er sich auch bestimmt (.) denn lässt man den EINMAL alleine arbeiten

now he must be thinking as well (.) then you let him work alone FOR ONCE

BEN's concerns confirm the previously discussed significance of being able to work alone with a machine, as this signified the relative independence or maturity of a production worker. Apparently, BEN was afraid that he would fail the 'maturity test' in the eyes of his manager, by not being able to form a production work assemblage with the core shooting machine. His fear for the manager's judgment may be partly understood against the background of BEN's status as a temporary worker, which implied that he had practically no job security (see also Hovens 2020). I responded to BEN's concerns by saying that he might become a more technically skilled worker due to experiences such as this one. BEN briefly indicated that he had heard me by saying " $j a$ " ("yeah"), but he did not seem comforted. After all, what mostly mattered to him was his manager's judgment, not his personal development.

In the end, however, it seemed like BEN did not need to worry about being blamed. When the team manager approached our workstation, he started to laugh and said (in German, combined with the Limburgish pronoun "dae"): "wo kommt DAE her?" ("where does THAT come from?"). The team manager was an older (>40) man from Limburg, the Netherlands, who spoke Dutch and Limburgish as his first, and German as his second language, which he regularly mixed with resources that are typically associated with Dutch or Limburgish. Visually, he had the same working outfit as any other production worker, so his distinct position in the workplace had to be (re)produced via other means. His laughter and linguistic accommodation, with which he seemingly tried to comfort BEN, are examples of such means. In this way, the manager discursively (re)produced the idea that he was in the position to declare that there was no reason for BEN to be worried. 
After this brief interaction, the manager started to inspect the crushed screw and said (in German) that he needed a screw driver. It appeared that his attempts to comfort BEN had not been sufficiently effective yet, however, as is shown by another brief interaction between BEN and the team manager (MAN) that followed (extract 4).

\section{Extract 4. "That was nobody"}

Italics $=$ original transcription (associated with German)

Italics underlined $=$ original transcription (associated with Dutch)

*Italics underlined with asterisks $*$ original transcription (associated with Limburgish)

Bold italics $=$ English translation

01

BEN: ich war das nicht

BEN: it wasn't me

02

MAN: huhahahahahahahahaha (.1) das war keiner (.5) *den* ${ }^{*}=e: h$ (.) hol maar even ne=ne=ne (.) hammer (.) und=ne schraubezieher

MAN: huhahahahahahahahaha (.1) that was nobody (.5) then=e:h (.) just quickly get $a=a=a$ (.) hammer (.) and=a screw driver

Again, as this interaction shows, the team manager did not seem interested in blaming BEN. Rather, it appeared that he wanted to take care of the issue as quickly as possible so that a production work assemblage could emerge again. Thus, similar to the sites studied by Kleifgen (2013) and Handford and Matous (2015), working speed was clearly of central importance here. To achieve such speed, the team manager tried to take care of both a nonhuman actant (the crushed screw) and a human actant (BEN). In a way, both resisted a quick emergence of a new work assemblage: the screw due to the leakage it caused, and BEN due to his concern to make sure that he would not be blamed. Regarding the first actant, the manager told BEN to 
get him a hammer and a screw driver, with which he wanted to remove the crushed screw from the core shooting machine. Regarding the second actant, the team manager gave a prolonged laugh and said "that was nobody" in an attempt to comfort BEN and remove any concerns about causes and blame.

Unfortunately, it turned out that the resistance of the crushed screw was so strong that the team manager could not remove it with a hammer and a screw driver. Therefore, the manager decided to use an angle grinder instead, with which he could make the surface of the machine's box even again. This appeared to work well. While the managerangle grinder assemblage was producing some observable effects in this way, BEN asked the manager how the screw could have got inside the machine. Like the crushed screw, BEN's concerns were apparently so strong that they could not be easily removed either. Extract 5 shows BEN's question and the interaction between him and the team manager that followed afterwards.

\section{Extract 5. "It's better when it's here than there"}

Italics $=$ original transcription (associated with German)

*Italics underlined with asterisks* $=$ original transcription (associated with Limburgish)

Bold italics $=$ English translation

\section{BEN: how could it have happened then?}

MAN: weib ich nicht (.) WENN (.) ei=eine schraube ist von e:h (.1) von die: $h$ (.) der begasswagen der ist $(x x x)$ der seite wo der (.) mit DRÜCK der kern in der abdrück (bleiben) gedrückt (.) dass $D E: R$ rausgelaufen ist (.1) ( $x x x)$ dazwischen gefallen

MAN: I don't know (.) WHEN (.) $a=a$ screw is from e:h (.1) from the:h (.) the gas carriage it has (xxx) the side where it (stay) pressed the core (.) with PRESSURE into the imprint (.) so that HE leaked out (.1) (xxx) fallen in-between 


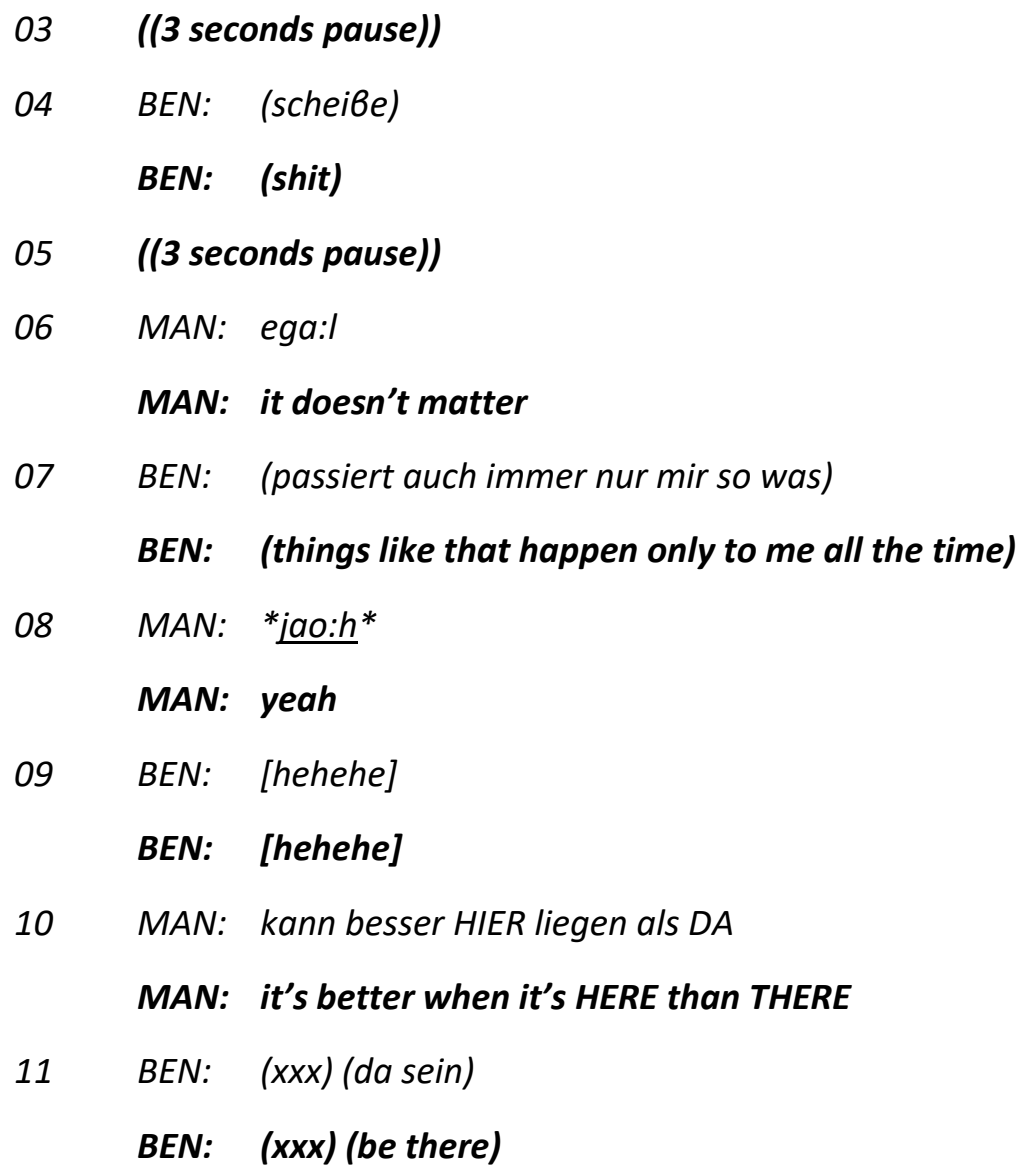

Similar to extract 4, this interaction shows that the team manager did not seem interested in blaming anyone, which he now also made explicit by saying "egal" ("it doesn't matter"; line 6). Still, BEN brought up the matter of blame again by saying "things like that happen only to me all the time" (line 7), as if his presence or involvement had something to do with the screw getting inside the machine. It is not clear if the manager understood these words, but by saying that it is better when the screw is "here" than "there" (line 10), he made another attempt to comfort BEN again, by implying that the situation could have been worse still.

Unfortunately, I cannot hear BEN's final response in this sequence (line 11). Based on what happened afterwards, however, it is clear that he did not feel completely at ease still. About five minutes after the interaction 
of extract 5 had occurred, BEN tried to minimise any potential blame again by telling the manager that this was the first time that something like this had happened to him. In response, the manager tried to make clear again that it did not matter. Furthermore, shortly after the manager had left our workstation, BEN told me that he was still wondering how a screw could have got inside the machine. It appeared, in other words, that the manager had not entirely managed to remove BEN's concerns.

Overall, this section has shown how a crushed screw initiated a breakdown of a production work assemblage, and how different human actants tried to influence other human and non-human actants so that a new work assemblage could emerge again. The individual responsibilities for this process were more or less taken for granted by the human participants. Furthermore, the section has shown that BEN and the team manager (re)produced an inter-actant workplace relation that placed the latter in the position to blame any human worker for the resistance of the machine, which he decided not to do.

Despite his repeatedly uttered decision, however, the team manager did not successfully remove BEN's concerns about being blamed, which simultaneously undermined the manager's position to decide about these matters, and which delayed the process of letting a new production work assemblage emerge again. Possibly, his status as a temporary worker, and the machine as a non-human actant had a stronger effect on BEN's concerns. Still, the manager made several attempts to comfort BEN by employing, among others, laughter and linguistic accommodation (in this case, improvised languaging -see Jørgensen and Varga 2011- as he mixed German with resources that are typically associated with Dutch and Limburgish). The fact that these attempts did not turn out to be successful confirm the idea that the manager did not simply 'have' power (see Latour 1986). As with the crushed screw, all he could do was to mobilise certain actants or resources (an angle grinder, extensive laughter) and hope that these resources would link up with particular other actants (the crushed screw, BEN) and produce a desired effect (as a new production work assemblage). Thus, in the end, the machine-initiated renegotiation of BEN's newly obtained hierarchical workplace position also led to a (re)negotiation of the team manager's position as the ultimate judge with regard to matters of blame. 


\section{5 "Do it yourself just once": The breakdown of a work assemblage after human resistance}

The situation analysed in this section is set in the Casting Department of the metal foundry. As discussed previously, this department provided more opportunities for work interactions between more than two human actants. Whereas people typically worked alone or in pairs in the Core Shooting Department, most people in the Casting Department worked in one out of two groups, each of which worked at a different conveyor belt. At the first, larger conveyor belt, people placed sand cores (which forklift truck drivers brought from the Core Shooting Department) onto the belt. This belt transported the sand cores to the casting machine, which cast the foundry's metal products. The products, when cast, were transported by hooks (which were connected to rails in the ceiling) to the second, smaller conveyor belt. The main task of people working at this second belt was to cut certain redundant parts off the products. Hence, this belt was commonly referred to with the Dutch word "kniptafel", which literally means "cutting table" (figure 10).

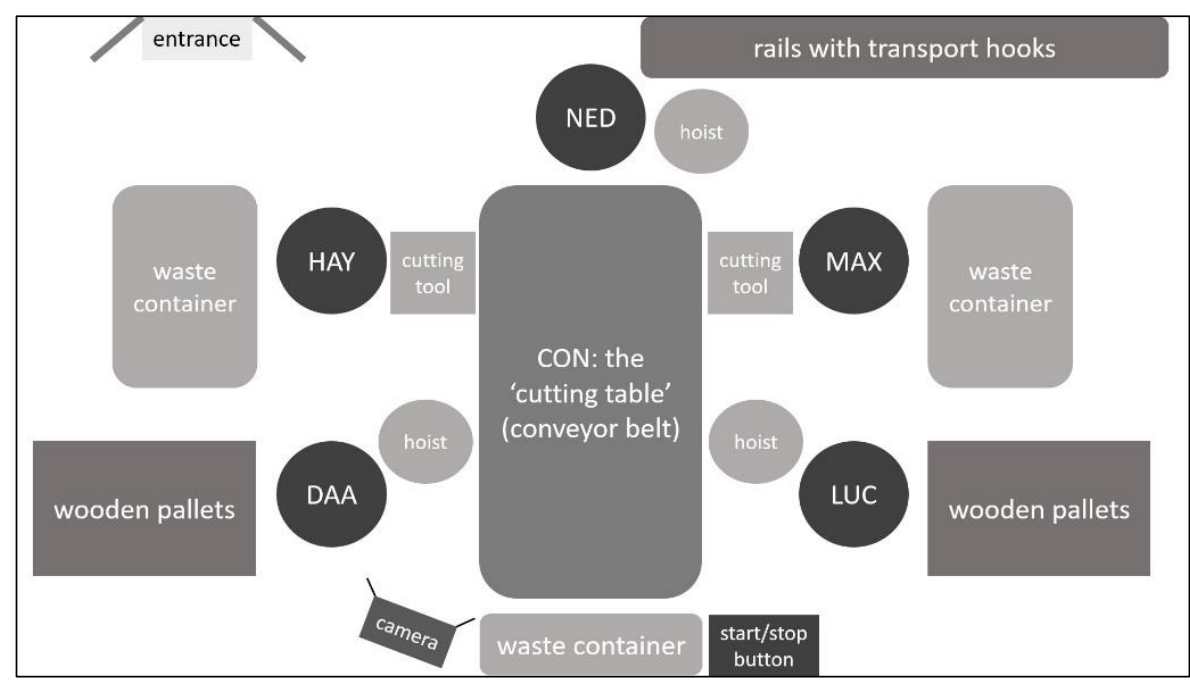

Figure 10. The spatial organisation of the workers at the cutting table

Figure 10 shows the spatial organisation of the workers at the cutting table during one night shift, when I briefly participated in the work 
practices at this conveyor belt. This organisation seemed to follow a hierarchical logic, (re)producing inter-actant workplace relations. At the head of the table was NED, an older ( $>40)$ worker from Germany who had worked in the foundry for many years already, and who spoke German as his first, and Dutch and Limburgish as his second languages. His task was to take the metal products off the transport hooks and place them on the cutting table. The products would then first pass HAY and MAX, who were both relatively experienced workers as well, and who were doing the cutting job. HAY was an older (>40) worker from the Netherlands whom I believe could speak Dutch and Limburgish as his first, and German as his second language, but I hardly heard him speak overall. MAX was a somewhat older (>30) worker from Germany who spoke German as his first language, and he also used specific words that are typically associated with Dutch or Limburgish at times (see further below). At the end of the table were LUC and I (DAA), two relative newcomers who would lift the metal products from the belt and place them on wooden pallets behind us. LUC was an older ( $>40)$ worker from Germany who spoke German as his first language, and I did not hear him speak any other language. I was a younger $(<30)$ worker from the Netherlands and I spoke Dutch and Limburgish as my first, and German as my second language.

While I was working at the cutting table, the conveyor belt had to be paused several times, because the two newcomers (i.e., LUC and I) could not keep up with its speed. As far as I understood, the speed could not be changed. Put in linguistic terms, the belt did not accommodate to us, and this non-human actant thus basically set the norm for our working speed. One of the few ways to resist the speed dictations was to press the 'on/off' button. Typically, NED and MAX said when this button had to be pressed. In this way, they placed their own authority above that of the belt. Hence, in the work assemblage that these human and non-human actants constructed that night, HAY, LUC and I were trying to obey the belt's speed dictations, unless NED and/or MAX said that the belt should be paused. Thus, we were (re)producing particular, hierarchical inter-actant workplace relations with NED and MAX on top, the conveyor belt in the middle, and HAY, LUC, and I at the bottom.

Similar to the team manager from the previous section, however, NED and MAX did not simply 'have' power. Instead, they were depending on the cooperation from diverse human and non-human actants for the work assemblage and its inter-actant relations to emerge and be reproduced. When it comes to the conveyor belt, I did not detect any 
resistance (such as a technical issue) against this organisation during this work shift. HAY seemed to be cooperative as well, probably because he did not have any problems keeping up with the dictated working speed. As for myself, I was very cooperative too, since I was quite happy about everyone agreeing with me making a video recording (see chapter 2.5). Therefore, in order to maintain my 'research assemblage', I did not want to cause any trouble.

LUC, on the other hand, resisted several times. He did not take the situated, inter-actant workplace relations for granted, which may be partly explained by the fact that he seemed older than MAX, who often communicated the orders to him. LUC was working right next to the conveyor belt's 'on/off' button (figure 10). Hence, when NED and MAX thought that the belt had to be paused, one of them -but mainly MAXwould usually order LUC to press this button. The reason why MAX in particular would communicate the orders might be that he just happened to be physically closer to LUC (figure 10). Besides that, as a younger worker than LUC, and as a less experienced worker than NED and HAY (both of whom seemed to have a permanent contract), MAX might have felt a stronger need to confirm his position in the (re)produced workplace relations at the conveyor belt.

Interestingly, even though LUC, NED, and MAX all spoke German as a first language, and even though I never heard LUC speak any Dutch, MAX used Dutch words when he ordered LUC to turn on the conveyor belt (in which case he would say "lopen!", which literally means "walk!", and which could be translated as "let it run!"), or to turn off the conveyor belt (in which case he would say "stoppen!", which means "stop!"). One possible interpretation of this is to consider these verbal resources as institutional key words from a shared repertoire in the Casting Department's community of practice (Lave and Wenger 1991; Wenger 1998), and MAX's orders might have been a way to share such resources with LUC. An alternative or additional interpretation is that MAX used these institutional key words as a means to present himself as a member of this in-group, thereby legitimising or (re)confirming his hierarchical position in this work environment. In that sense, MAX's utterances were examples of strategic code-switching (Muysken 2000) as opposed to the more improvised languaging practices from the participants in the previous section, as well as examples of linguistic divergence as opposed to the accommodation practices from the previous section. 
The first time the work assemblage at the cutting table was broken down during my presence happened about seven minutes after I joined. LUC and I could not keep up with the conveyor belt's speed, and therefore, MAX ordered LUC to stop the belt (using the Dutch word "stoppen!"). LUC was busy trying to keep up with the speed, however, so he did not respond and continued his work. With an angry voice, MAX made clear to LUC in German what he was supposed to do: "drück doch auf aus!" ("just press off!"). In response, LUC questioned (in German) the assumption that he would be the one having to press the button: "tu das selber eben mal!" ("do it yourself just once!"). However, when MAX pointed at the products that were about to fall off the conveyor belt (while saying something I cannot understand), LUC decided to press 'off' in the end, and so the assemblage broke down.

When LUC and I had managed to catch up a bit, NED ordered LUC to start the conveyor belt again by using the German word "laufen!" (which means "walk!" as well). MAX followed quickly, and said (with a louder voice) the Dutch word "lopen!" several times. The difference in their linguistic behaviour might be partly explained again by MAX needing to make more effort to (re)confirm or (re)produce the hierarchical workplace relations. LUC did not respond verbally, however, and continued what he was doing (fixing some wooden pallets behind him). About 30 seconds after receiving the orders from NED and MAX, he decided to press the 'off' button, underlining his individual agency as a human actant in this work assemblage, while confirming that NED and MAX did not simply 'have' power.

The second breakdown happened more or less four minutes later. This time, LUC initiated a renegotiation of the inter-actant workplace relations in the work assemblage by pressing the 'off' button on his own initiative. Significantly, this resistance from a human actant and relative newcomer such as LUC would not have been possible without the conveyor belt enabling human workers to press an 'on/off' button. Indeed, if the conveyor belt's job (i.e., transporting products) had been done by, say, a line of human workers instead, LUC would have had to put much more effort into causing a breakdown of the production process. Extract 6 (below) shows the interactions that followed after LUC's resistance. In this extract, "CON" refers to the conveyor belt. Furthermore, as opposed to the previous abstracts, extract 6 is presented in a table-like manner, highlighting the simultaneity of the ongoing verbal and non-verbal interactions that were captured on video. 


\section{Extract 6. LUC's resistance}

Text with no special fonts $=$ description of non-verbal action

Empty cell $=$ the same description as above still applies

Italics = original transcription (associated with German)

Italics underlined $=$ original transcription (associated with Dutch)

Bold italics $=$ English translation

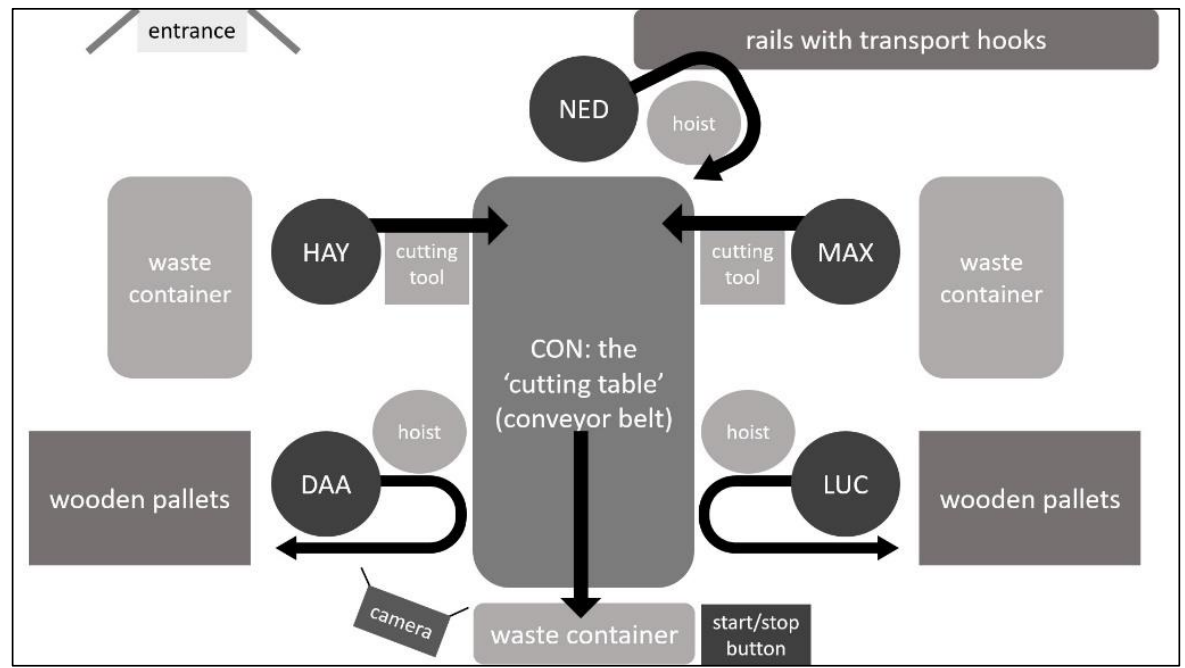

Figure 11. The spatial organisation of the workers at the cutting table during line 1 of extract 6 . The arrows indicate the direction of the work actions and the gazes of the human participants, as well the running direction of the conveyor belt (CON).

\begin{tabular}{|c|c|c|c|c|c|c|}
\hline & CON & NED & HAY & MAX & DAA & LUC \\
\hline 1 & running & $\begin{array}{l}\text { places } \\
\text { products } \\
\text { on CON }\end{array}$ & \multicolumn{2}{|c|}{ cut products } & \multicolumn{2}{|c|}{ lift products from CON } \\
\hline 2 & & & & & \multicolumn{2}{|c|}{$\begin{array}{l}\text { do not keep up with } \\
\text { CON's speed }\end{array}$} \\
\hline
\end{tabular}


132 - Power Dynamics at Work

\begin{tabular}{|c|c|c|c|c|c|c|}
\hline 3 & & & & & $\begin{array}{l}\text { continues } \\
\text { lifting } \\
\text { products } \\
\text { from CON }\end{array}$ & $\begin{array}{l}\text { presses } \\
\text { the 'off' } \\
\text { button, } \\
\text { lets his } \\
\text { hoist } \\
\text { swing in } \\
\text { the air, } \\
\text { and } \\
\text { starts } \\
\text { fixing } \\
\text { some } \\
\text { pallets } \\
\text { behind } \\
\text { him }\end{array}$ \\
\hline 4 & $\begin{array}{l}\text { stops } \\
\text { running }\end{array}$ & & & & & $\begin{array}{l}\text { still } \\
\text { fixing the } \\
\text { pallets }\end{array}$ \\
\hline 5 & & look at & $U C$ & & & \\
\hline 6 & & & $\begin{array}{l}\text { looks } \\
\text { at NED }\end{array}$ & & & \\
\hline 7 & & & & $\begin{array}{l}\text { turns } \\
\text { around, } \\
\text { looks at } \\
\text { LUC and } \\
\text { says: } \\
\frac{M A A R}{M A A R} \\
\frac{M A A R}{M A A R} \\
\frac{M A A R}{M Y M Y} \\
M Y M Y \\
M Y\end{array}$ & & \\
\hline 8 & & & \multicolumn{2}{|c|}{ look at LUC } & & \\
\hline 9 & & $\begin{array}{l}\text { says with a } \\
\text { soft voice: } \\
\text { was ist los? }\end{array}$ & & $\begin{array}{l}\text { looks at } \\
\text { CON and } \\
\text { continues }\end{array}$ & & \\
\hline
\end{tabular}


Emerging Production Work Assemblages - 133

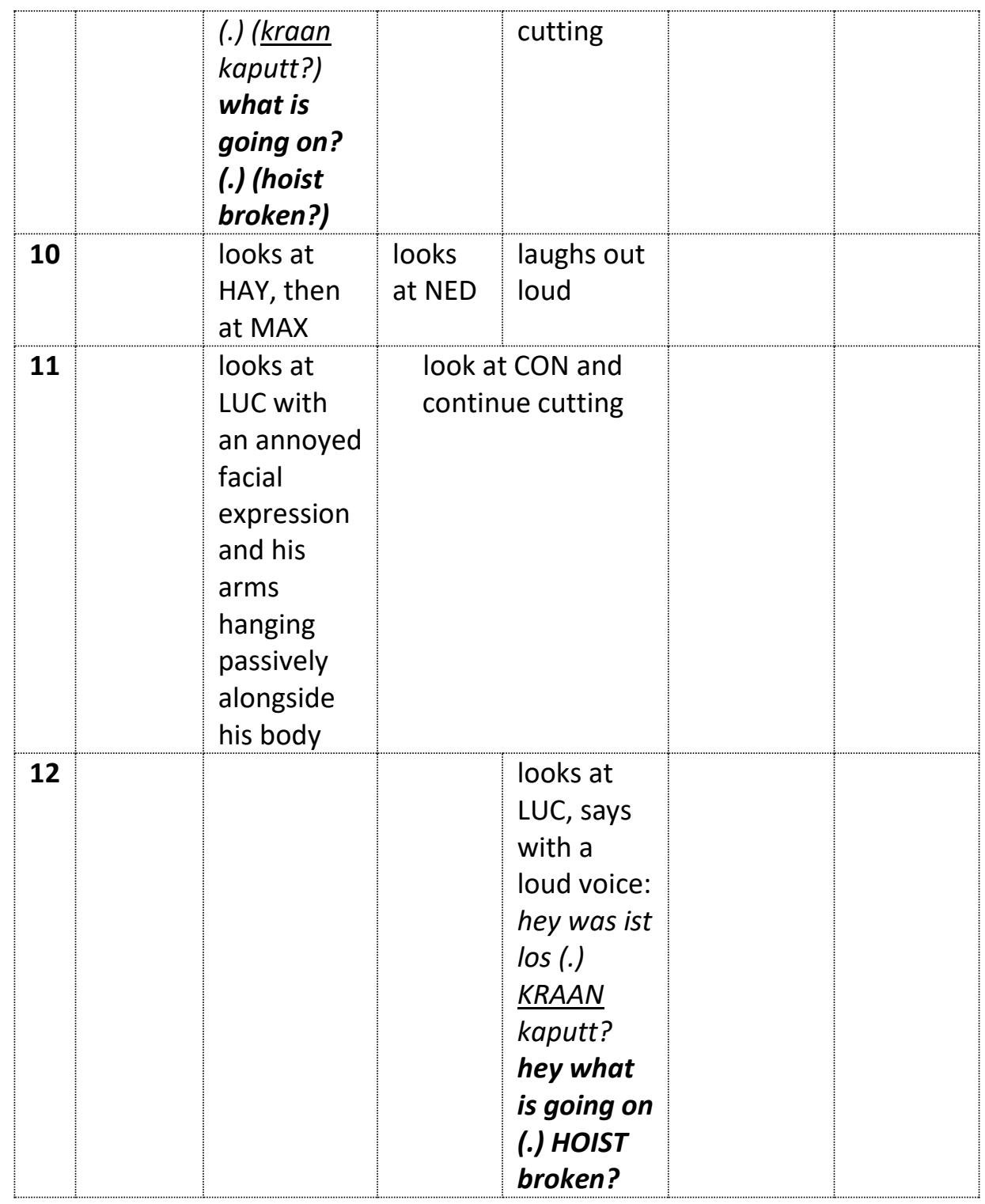




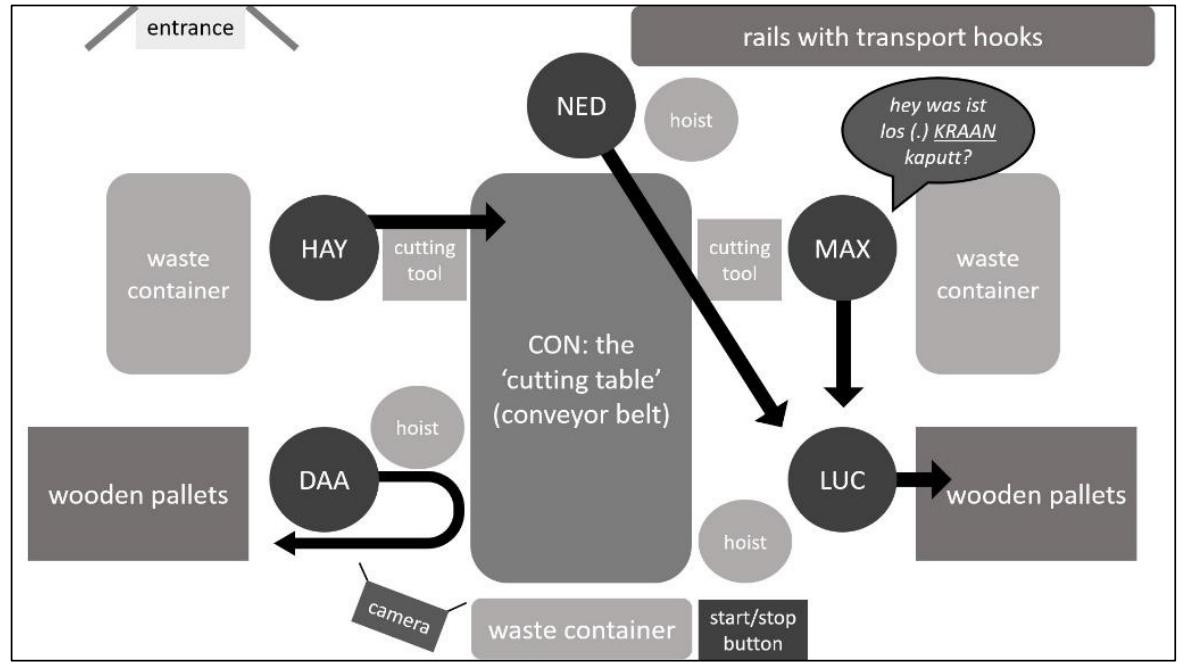

Figure 12. The spatial organisation of the workers at the cutting table during line 12 of extract 6 . The arrows indicate the direction of the gazes of the human participants. The text balloon shows the verbal utterances from

MAX ("hey what is going on (.) HOIST broken?").

\begin{tabular}{|l|l|l|l|l|l|l|}
\hline 13 & CON & NED & HAY & MAX & DAA & LUC \\
\hline $\begin{array}{ll}\text { looks at } \\
\text { CON }\end{array}$ & $\begin{array}{l}\text { looks at } \\
\text { LUC }\end{array}$ & $\begin{array}{l}\text { starts } \\
\text { lifting } \\
\text { products } \\
\text { from CON } \\
\text { again }\end{array}$ \\
\hline $\mathbf{1 4}$ & & $\begin{array}{l}\text { starts } \\
\text { placing } \\
\text { products } \\
\text { on CON } \\
\text { again } \\
\text { cannot } \\
\text { place } \\
\text { products } \\
\text { on CON } \\
\text { anymore, } \\
\text { looks in } \\
\text { the } \\
\text { direction }\end{array}$ & $\begin{array}{llll}\text { stops } \\
\text { cutting, } \\
\text { looks at } \\
\text { CON }\end{array}$ & $\begin{array}{l}\text { looks at } \\
\text { LUC with } \\
\text { one hand } \\
\text { resting on } \\
\text { his waist, } \\
\text { such that } \\
\text { his arm } \\
\text { forms a }\end{array}$ & \\
\hline
\end{tabular}


Emerging Production Work Assemblages - 135

\begin{tabular}{|c|c|c|c|c|c|}
\hline & & $\begin{array}{l}\text { of MAX } \\
\text { and LUC }\end{array}$ & & $\begin{array}{l}\text { triangular } \\
\text { shape }\end{array}$ & \\
\hline 16 & & & & $\begin{array}{l}\text { looks at } \\
\text { HAY, } \\
\text { pauses, } \\
\text { then looks } \\
\text { at NED, } \\
\text { and pauses } \\
\text { again }\end{array}$ & \\
\hline 17 & & $\begin{array}{l}\text { looks at } \\
\text { MAX and } \\
\text { nods his } \\
\text { head, } \\
\text { while } \\
\text { raising his } \\
\text { eyebrows } \\
\text { and } \\
\text { moving his } \\
\text { lips }\end{array}$ & & $\begin{array}{l}\text { looks at } \\
\text { NED }\end{array}$ & \\
\hline 18 & & & $\begin{array}{l}\text { looks at } \\
\text { LUC }\end{array}$ & $\begin{array}{l}\text { looks at } \\
\text { LUC and } \\
\text { says: } \\
\text { LOPEN } \\
\text { LET IT RUN }\end{array}$ & \\
\hline 19 & & \multicolumn{3}{|c|}{ look at CON } & $\begin{array}{l}\text { presses } \\
\text { the 'on' } \\
\text { button }\end{array}$ \\
\hline 20 & $\begin{array}{l}\text { starts } \\
\text { running }\end{array}$ & $\begin{array}{l}\text { continues } \\
\text { placing } \\
\text { products } \\
\text { on CON }\end{array}$ & conti & e cutting & $\begin{array}{l}\text { continues } \\
\text { lifting } \\
\text { products } \\
\text { from CON }\end{array}$ \\
\hline
\end{tabular}

Similar to the extracts from the previous sections, extract 6 shows that the breakdown was followed by (in this case) a brief moment of people observing a resisting (in this case human) actant (lines 5 and 7). HAY's quick gaze at NED (line 6) may also indicate who was considered responsible for dealing with the resisting co-worker (i.e., NED). MAX appeared to be more 
pro-active in this respect again, however (line 7). The idea that MAX's responsibility might have been assumed to be greater than NED's may partly explain why LUC did not seem very responsive to the various utterances aimed at him.

Furthermore, the interactions from extract 6 show the diverse interactional resources that primarily NED and MAX employed in their attempts to break LUC's resistance, so that a production work assemblage could emerge again with a working speed dictated by the conveyor belt (CON), or perhaps NED and MAX, but at least not by LUC. One such resource was the act of looking at LUC (e.g., in lines 5 and 8), which might have made him feel more self-conscious. One additional resource was body language (in lines 11 and 15), with which both NED and MAX signified nonverbally that LUC was making them wait, and that they were annoyed by that. Moreover, NED and (particularly) MAX were also employing Dutch language resources again (such as "kraan" in lines 9 and 12), thereby presenting themselves as members of an in-group.

Repeatedly saying "maar maar maar maar maar" (line 7), which literally means "but but but but but", and which could be translated as "my my my my my", was a specific running joke in the Casting Department, where it was typically used to mock someone who had just done something wrong (such as dropping something). Hence, this phrase can be considered a verbal artifact from a shared repertoire in the Casting Department's community of practice as well. Probably, a repetitive phrase such as "maar maar maar maar maar" could thrive there as it enabled understanding in a loud work environment with sometimes large physical distances between people. The exact origins and spread of this phrase are unknown, but it is commonly used in the Dutch province of Limburg. Thus, by using this phrase, MAX once again positioned himself as a member of an in-group, which could be interpreted as an attempt to legitimise the situated, hierarchical inter-actant workplace relation between LUC and him that night.

Despite the numerous interactional attempts from NED and MAX to discipline LUC, however, the latter continued focussing on his work tasks while not looking at or giving any verbal response to them. Only in line 19, after MAX had said the Dutch word "lopen!" again, LUC indicated that he had noticed his human co-workers by pressing the 'on' button. Furthermore, during the break that followed upon these interactions, and during which MAX, LUC, and I (among others) gathered at a smoking section 
outside the foundry building, LUC explicated his frustrations to MAX (in German) by angrily telling him that his continuous shouting got on his nerves, while he should have some understanding for the fact that there were two newcomers (i.e., he and I) working at the cutting table that night. He also referred to a forklift truck driver who, according to him, was not helping much by fixing the wooden pallets for us. In other words, despite obeying the order from MAX in line 19, LUC underlined that MAX had not managed to discipline him. He signified that he was not intimidated by the communicative behaviour of his colleagues, highlighting once more that they did not 'have' power and that agency was distributed.

Finally, an open question is how much the behaviour of LUC, MAX, and others was affected by the presence of a video camera. In several nonanalysed parts of the recording, there are moments when MAX shows that he is aware of this camera, as he for example points at it or verbally refers to it. Since it was not unusual for participants to think that my research findings would reach the foundry's management somehow, it is possible that MAX showed what he might have thought of as desirable behaviour in the eyes of the management. Hence, he might have felt more pressure to go against any breakdown of the work assemblage, and more eager to use Dutch rather than German words. As for LUC, he might have felt more strongly that he did not want to be humiliated by MAX while being filmed. Thus, it is likely that the video camera, as a non-human actant in the emerging assemblages, amplified or exaggerated certain feelings and behaviours among the human actants, and in that way also affected the data that I have discussed here.

\subsection{Conclusion and discussion}

This article has shown how diverse humans and machines in a metal foundry in the Dutch province of Limburg, as production work assemblages with inherent inter-actant hierarchies, together produced material products, thereby contributing to the company's emerging competitiveness. The article has focused on two cases of an assemblage breaking down, which posed a threat to its hierarchical organisation and to the emerging competitiveness, and which specific participants tried to manage expeditiously. Furthermore, it highlighted which interactional resources (such as specific tools and verbal resources) were mobilised to make a new production work assemblage emerge again, and how effective 
these resources turned out to be in practice. This final section discusses two findings.

The first finding is that processes that are conventionally thought of as contributing to a company's competitiveness may not always do so in practice. More specifically, it may seem obvious that expeditious production work practices by humans and machines (enabled by mechanisation processes), and the use of temporary workers carrying the risks of changing demands for products (enabled by labour market liberalisation processes) contribute to this competitiveness. This article has shown several examples, however, of time pressure and/or job insecurity negatively affecting a specific company's competitiveness, through BEN's anxiety delaying the establishment of a new production work assemblage, and through LUC's irritation leading to a breakdown of a production work assemblage, which a machine (i.e., mechanisation processes) enabled him to initiate. Perhaps even MAX's responses to that breakdown could be interpreted as a delaying element influenced by time pressure and/or job insecurity. Hence, from a management perspective, the larger question emerging from these examples is how to ensure a company's survival, while also encouraging people like BEN, LUC, and MAX to feel at ease in this work environment, as this appears to significantly affect the company's competitiveness as well. Furthermore, from the perspective of workers like BEN, LUC, and MAX, the examples show that a company's competitiveness cannot emerge without their cooperation, and this constitutes their potential position when it comes to (re)negotiations of any hierarchical workplace relation with their management.

The second finding concerns how much a verbal artifact from a shared repertoire in a workplace community of practice can reveal about the circumstances in which it has emerged. The second case analysed showed an example of MAX saying "maar maar maar maar maar", which can best be translated as "my my my my my", and which had emerged as a running joke in the Casting Department, where it was typically used to mock someone who had just done something wrong. To begin with, it was no coincidence that this running joke emerged in the Casting Department, as opposed to the Core Shooting Department from the first analysed case, or the Finishing Department from Hovens (2020). After all, it was the Casting Department that enabled regular interactions involving more than two workers, as people typically worked in groups at a conveyor belt there. Secondly, it was no coincidence that this running joke had a rather simple and repetitive form, as only verbal resources with these characteristics 
could probably thrive in a loud work environment with sometimes large physical distances between people, who, in addition, might have quite different language backgrounds. And thirdly, it was no coincidence that this running joke was used to mock people who had done something wrong. As discussed above, time pressure and job insecurity appeared as key rationales for behaviour observed in the foundry's production departments, and the emergence of a verbal resource that can be used -in diverse waysto respond to such pressures thus probably corresponded to an actual need in this work environment.

Future studies could have a fresh look at linguistic data from historical cases such as Pecht (2021) to see whether specific verbal resources from a shared workplace repertoire may similarly echo the circumstances from which they have emerged. Furthermore, future studies could include more locations to develop a more comprehensive understanding of how particular political-economic assemblages or commodity chains emerge in practice (see also Latour 2005; Thurlow 2020). Besides that, future (comparative) workplace studies may further explore whether aspects of gender influence interactions such as the ones analysed in this article. Finally, the relationship between human emotions and machines may be worth exploring in more detail as well. After all, as it appeared that BEN was quite impressed by the resistance of a machine, that LUC was quite annoyed by a conveyor belt not accommodating his working speed, and that the mutual responses between LUC and MAX were probably influenced by the presence of my video camera, it may be worth exploring how such emotional responses emerge, and how this may or may not be different from what is known about human-human interaction to date. 
140 - Power Dynamics at Work 


\section{Conclusion and Discussion}

This dissertation has presented a linguistic ethnography of a multilingual metal foundry in the Dutch province of Limburg, in the Dutch-German borderland. The main research question was: How do power dynamics emerge in a contemporary multilingual blue-collar work environment in a cross-border region? The term power dynamics in this dissertation referred to the human-human and human-machine interactions which produced particular effects, which hierarchised the relations among the interacting actants, and which did (not) contribute to relevant purposes such as productivity, workplace safety, and job satisfaction. Overall, the dissertation gave a detailed impression of the open and negotiable character of power dynamics at work, which was arguably amplified by the impacts of transient work relations, language diversity, mechanisation, and the metal foundry's location in a border area. Two innovative elements of the dissertation were its discussion of the perspectives of both majoritised and minoritised blue-collar workers, and its discussion of the interactional role of machines, which was approached from a posthumanist perspective (Latour 2005; Pennycook 2018). Ultimately, the dissertation aimed to contribute to better understandings and representations of blue-collar lifeworlds in this way, which may in turn lead to better informed languagepolitical interventions in historically emerged (socio)linguistic landscapes in Limburg and elsewhere. This final chapter discusses the main findings and their implications.

\subsection{The perspective of 'local' majoritised speakers}

Chapter 3 focussed on a group of senior production workers in the metal foundry, who were unhappy with the language diversity that had emerged in the production departments over time. Some labour recruiters referred to these workers as the foundry's "old guard". They typically spoke Dutch and Limburgish as their first languages, and when it comes to second languages, they typically preferred speaking German instead of English. As Dutch was the most frequently used written language in the foundry, and as the foundry's management made it clear that non-Dutch speakers were expected to learn Dutch over time, the old guard may be considered part of the company's sociolinguistic norm centre. Overall, however, they were well aware that most non-Dutch speakers did not learn a lot of Dutch over time. This was especially so during times of economic growth, when many 


\section{2 - Power Dynamics at Work}

temporary workers were recruited -an increasing number of whom did not speak Dutch, German, or Limburgish- and when turnover rates were high. Therefore, as long as they continued working in the foundry, the members of the old guard knew that they would probably have to adjust to a specific linguistically diverse reality at work, which they often did reluctantly, and which made the sociolinguistic centre-periphery dynamics more complex and multidimensional.

Even though many of the old guard mentioned communication problems to me, it became clear that these were not the only, or even the main, reason why they felt unhappy about the language diversity that had emerged in the foundry. Indeed, several members I talked with explained that this emerged diversity was part of a broader development, which made them feel that people had less respect for them nowadays, and that companies such as the metal foundry did not fully represent the interests of 'local' majoritised workers anymore. The foundry used to be open for Dutch speakers only (typically, Dutch-Limburgish bilinguals), it used to be known for its high wages, and it used to have a director who had a good personal relationship with many production workers, and whom many could identify with, as he spoke Limburgish and had a working class background. By the time when I did my fieldwork in 2017, all of this had changed, although the foundry's wages were allegedly still relatively high compared to other nearby blue-collar workplaces (yet not so high that the company could attract Dutch and Limburgish speakers only). On top of that, since the global financial crisis of 2007-2008, the foundry had started to rely increasingly on temporary workers, many of whom did not speak Dutch or Limburgish.

Within these circumstances, many of the old guard felt that what used to be a relatively secure position in the workplace was now under threat. Hence, it became clear that any change in the foundry's language policies should not only take into account possible communication issues, but also any possible effects on how much different people feel that their social-economic interests are being threatened. In theory, the foundry's management could have argued that by opening up to a linguistically more diverse workforce, the company could increase its production and make (more) profit, which could help the company (and the jobs it provided) to survive, and which could be invested in higher wages and more permanent contracts. Of course, as long as such a discourse is not accompanied by any noticeable effects, it probably does not make much of a difference, but if and when it is, people will be more likely to accept a specific language 
diversity at work. Therefore, rather than stating that everyone is expected to learn a particular majoritised language, which may frustrate both minoritised and majoritised speakers as long as it is not likely to happen in practice, it is probably wiser to consider a more realistic, inclusive language policy (see, e.g., Backus et al. 2013) and to legitimise this policy in a way that both minoritised and majoritised workers can feel happy with. After all, it is probably in the interests of all involved workers, managers, and society at large when everyone feels that a company is the best, most welcoming, and most pleasant place to work.

\subsection{The interactional role of machines}

Chapter 4 focussed on one specific individual in the metal foundry, namely a new, temporary production worker from Poland (VIN). In the analysed shift, VIN had to learn how to work productively with a particular machine. At first, he received some help from a more experienced, senior worker from Limburg, the Netherlands (PER), who could be considered a typical, outspoken member of the old guard. In many ways, this situation was a critical case, as many circumstances for the workplace learning process were not ideal. VIN could only rely on PER's help for a few hours, they did not have a shared work history yet, their individual language repertoires did not overlap much, and PER did not consider VIN's presence as a labour migrant in the foundry legitimate. Yet, despite all these odds, the chapter showed how VIN managed to become a more skilled worker with regard to the interactions with the machine, and thus, become a less peripheral worker in the particular workplace hierarchy of his department's community of practice (Lave and Wenger 1991; Wenger 1998).

Overall, the chapter highlighted several important functions of observed human-machine interactions for VIN's workplace learning process. Clearly, it was not just PER's verbal utterances that mattered when he explained particular interactions with the machine, but also the diverse signs that the machine itself produced, as well as the interactions between PER and the machine that occurred. By observing all these signs and by hypothesising about them, VIN more or less managed to work out how to reproduce the human-machine interactions. Furthermore, after PER had left the workstation, the machine acquired an even more prominent role, by communicating to VIN and me where, and where not, to stand and walk during the ongoing interactions. The machine's capacities were certainly 


\section{4 - Power Dynamics at Work}

not unlimited, however, particularly when a newcomer in the foundry (such as, in this case, VIN) was not able to read Dutch. Interestingly, on the machine's control panel, the emergency stop button was highlighted with English words and several non-verbal signs, while other buttons only had Dutch descriptions and arguably less clear non-verbal signs. Thus, as an affordance (Gibson 2015) and a literacy artifact (Barton and Hamilton 2005), the machine enabled the development of safe work practices rather than a broader work expertise in case a newcomer could not read (technical) Dutch.

Because the analysed workplace learning process was a critical case, the findings represented a reasonable minimum of what humanmachine interactions can achieve with regard to such processes. Under less challenging circumstances, with a control panel (or an interface) that accommodates a more diverse workforce, and with more opportunities for additional human-human interaction between motivated co-workers who have time to build up a shared work history, the potential of humanmachine interaction is probably (much) greater. Thus, on the one hand, chapter 4 showed that machines have the capacity to (partly) take over certain human communication tasks at work, and that they can help to overcome possible language barriers, while on the other hand, the chapter argued that machines may be better considered an addition to, rather than a replacement of human workers when it comes to the development of productive, safe, and satisfying work practices. Again, as it is probably in the interests of all involved workers, managers, and society at large when everyone feels that a company is the best, most welcoming, and most pleasant place to work, it can be worth considering how (more) workers can profit more fully from technological developments in the workplace, and how 'peripheral' workers such as VIN can be facilitated in the process of becoming more 'central' workers in a particular workplace hierarchy.

\subsection{Emerging competitiveness at work}

Chapter 5 discussed how diverse humans and machines together managed to be productive, as an assemblage (Bennett 2010; Deleuze and Guattari 1980; Latour 2005), and how the company's competitiveness at least partly emerged from such production work assemblages with particular inherent workplace hierarchies. Specifically, the chapter analysed two cases of a breakdown of a production process (i.e., an interruption of speed), which 
posed a threat to this hierarchical organisation and the metal foundry's competitiveness, and which specific participants tried to manage expeditiously. Furthermore, it highlighted specific verbal resources (e.g., "lopen!") and other resources (e.g., an angle grinder), and assessed how effective these resources were in the process of establishing a new production work assemblage.

The main participants of the two case studies, BEN and LUC, were both German-speaking cross-border labour commuters from Germany and relative newcomers in the metal foundry. In the first case, BEN was for the first time working with a machine without any help from a more experienced human colleague, which could be interpreted as a sign that he was gradually becoming a more 'central' worker in the studied community of practice. Unfortunately for BEN, however, the machine was producing many broken products, and he did not understand why this was happening. In this way, the machine initiated a renegotiation of BEN's newly obtained hierarchical positioning. By frequently showing how deeply concerned he was about this, BEN accepted that the machine could indeed affect his positioning in this way. When the team manager came to investigate the situation, he tried to reassure BEN that no human worker was to be blamed. BEN did not appear to be comforted, however, as he continued to express his concerns about being blamed, which might be explained by his status as a temporary worker with little job security and by the lack of time to make him feel at ease. Ironically, however, BEN's anxiety actually slowed down the process of establishing a new production work assemblage. Furthermore, in this way, the machine-initiated renegotiation of BEN's hierarchical positioning also led to a (re)negotiation of the team manager's position as the ultimate judge with regard to matters of blame.

In the second case, LUC and I (two relative newcomers) did not manage to keep up with the working speed that was 'dictated' by a conveyor belt, while three other, more experienced/'central' and mainly German-speaking colleagues did not appear to have problems with this. LUC became quite annoyed by our hierarchical positioning in this production work assemblage, as human actants who had to follow the speed dictations from a non-human actant. This non-human actant also enabled resistance to its speed dictations through an on/off button, however, which would not have been possible if the production work was entirely done by human actants. Indeed, at one point, LUC decided to press this button, causing our production work assemblage to break down, and initiating a renegotiation of the hierarchical workplace relations. Two of the 
more 'central' colleagues at the belt did not approve of this action, and even though LUC and his more 'central' colleagues all spoke German as their first language, the latter used particular Dutch orders (e.g., "lopen!", which can best be translated as "let it run!") and a particular repetitive Dutch phrase ("maar maar maar maar maar", which can best be translated as "my my my my my") in response to the situation. These verbal resources could be considered institutional key words from a shared repertoire of this department's community of practice, and their use might thus have been a way to share these resources with LUC. An alternative or additional interpretation is that they were used by the 'central' workers as a means to present themselves as 'central' members of this community, thereby (re)confirming or legitimising the hierarchical workplace relations that LUC had started to challenge.

Together, the analysed cases from chapter 5 presented a complex picture of the metal foundry's competitiveness. On the one hand, it may seem obvious that expeditious production work practices by humans and machines, and the use of temporary workers who take over the risks of changing product demands both increase this competitiveness. On the other hand, however, the chapter showed several examples of time pressure and job insecurity negatively affecting the company's productivity (through BEN's anxiety, and LUC's irritation), while machines enabled human actants (such as, in this case, LUC) to initiate a breakdown of a production process. Hence, the larger question emerging from this chapter was how to simultaneously ensure a company's survival, while also encouraging people to feel that this company is the best, most welcoming, and most pleasant place to work, as the latter seemed to significantly affect the company's competitiveness as well.

\subsection{Theoretical and practical takeaways}

Overall, at least three general takeaways can be drawn from the discussions above. First of all, as the cases from VIN and BEN have illustrated, human workers in the metal foundry often had more problems understanding machines than each other. In this respect, it makes sense to conceptualise language and language policy more broadly, and consider how humanmachine interactions in a work environment like the metal foundry can be improved. Secondly, the research has underlined the urgency for both linguistic ethnographers and company managers to pay more attention to 
questions concerning the legitimacy of language-political interventions in blue-collar work environments and elsewhere. Specifically, they need to consider why different workers (including PER and other members of the "old guard") find specific interventions (not) legitimate. If these reasons are poorly understood, any intervention might be doomed to fail, and possibly lead to social tensions in the workplace and society at large.

This brings me to the third take-away from this research, which is that it is crucial for linguistic ethnographers and other human languagepolicy actants to understand that a workplace value such as inclusivity (Backus et al. 2013) is not just an interest of specific minoritised workers, but an interest of everyone. Hence, it is important for whichever organisation to consider whether the social-economic and sociolinguistic interests of different individuals are sufficiently represented, and if this is so, to show them that this is the case. Given that the metal foundry may be considered a "laboratory of European integration" (Knippenberg 2004), as proposed in chapter 1, this take-away indeed applies to more than just blue-collar work environments like the metal foundry. After all, in terms of place-making processes (Thissen 2018), it is probably in the interests of all concerned residents, politicians, and entrepreneurs when people feel that a particular geographical area is the best, most welcoming, and most pleasant place to live. 
148 - Power Dynamics at Work 


\section{References}

Actieteam Grensoverschrijdende Economie en Arbeid. 2017. "Grenzen slechten, regio's verbinden, mensen bewegen: Rapportage Actieteam Grensoverschrijdende Economie en Arbeid." Website Vereniging van Nederlandse Gemeenten, 30 January. Accessed 5 April 2020. https://vng.nl/sites/default/files/publicaties/2017/170126 rapport met actieagenda embargo.pdf

Agha, Asif. 2003. "The Social Life of Cultural Value." Language \& Communication 23: 231-273. https://doi.org/10.1016/S02715309(03)00012-0

Arundale, Robert B. 2020. Communicating \& Relating: Constituting Face in Everyday Interaction. Oxford/New York: Oxford University Press.

Backus, Ad, Durk Gorter, Karlfried Knapp, Rosita Schjerve-Rindler, Jos Swanenberg, Jan D. ten Thije, and Eva Vetter. 2013. "Inclusive Multilingualism: Concept, Modes and Implications." European Journal of Applied Linguistics 1 (2): 179-215. https://doi.org/10.1515/eujal-2013-0010

Barton, David, and Mary Hamilton. 2005. "Literacy, Reification and the Dynamics of Social Interaction." In Beyond Communities of Practice: Language, Power and Social Context, edited by David Barton and Karin Tusting, 14-35. Cambridge: Cambridge University Press.

Baxter, Judith, and Kieran Wallace. 2009. "Outside In-Group and Out-Group Identities? Constructing Male Solidarity and Female Exclusion in UK Builders' Talk." Discourse \& Society 20 (4): 411-429. https://doi.org/10.1177/0957926509104021

Bell, Emma. 1999. "The Negotiation of a Working Role in Organizational Ethnography." International Journal of Social Research Methodology $\quad 2 \quad$ (1): $17-37$. https://doi.org/10.1080/136455799295168

Bennett, Jane. 2010. Vibrant Matter: A Political Ecology of Things. Durham/London: Duke University Press. 
Berkhout, Ernest, Paul Bisschop, and Maikel Volkerink. 2014. Grensoverschrijdend aanbod van personeel: Verschuivingen in nationaliteit en contractvormen op de Nederlandse arbeidsmarkt 2001-2011. Amsterdam: SEO Economisch Onderzoek.

Billig, Michael. 1995. Banal Nationalism. Thousand Oaks: SAGE Publications.

Blommaert, Jan. 2013. Ethnography, Superdiversity and Linguistic Landscapes: Chronicles of Complexity. Bristol/Buffalo/Toronto: Multilingual Matters.

Bourdieu, Pierre. 1991. Language and Symbolic Power. Cambridge, MA: Harvard University Press.

Brambilla, Chiara. 2015. "Exploring the Critical Potential of the Borderscapes Concept." Geopolitics 20 (1): 14-34. https://doi.org/10.1080/14650045.2014.884561

Brown, Penelope, and Stephen C. Levinson. 1987. Politeness: Some Universals in Language Usage. Cambridge: Cambridge University Press.

Cajot, José. 1996. De Nederlands-Duitse staatsgrens als scheidingslijn tussen klanken, vormen en woordgeslachten. Paper presented at the 21st congress of the Vereniging voor Limburgse Dialect- en Naamkunde in Rolduc, Kerkrade on 18 November 1995. Accessed 5 June 2017. http://www.dbnl.org/tekst/cajo001nede01 01/cajo001nede01 01 0001.php

Canagarajah, Suresh. 2018. "Translingual Practice as Spatial Repertoires: Expanding the Paradigm beyond Structuralist Orientations." Applied Linguistics 39 (1): 31-54. https://doi.org/10.1093/applin/amx041

Canagarajah, Suresh. 2020. "Transnational Work, Translingual Practices, and Interactional Sociolinguistics." Journal of Sociolinguistics 24 (5): 555-573. https://doi.org/10.1111/josl.12440

Coghlan, David, and Mary Brydon-Miller. 2014. The SAGE Encyclopedia of Action Research. Thousand Oaks: SAGE Publications.

Cornelissen, Georg. 1995. "De dialecten in de Duits-Nederlandse Roerstreek: Grensdialectologisch bekeken." Mededelingen van de Vereniging voor Limburgse Dialect- en Naamkunde 83. Accessed 5 June 
http://www.dbnl.org/tekst/corn022dial01 01/corn022dial01 010 001.php

Cornelissen, Georg. 2008. Meine Oma spricht noch Platt: Wo bleibt der Dialekt im Rheinland? Cologne: Landschaftsverband Rheinland.

Cornelissen, Georg. 2015. Kleine Sprachgeschichte von NordrheinWestfalen. Cologne: Greven Verlag.

Cornips, Leonie. 2003. Heerlens Nederlands. The Hague: Sdu.

Cornips, Leonie. 2013. "Recent Developments in the Limburg Dialect Region." In Language and Space: An International Handbook of Linguistic Variation. Volume 3: Dutch, edited by Frans Hinskens and Johan Taeldeman, 378-399. Berlin: De Gruyter.

Cornips, Leonie. 2019. "The Final Frontier: Non-Human Animals on the Linguistic Research Agenda." Linguistics in the Netherlands 36 (1): 13-19. https://doi.org/10.1075/avt.00015.cor

Cornips, Leonie. 2020a. “Dialect Acquisition by 'New Speakers' of Dutch and Their Linguistic Othering." Journal of Multilingual and Multicultural Development. https://doi.org/10.1080/01434632.2020.1730384

Cornips, Leonie. 2020b. "The Impact of Preschool Attendance on Children's Bidialectism in the Netherlands: Why Toddlers May Stop Speaking a Regional Language (Limburgish) at Home." Language in Society 49 (3): 333-355. https://doi.org/10.1017/S0047404520000275

Cornips, Leonie, and Vincent A. de Rooij. 2015. "Belonging through Languagecultural Practices in the Periphery: The Politics of Carnival in the Dutch Province of Limburg." Anthropological Journal of $\begin{array}{llll}\text { European } \quad \text { Cultures } 24 & \text { (1): }\end{array}$ https://doi.org/10.3167/ajec.2015.240106

Cornips, Leonie, and Ad Knotter. 2016. De uitvinding van Limburg: De territorialisering van geschiedenis, taal en identiteit. Maastricht: Sociaal Historisch Centrum Limburg.

Cornips, Leonie, and Louis van den Hengel. 2021. "Place-Making by Cows in an Intensive Dairy Farm: A Sociolinguistic Approach to Nonhuman Animal Agency." In Animals in Our Midst: The Challenges of Coexisting with Animals in the Anthropocene, edited by Bernice Bovenkerk and Jozef Keulartz, 177-202. Cham: Springer. 
Creese, Angela, and Fiona Copland. 2017. "Linguistic Ethnography." In Research Methods in Language and Education: Encyclopedia of Language and Education Volume 10, edited by Kendall King and Nancy Hornberger, 339-351. Cham: Springer.

Daly, Nicola, Janet Holmes, Jonathan Newton, and Maria Stubbe. 2004. "Expletives as Solidarity Signals in FTAs on the Factory Floor." Journal of Pragmatics 36 (5): 945-964. https://doi.org/10.1016/j.pragma.2003.12.004

Decoville, Antoine, Frédéric Durand, Christophe Sohn, and Olivier Walther. 2013. "Comparing Cross-border Metropolitan Integration in Europe: Towards a Functional Typology." Journal of Borderlands Studies 28 (2): 221-237. https://doi.org/10.1080/08865655.2013.854654

Deleuze, Gilles, and Félix Guattari. 1980. Mille plateaux. Paris: Les Éditions de Minuit.

Dijkstra, Bianca E., Matt Coler and Gisela Redeker. 2020. "The Multilingual Workplace Realities of Polish Truckers: A Case Study in the Netherlands." Multilingua. https://doi.org/10.1515/multi-2020$\underline{0038}$

Dings, Marcel. 2017. Stenen en pannen: Geschiedenis en inventarisatie van de grofkeramische industrie in Limburg. Roermond: Werkgroep Industrieel Erfgoed Limburg.

Driessen, Geert. 2006. Ontwikkelingen in het gebruik van streektalen en dialecten in de periode 1995-2003. Toegepaste Taalwetenschap in Artikelen 75 (1): 103-113. https://doi.org/10.1075/ttwia.75.10dri

Duchêne, Alexandre. 2011. "Néoliberalisme, inégalités sociales et plurilinguisme: L'exploitation des ressources langagières et des locuteurs." Langage et société 2 (136): 81-108. https://doi.org/10.3917/ls.136.0081

Duitsland Instituut Amsterdam. 2018. Schoolvak Duits: Feiten en cijfers. 19 January 2020. https://duitslandinstituut.nl/naslagwerk/1223/feiten-en-cijfers

Eckert, Penelope, and Sally McConnell-Ginet. 1992. "Think Practically and Look Locally: Language and Gender as Community-Based Practice." 
Annual Review of Anthropology 21: 461-488. https://doi.org/10.1146/annurev.an.21.100192.002333

Engelbrecht, Jörg. 1997. Räume und Grenzen in historischer Perspektiv: Die Entwicklung der deutsch-niederländischen Grenze im Wandel der Jahrhunderte. Dorenburg: Museumsverein.

Entzinger, Han. 2014. The Growing Gap between Facts and Discourse on Immigrant Integration in the Netherlands. Identities 21 (6): 693707. https://doi.org/10.1080/1070289X.2013.828616

Eurostat. 2018. "Statistics on Commuting Patterns at Regional Level." Eurostat website, 13 September. Accessed 26 May 2020. https://ec.europa.eu/eurostat/statisticsexplained/index.php?title=Statistics on commuting patterns at $r$ egional level\&oldid=403318\#General overview

Favell, Adrian. 2009. "Immigration, Migration, and Free Movement in the Making of Europe." In European Identity, edited by Jeffrey T. Checkel and Peter J. Katzenstein, 167-189. Cambridge: Cambridge University Press.

Fox, Nick J., and Pam Alldred. 2020. "Re-Assembling Climate Change Policy: Materialism, Posthumanism, and the Policy Assemblage." The British Journal of Sociology 71 (2): 269-283. https://doi.org/10.1111/1468-4446.12734

Franziskus, Anne. 2016. "'One does not say Moien, one has to say Bonjour.' Expressing Language Ideologies through Shifting Stances in Spontaneous Workplace Interactions in Luxembourg." Journal of Linguistic Anthropology $26 \quad$ (2): 204-221. https://doi.org/10.1111/jola.12124

Franziskus, Anne, Julia de Bres, and Peter Gilles. 2013. "I learnt English the wrong thing, eh.' Power, Interests and Language Practices among Cross-border Workers in Luxembourg." In Theorising Power through Analyses of Border Relationships, edited by Harlan Koff, Christian Schulz, and Peter Gilles, 249-269. Brussels: PIE Peter Lang.

Franziskus, Anne, and Peter Gilles. 2012. “'Et le präis direct etikett?' NonOverlapping Repertoires in Workplace Communication in Luxembourg." Sociolinguistica 26: 58-71. https://doi.org/10.1515/soci.2012.26.1.58 
García, Ofelia, and Li Wei. 2014. Translanguaging: Language, Bilingualism and Education. Basingstoke/New York: Palgrave Macmillan.

Gherardi, Silvia, and Davide Nicolini. 2002. "Learning the Trade: A Culture of Safety in Practice." Organization 9 (2): 191-223. https://doi.org/10.1177/1350508402009002264

Gibson, James J. 2015. The Ecological Approach to Visual Perception: Classic Edition. London/New York: Psychology Press. First published 1979.

Gibson, Melissa K., and Michael J. Papa. 2000. "The Mud, the Blood, and the Beer Guys: Organizational Osmosis in Blue-Collar Work Groups." Journal of Applied Communication Research 28 (1): 68-88. https://doi.org/10.1080/00909880009365554

Giesbers, Charlotte H.E. 2008. "Dialecten op de grens van twee talen: Een dialectologisch en sociolinguïstisch onderzoek in het Kleverlands dialectgebied." PhD dissertation, University of Nijmegen. https://repository.ubn.ru.nl/bitstream/handle/2066/67849/67849. pdf?sequence $=1$

Goffman, Erving. 1967. Interaction Ritual: Essays in Face-to-Face Behavior. Chicago: Adline Publishing Company.

Goldstein, Tara. 1997. Two Languages at Work: Bilingual Life on the Production Floor. Berlin: De Gruyter.

Gonçalves, Kellie, and Helen Kelly-Holmes. 2021. "Introduction." In Language, Global Mobilities, Blue-Collar Workers and Blue-Collar Workplaces, edited by Kellie Gonçalves and Helen Kelly-Holmes, 126. London/New York: Routledge.

Gonçalves, Kellie, and Anne Schluter. 2017. "'Please do not leave any notes for the cleaning lady, as many do not speak English fluently.' Policy, Power, and Language Brokering in a Multilingual Workplace." Language Policy 16: 241-265. https://doi.org/10.1007/s10993-0169406-2

Goodwin, Charles. 1994. "Professional vision." American Anthropologist 96 (3): 606-633. https://doi.org/10.1525/aa.1994.96.3.02a00100

Haberland, Hartmut, and Janus Mortensen. 2019. "Transience." In Handbook of Pragmatics: $22^{\text {nd }}$ Annual Installment, edited by Jan-Ola 
Östman and Jef Verschueren, 225-236. Amsterdam/Philadelphia: John Benjamins Publishing Company.

Handford, Michael, and Petr Matous. 2015. "Problem-Solving Discourse on an International Construction Site: Patterns and Practices." English for Specific Purposes 38: 85-98. https://doi.org/10.1016/i.esp.2014.12.002

Hawkins, Robert L. 2010. "Outsider in: Race, Attraction, and Research in New Orleans." Qualitative Inquiry 16 (4): 249-261. https://doi.org/10.1177/1077800409351972

Heller, Monica, and Alexandre Duchêne. 2012. "Pride and Profit: Changing Discourses of Language, Capital and Nation-State." In Language in Late Capitalism: Pride and Profit, edited by Alexandre Duchêne and Monica Heller, 1-21. New York/London: Routledge.

Heller, Monica, Joan Pujolar, and Alexandre Duchêne. 2014. "Linguistic Commodification in Tourism." Journal of Sociolinguistics 18 (4): 539-566. https://doi.org/10.1111/iosl.12082

Hiss, Florian. 2017. "Workplace Multilingualism in Shifting Contexts: A Historical Case." Language in Society 46: 697-718. https://doi.org/10.1017/S0047404517000628

Holland, Dorothy, William Lachicotte Jr., Debra Skinner, and Carole Cain. 1998. Identity and Agency in Cultural Worlds. London/Cambridge, MA: Harvard University Press.

Holm, Anna-Elisabeth, Bernadette O'Rourke, and Mike Danson. 2020. "'Employers could use us, but they don't.' Voices from Blue-Collar Workplaces in a Northern Periphery." Language Policy 19: 389-416. https://doi.org/10.1007/s10993-019-09513-4

Holmes, Janet, and Meredith Marra. 2002. "Having a Laugh at Work: How Humour Contributes to Workplace Culture." Journal of Pragmatics 34 (12): 1683-1710. https://doi.org/10.1016/S03782166(02)00032-2

Holmes, Janet, and Maria Stubbe. 2015. Power and Politeness in the Workplace: A Sociolinguistic Analysis of Talk at Work. London/New York: Routledge. First published 2003. 
Holmes, Janet, and Jay Woodhams. 2013. "Building Interaction: The Role of Talk in Joining a Community of Practice." Discourse \& $\begin{array}{llll}\text { Communication } & 7 & \text { (3): }\end{array}$ https://doi.org/10.1177/1750481313494500

Horner, Kristine, and Jean Jacques Weber. 2008. "The Language Situation in Luxembourg." Current Issues in Language Planning 9 (1): 69-128. https://doi.org/10.2167/cilp130.0

Hovens, Daan. 2012. "What is the Language of the Euregio Rhine-MeuseNorth? Euregional Integration and the Future of Languages near the Dutch-German Border." Master's thesis, University of Göttingen and Uppsala University.

Hovens, Daan. 2020. "Workplace Learning through Human-Machine Interaction in a Transient Multilingual Blue-Collar Work Environment." Journal of Linguistic Anthropology 30 (3): 369-388. https://doi.org/10.1111/jola.12279

Hovens, Daan. 2021. "Language Policy and Linguistic Landscaping in a Contemporary Blue-Collar Workplace in the Dutch-German Borderland." Language Policy. https://doi.org/10.1007/s10993-020$\underline{09572-y}$

Hülmbauer, Cornelia, Heike Böhringer, and Barbara Seidlhofer. 2008. "Introducing English as a Lingua Franca (ELF): Precursor and Partner in Intercultural Communication." Synergies Europe 3: 25-36. https://www.gerflint.fr/Base/Europe3/hulmbauer.pdf

Iaon, Alexandru. 2020. "Isolation: Does it Represent a New Stage of Posthumanism?" International Journal of Communication Research 10 349-355.

https://www.ijcr.eu/articole/519 03\%20Alexandru\%20loan.pdf

ITEM. 2018. "Cross Border Knowledge for Policy and Practice: Concise Information Brochure." Maastricht University website, May. Accessed $25 \quad$ February 2021. https://www.maastrichtuniversity.nl/sites/default/files/item consi ce information brochure en.pdf

Jacobs, Antoine. 2008. "Die Sprachverhältnisse in Niederländisch-Limburg, unter besonderer Berücksichtigung der kirchlichen Amtssprache." In Historism and Cultural Identity in the Rhine-Meuse Region: 
Tensions between Nationalism and Regionalism in the Nineteenth Century, edited by Wolfgang Cortjaens, Jan De Maeyer, and Tom Verschaffel, 113-136. Leuven: Leuven University Press.

Johnson, David C. 2013. Language Policy. Basingstoke: Palgrave Macmillan.

Jørgensen, Jens Normann, and Somogy Varga. 2011. "Norms and Practices of Polylingual Behaviour: A Sociolinguistic Model." ESUKA - JEFUL 2 (2): 49-68. https://doi.org/10.12697/jeful.2011.2.2.03

King, Brian W. 2014. "Tracing the Emergence of a Community of Practice: Beyond Presupposition in Sociolinguistic Research." Language in Society 43: 61-81. https://doi.org/10.1017/S0047404513000870

Kleifgen, Jo Anne. 2013. Communicative Practices at Work: Multimodality and Learning in a High-Tech Firm. Bristol/Buffalo/Toronto: Multilingual Matters.

Knippenberg, Hans. 2004. "The Maas-Rhine Euroregion: A Laboratory for European Integration?" Geopolitics 9 (3): 608-626. https://doi.org/10.1080/14650040490478675

Korres, Achim. 2006. "Paspoortregime en migratie in het Duits-Nederlandse grensgebied in de negentiende en twintigste eeuw tot ca. 1940." In Studies over de sociaal-economische geschiedenis van Limburg L1, edited by Ad Knotter and Willibrord Rutten, 117-144. Maastricht: Sociaal Historisch Centrum Limburg.

Kraft, Kamilla. 2017. "Constructing Migrant Workers: Multilingualism and Communication in the Transnational Construction Site." PhD dissertation, University of Oslo.

Kraft, Kamilla. 2019. "Language Policies and Linguistic Competence: New Speakers in the Norwegian Construction Industry." Language Policy 18: 573-591. https://doi.org/10.1007/s10993-018-9502-6

Kraft, Kamilla. 2020a. "Trajectory of a Language Broker: Between Privilege and Precarity." International Journal of Multilingualism 17 (1): 80 96. https://doi.org/10.1080/14790718.2020.1682256

Kraft, Kamilla. 2020b. "Linguistic Securitisation as a Governmentality in the Neoliberalising Welfare State." In Language and Neoliberal Governmentality, edited by Luisa Martín Rojo and Alfonso Del Percio, 29-48. London/New York: Routledge. 
Labov, William. 1972. Sociolinguistic Patterns, No. 4. Philadelphia: University of Pennsylvania Press.

Landry, Rodrigue, and Richard Y. Bourhis. 1997. "Linguistic Landscape and Ethnolinguistic Vitality: An Empirical Study." Journal of Language and Social Psychology $16 \quad$ (1): 23-49. https://doi.org/10.1177/0261927X970161002

La Pastina, Antonio C. 2006. "The Implications of an Ethnographer's Sexuality." Qualitative Inquiry 12 (4): 724-735. https://doi.org/10.1177/1077800406288615

Latour, Bruno. 1986. "The Powers of Association." In Power, Action, and Belief: A New Sociology of Knowledge?, edited by John Law, 264280. Boston/London: Routledge \& Kegan Paul.

Latour, Bruno. 1992. "Where Are the Missing Masses? The Sociology of a Few Mundane Artifacts." In Shaping Technology - Building Society: Studies in Sociotechnical Change, edited by Wiebe Bijker and John Law, 225-258. Cambridge, MA: MIT Press.

Latour, Bruno. 2005. Reassembling the Social: An Introduction to ActorNetwork-Theory. Oxford: Oxford University Press.

Lave, Jean, and Étienne Wenger. 1991. Situated Learning: Legitimate Peripheral Participation. Cambridge: Cambridge University Press.

Lønsmann, Dorte. 2014. "Linguistic Diversity in the International Workplace: Language Ideologies and Processes of Exclusion." Multilingua 33 (12): 89-116. https://doi.org/10.1515/multi-2014-0005

Lønsmann, Dorte. 2016. "Negotiating Positionality in Ethnographic Investigations of Workplace Settings: Student, Consultant or Confidante?" In The Ins and Outs of Business and Professional Discourse Research: Reflections on Interacting with the Workplace, edited by Glen Michael Alessi and Geert Jacobs, 13-36. Cham: Springer.

Lønsmann, Dorte, and Kamilla Kraft. 2017. "Language in Blue-Collar Workplaces." In The Routledge Handbook of Language in the Workplace, edited by Bernadette Vine, 138-149. London/New York: Routledge. 
Lucas, Kristen. 2011. "Blue-Collar Discourses of Workplace Dignity: Using Outgroup Comparisons to Construct Positive Identities." Management Communication Quarterly 25 (2): 353-374. https://doi.org/10.1177/0893318910386445

Mortensen, Janus. 2017. "Transient Multilingual Communities as a Field of Investigation: Challenges and Opportunities." Journal of Linguistic Anthropology 27 (3): 271-288. https://doi.org/10.1111/jola.12170

Muysken, Pieter. 2000. Bilingual Speech: A Typology of Code-Mixing. Cambridge: Cambridge University Press.

Pabst, Klaus. 1992. "Loyalitätsprobleme einer Grenzbevölkerung: Das Beispiel Niederländisch-Limburgs im 19. und 20. Jahrhundert." In Nation - Nationalismus - Postnation: Beiträge zur Identitätsfindung der Deutschen im 19. und 20. Jahrhundert, edited by Harm Klueting, 27-46. Cologne/Vienna/Weimar: Böhlau Verlag.

Pecht, Nantke. 2021. "Language Contact in a Mining Community: A Study of Variation in Personal Pronouns and Progressive Aspect in Cité Duits." PhD dissertation, Maastricht University / LOT. https://doi.org/10.26481/dis.20210127np

Peck, Jamie, Nik Theodore, and Kevin Ward. 2005. "Constructing Markets for Temporary Labour: Employment Liberalization and the Internationalization of the Staffing Industry." Global Networks 5 (1): 3-26. https://doi.org/10.1111/j.1471-0374.2005.00105.x

Pennycook, Alastair. 2018. Posthumanist Applied Linguistics. London/New York: Routledge.

Pennycook, Alastair. 2019. "Linguistic Landscapes and Semiotic Assemblages." In Expanding the Linguistic Landscape: Linguistic Diversity, Multimodality and the Use of Space as a Semiotic Resource, edited by Martin Pütz and Neele Mundt, 156-184. Bristol/Blue Ridge Summit: Multilingual Matters.

Pennycook, Alastair. 2021. "Blue-Collar Work and Multilingualism: C'est Tough." In Language, Global Mobilities, Blue-Collar Workers and Blue-Collar Workplaces, edited by Kellie Gonçalves and Helen KellyHolmes, 224-236. London/New York: Routledge. 
Pennycook, Alastair, and Emi Otsuji. 2015. "Metrolingual Multitasking and Spatial Repertoires: 'Pizza mo two minutes coming."' Journal of Sociolinguistics 18 (2): 161-184. https://doi.org/10.1111/josl.12079

Pietikäinen, Sari, and Helen Kelly-Holmes. 2013. Multilingualism and the Periphery. Oxford: Oxford University Press.

Pigg, Stacey. 2014. "Emplacing Mobile Composing Habits: A Study of Academic Writing in Networked Social Spaces." College Composition $\begin{array}{llll}\text { and } \quad 60 m m u n i c a t i o n & \text { (2): }\end{array}$ https://library.ncte.org/journals/CCC/issues/v66-2/26224

Piller, Ingrid, and Loy Lising. 2014. "Language, Employment, and Settlement: Temporary Meat Workers in Australia." Multilingua 33 (1-2): 35-59. https://doi.org/10.1515/multi-2014-0003

Pollux, Frans. 2019. "Duits mallotig? Engels - dá's pas pittig: chaotische uitspraak en spelling." Dagblad de Limburger, 9 August 2019. Accessed $\quad 5 \quad$ April 2020. https://www.limburger.nl/cnt/dmf20190808 00117772/duitsmallotig-engels-da-s-pas-pittig-chaotische-uitspraak-en-spelling

Redder, Angelika. 2008. "Functional Pragmatics." In Handbook of Interpersonal Communication, edited by Gerd Antos and Eija Ventola, 133-178. Berlin: De Gruyter.

Rickert, Thomas. 2013. Ambient Rhetoric: The Attunements of Rhetorical Being. Pittsburgh: University of Pittsburgh Press.

Roberts, Celia. 2013. "The Gatekeeping of Babel: Job Interviews and the Linguistic Penalty." In Language, Migration and Social Inequalities: A Critical Sociolinguistic Perspective on Institutions and Work, edited by Alexandre Duchêne, Melissa Moyer, and Celia Roberts, 81-94. Bristol/Buffalo/Toronto: Multilingual Matters.

Scollon, Ron, and Suzie Wong Scollon. 2003. Discourses in Place: Language in the Material World. London/New York: Routledge.

Scollon, Ron, and Suzie Wong Scollon. 2007. "Nexus Analysis: Refocusing Ethnography on Action." Journal of Sociolinguistics 11 (5): 608-625. https://doi.org/10.1111/j.1467-9841.2007.00342.x

Selting, Margret, Peter Auer, Dagmar Barth-Weingarten, Jörg Bergmann, Pia Bergmann, Karin Birkner, Elizabeth Couper-Kuhlen, Arnulf 
Deppermann, Peter Gilles, Susanne Günthner, Martin Hartung, Friederike Kern, Christine Mertzlufft, Christian Meyer, Miriam Morek, Frank Oberzaucher, Jörg Peters, Uta Quasthoff, Wilfried Schütte, Anja Stukenbrock, and Susanne Uhmann. 2009. "Gesprächsanalytisches Transkriptionssystem 2 (GAT 2)." Gesprächsforschung - Online-Zeitschrift zur verbalen Interaktion 10: 353-402. Accessed 19 January 2020. https://pub.unibielefeld.de/record/2472604

Shohamy, Elana. 2006. Language Policy: Hidden Agendas and New Approaches. London/New York: Routledge.

Shohamy, Elana. 2015. "LL Research as Expanding Language and Language Policy." Linguistic Landscape 1 (1-2): 152-171. https://doi.org/10.1075/ll.1.1-2.09sho

Shohamy, Elana. 2019. "Linguistic Landscape after a Decade: An Overview of Themes, Debates and Future Directions." In Expanding the Linguistic Landscape: Linguistic Diversity, Multimodality and the Use of Space as a Semiotic Resource, edited by Martin Pütz and Neele Mundt, 62-86. Bristol/Blue Ridge Summit: Multilingual Matters.

Söderlundh, Hedda, Linda Kahlin, and Matylda Weidner. 2020. "Arbetsmigration och flerspråkig interaktion på byggarbetsplatser." Nordand 15 (2): 93-110. https://doi.org/10.18261/issn.2535-33812020-02-04

Spolsky, Bernard. 2004. Language Policy. Cambridge: Cambridge University Press.

Spradley, James P. 1980. Participant Observation. Orlando: Harcourt Brace Jovanovich College Publishers.

Standing, Guy. 2011. The Precariat: The New Dangerous Class. London: Bloomsbury.

Statistics Netherlands [Centraal Bureau voor de Statistiek]. 2020a. "Bevolking; leeftijd, migratieachtergrond, geslacht, regio, 1 jan. 1996-2020." Statistics Netherlands website, 23 July. Accessed 22 February 2021. https://opendata.cbs.nl/statline/\#/CBS/nl/dataset/37713/table?fro $\underline{\text { mstatweb }}$ 
Statistics Netherlands [Centraal Bureau voor de Statistiek]. 2020b. "Bevolkingsontwikkeling; levend geborenen, overledenen en migratie per regio." Statistics Netherlands website, 18 August. Accessed $22 \quad$ February 2021. https://opendata.cbs.nl/\#/CBS/nl/dataset/37259ned/table?dl=4666 $\underline{4}$

Statistics Netherlands [Centraal Bureau voor de Statistiek]. 2021. "Grenspendel werknemers; nationaliteit, woonland, werkregio (NUTS 3)." Statistics Netherlands website, 12 February. Accessed 22 February 2021. https://opendata.grensdata.eu/\#/InterReg/nl/dataset/22003NED/t able?ts=1610667017756

Strömmer, Maiju. 2021. "Physical Work, Customer Service, or Teamwork? Language Requirements for Seasonal Cleaning Work in the Booming Arctic Tourism Industry." In Language, Global Mobilities, Blue-Collar Workers and Blue-Collar Workplaces, edited by Kellie Gonçalves and Helen Kelly-Holmes, 187-203. London/New York: Routledge.

Strüver, Anke. 2005. Stories of the 'Boring Border': The Dutch-German borderscape in People's Minds. Münster: LIT Verlag.

Suchman, Lucy. 2007. Human-Machine Reconfigurations: Plans and Situated Actions. Cambridge: Cambridge University Press.

Sunaoshi, Yukako. 2005. "Historical Context and Intercultural Communication: Interactions between Japanese and American Factory Workers in the American South." Language in Society 34 (2): 185-217. https://doi.org/10.1017/S0047404505050086

Svensson, Sara, and Carl Nordlund. 2015. "The Building Blocks of a Euroregion: Novel Metrics to Measure Cross-border Integration." Journal of European Integration 37 (3): 371-389. https://doi.org/10.1080/07036337.2014.968568

Ten Thije, Jan D., and Ludger Zeevaert, eds. 2007. Receptive Multilingualism: Linguistic Analyses, Language Policies and Didactic Concepts. Amsterdam: John Benjamins.

Theodoropoulou, Irene. 2020. "Blue-Collar Workplace Communicative Practices: A Case Study in Construction Sites in Qatar." Language Policy 19: 363-387. https://doi.org/10.1007/s10993-019-09518-z 
Thissen, Lotte C.S. 2018. "Talking in and out of Place: Ethnographic Reflections on Language, Place and (Un)Belonging in Limburg, the Netherlands." PhD dissertation, Maastricht University. https://doi.org/10.26481/dis.20180111lt

Thurlow, Crispin. 2020. "Expanding Our Sociolinguistic Horizons? Geographical Thinking and the Articulatory Potential of Commodity Chain Analysis." Journal of Sociolinguistics 24: 350-368. https://doi.org/10.1111/josl.12388

Tollefson, James W., and Miguel Pérez-Milans. 2018. "Research and Practice in Language Policy and Planning." In The Oxford Handbook of Language Policy and Planning, edited by James W. Tollefson and Miguel Pérez-Milans, 1-32. Oxford: Oxford University Press.

Tutt, Dylan, Sarah Pink, Andy R.J. Dainty, and Alistair Gibb. 2013. "In the Air' and Below the Horizon: Migrant Workers in UK Construction and the Practice-Based Nature of Learning and Communicating OHS." Construction Management and Economics 31 (6): 515-527. https://doi.org/10.1080/01446193.2012.756145

Ueno, Naoki. 2000. "Ecologies of Inscription: Technologies of Making the Social Organization of Work and the Mass Production of Machine Parts Visible in Collaborative Activity." Mind, Culture, and Activity 7 (1-2): 59-80. https://doi.org/10.1080/10749039.2000.9677648

Uitzendbureau.nl. 2018. "CAO." Website uitzendbureau.nl. Accessed on December 21, 2018. https://www.uitzendbureau.nl/info/cao

Urciuoli, Bonnie, and Chaise LaDousa. 2013. "Language Management/Labor." Annual Review Of Anthropology 42: 175-190. https://doi.org/10.1146/annurev-anthro-092412-155524

Van de Weerd, Pomme L. 2020. "Nederlanders and Buitenlanders: A Sociolinguistic-Ethnographic Study of Ethnic Categorization among Secondary School Pupils." PhD dissertation, Maastricht University and Université libre de Bruxelles / LOT. https://doi.org/10.26481/dis.20201118lp

Van Houtum, Henk, and Martin van der Velde. 2004. "The Power of CrossBorder Labour Market Immobility." Tijdschrift voor Economische en Sociale Geografie 95 (1): 100-107. https://doi.org/10.1111/i.0040747X.2004.00296.X 
Van Rooy, Raf. 2020. Language or Dialect? The History of a Conceptual Pair. Oxford: Oxford University Press.

Wacjman, Judy. 2010. "Feminist Theories of Technology." Cambridge Journal of Economics 34: 143-152. https://doi.org/10.1093/cje/ben057

Watson, Matt. 2016. "Placing Power in Practice Theory." In The Nexus of Practices: Connections, Constellations, Practitioners, edited by Allison Hui, Theodore Schatzki, and Elizabeth Shove, 169-182. London/New York: Routledge.

Wenger, Étienne. 1998. Communities of Practice: Learning, Meaning, and Identity. Cambridge: Cambridge University Press.

Wickman, Forrest. 2012. "Working Man's Blues: Why Do We Call Manual Laborers Blue-Collar?" Slate, 1 May. Accessed 22 February 2021. https://slate.com/business/2012/05/blue-collar-white-collar-whydo-we-use-these-terms.html

Wilson, Nick. 2018. "Linguistic Ethnography." In The Routledge Handbook of Language in the Workplace, edited by Bernadette Vine, 40-50. London/New York: Routledge.

Wittgenstein, Ludwig. 1999. Philosophische Untersuchungen / Philosophical Investigations: Second Edition. Oxford / Malden: Blackwell Publishers. First published 1953. 


\section{Zusammenfassung (Deutsch) ${ }^{16}$}

Bei dieser Dissertation handelt es sich um eine linguistische Ethnographie einer Metallgießerei in der niederländischen Provinz Limburg im deutschniederländischen Grenzgebiet. Als ihre Daten im Jahr 2017 im Rahmen einer Feldforschung erhoben wurden, arbeiteten in den Produktionsabteilungen der Gießerei mehr als 300 Menschen mit vielen verschiedenen sprachlichen Hintergründen, darunter Sprecher des Niederländischen, Deutschen, Limburgischen und Polnischen sowie unter anderem des Arabischen, Griechischen, Russischen und Türkischen. Manche Arbeiter lebten auf der niederländischen, andere auf der deutschen Seite der Grenze. Etwas über die Hälfte waren Zeitarbeiter, und ein wichtiger Teil ihrer Tages- und Nachtarbeit bestand aus der Interaktion mit Maschinen.

Die Dissertation zeigt, dass Angehörige der majorisierten Sprachgruppe in der Gießerei die sprachliche Diversität bei der Arbeit tendenziell problematischer fanden als die Angehörigen von minorisierten Sprachgruppen. Weiterhin zeigt sie, dass die Kurzlebigkeit zahlreicher Beziehungen am Arbeitsplatz größere Herausforderungen an die Kommunikation und das Lernen im Prozess der Arbeit stellte als die sprachliche Diversität an sich. Tatsächlich fiel es den Arbeitern häufig schwerer, die Maschinen in der Gießerei zu verstehen, als einander zu verstehen. Die Dissertation reflektiert diese und andere Beobachtungen und wendet in ihren Beschreibungen der Lebenswelten von Industriearbeitern sowohl etablierte linguistisch-ethnographische als auch posthumanistische Konzepte an, um den komplexen Beziehungen zwischen verschiedenen Arbeitern als auch denen zwischen Arbeitern und Maschinen gerecht zu werden.

Wichtige Folgerungen aus den Erkenntnissen sind, dass Gestalter von Sprachpolitik nicht nur über die technischen Probleme der Kommunikation, sondern auch darüber nachdenken sollten, wie sie sprachpolitische Eingriffe legitimieren, und dass Überlegungen hinsichtlich 'effizienter', 'sicherer' und 'zufriedenstellender' Arbeitsplatzkommunikation auch stets die Interaktionen zwischen Mensch und Maschine einschließen sollten. Schließlich vertritt die Dissertation die These, dass solche Überlegungen zu besser informierten sprachpolitischen Interventionen führen könnten, was nicht nur den Interessen von Arbeitern zugute käme, die Minderheiten angehören, sondern auch den Interessen jener, die der Mehrheit angehören, sowie den Interessen unterschiedlicher Unternehmen und der Gesellschaft im Ganzen.

\footnotetext{
${ }^{16}$ The credits for this translation go to the anonymous translators from gengo.com. In addition, I would like to thank Susanne Tienken for proofreading.
} 


\section{Summary (English)}

This PhD dissertation is a linguistic ethnography of a metal foundry in the Dutch province of Limburg, in the Dutch-German borderland. When its fieldwork data were collected in 2017, over 300 people with many different language backgrounds worked in the production departments of the foundry, including Dutch, German, Limburgish, and Polish, as well as Arabic, Greek, Russian, and Turkish, among others. Some workers lived on the Dutch, others on the German side of the border. Slightly more than half were temporary workers, and an important part of their daily and nightly work consisted of interactions with machines.

The dissertation shows that majoritised speakers in the foundry tended to find the language diversity at work more problematic than minoritised speakers. Furthermore, it shows that the transience of many work relations posed a bigger challenge to workplace communication and workplace learning than language diversity in itself. In fact, workers often had a harder time understanding the machines in the foundry than each other. The dissertation reflects upon these and other observations, and it applies both established, linguistic-ethnographic, as well as posthumanist concepts in its descriptions of blue-collar life-worlds in order to do justice to the complex relations between different human workers, and between human workers and machines.

Important implications of the findings are that language policy makers should not only consider technical communication issues, but also how to legitimise their language-political interventions, and that concerns about 'efficient', 'safe', and 'satisfying' workplace communication should always include a consideration of human-machine interactions as well. Ultimately, the dissertation argues that these considerations can lead to better informed language-political interventions, which is not only in the interests of minoritised workers, but also in the interests of majoritised workers, and of different companies and society at large. 


\section{Samevatting (Limburgs: mix van versjiedene tale/dialekte en sjriefwiezes) ${ }^{17}$}

Dit proofsjrif is eine taalkundige etnografie vaan 'ne metaalgeeteriej in d' $r$ Nederlandse previnsie Limburg, in 't Nederlands-Duutsje grensgebeed. Wie de veldwerkdata vaan dit proofsjif verzammeld woorte in 2017, weerkte d'r mier es 300 luuj mit 'ne haup versjiedene taalachtergrung, waoronger Hollendsj, Duutsj, Limburgs en Pools, mer auch onger angere Arabisch, Grieks, Russisch en Turks. Manche productieweerkers woeënde aan d'r Nederlandse, angere aan d'r Duutsje kangk vaan de grens. Get mier es de hellef waar oetzendkrach, en ein belangriek deil van äör daagelikse en nachtelikke weerk besjting oet interacties mit mesjiene.

't Proofsjrif luuet zeen det sjpraekers vaan gemajoriseerde tale in $d^{\prime} r$ geeteriej de talige diversiteit oppe weerkvloor duk problematischer vonge es sjpraekers vaan geminoriseerde tale. Weijer bliek det 't duks tiedelikke karakter vaan de weerkrelaties 'ne grottere oetdaging veur d' $r$ communicatie en de lieërprocesse oppe weerkvloor vormde es $d^{\prime} r$ talige diversiteit an sich. In feite hadde de productieweerkers duk mieër meuite $d$ ' $r$ met um mesjiene in de geeteriej te begriepe es zich ongerein. ' $t$ Proofsjrif prakkezaert euver deze en angere observaties, en pas zoewaal gevestigde, taalkundig-etnografische, es auch posthumanistische concepte toe in zien besjrievinge van de laefwaerelde vaan de productieweerkers, met as doel om rech te doon aan de complexiteit vaan de relaties tussje productieweerkers ongerein, es auch die tussje productieweerkers en mesjiene.

Belangrieke implicaties van de bevinginge zien det taalbeleidsmakers neet allein motte kieke nao technische communicatiekwesties, mer auch nao wie zeej äöre taalpolitieke interventies 't beste kenne legitimere, en det d'r aug mot zien veur $d$ ' $r$ dimensie vaan mins-mesjiene-interacties beej euverwaeginge euver 'efficiënte', 'ziechere' en 'bevredigende' communicatie oppe weerkvloor. Oetendelik sjtelt 't proofsjrif det zolche euverwaeginge toet baeter geïnformeerde taalpolitieke interventies kenne leide, waat neet allein in 't belang vaan productieweerkers oet minderheidsgroepe is, mer auch vaan productieweerkers oet mieërderheidsgroepe, en vaan versjillende bedrieve en d'r samelaeving as gehieël.

\footnotetext{
${ }^{17}$ I would like to thank Hans Schmeets for his help with making this translation.
} 


\section{Samenvatting (Nederlands)}

Dit proefschrift is een taalkundige etnografie van een metaalgieterij in de Nederlandse provincie Limburg, in het Nederlands-Duitse grensgebied. Toen de veldwerkdata van dit proefschrift werden verzameld in 2017, werkten er meer dan $\mathbf{3 0 0}$ mensen met veel verschillende taalachtergronden in de productieafdelingen van de gieterij, waaronder Nederlands, Duits, Limburgs en Pools, en daarnaast onder andere Arabisch, Grieks, Russisch en Turks. Sommige productiewerkers woonden aan de Nederlandse, andere aan de Duitse kant van de grens. lets meer dan de helft was uitzendkracht, en een belangrijk deel van hun dagelijkse en nachtelijke werk bestond uit interacties met machines.

Het proefschrift laat zien dat sprekers van gemajoriseerde talen in de gieterij de talige diversiteit op de werkvloer vaak problematischer vonden dan sprekers van geminoriseerde talen. Verder blijkt dat het vaak tijdelijke karakter van de werkrelaties een grotere uitdaging vormde voor de communicatie en leerprocessen op de werkvloer dan de talige diversiteit an sich. In feite hadden de productiewerkers vaak meer moeite om de machines in de gieterij te begrijpen dan elkaar. Het proefschrift reflecteert op deze en andere observaties, en past zowel gevestigde, taalkundigetnografische als ook posthumanistische concepten toe in zijn beschrijvingen van de leefwerelden van de productiewerkers, met als doel om recht te doen aan de complexiteit van de relaties tussen productiewerkers onderling, als ook van die tussen productiewerkers en machines.

Belangrijke implicaties van de bevindingen zijn dat taalbeleidsmakers niet alleen moeten kijken naar technische communicatiekwesties, maar ook naar hoe ze hun taalpolitieke interventies het beste kunnen legitimeren, en dat er oog moet zijn voor de dimensie van mens-machine-interacties bij overwegingen over 'efficiënte', 'veilige' en 'bevredigende' communicatie op de werkvloer. Uiteindelijk stelt het proefschrift dat dergelijke overwegingen kunnen leiden tot beter geïnformeerde taalpolitieke interventies, wat niet alleen in het belang is van productiewerkers uit minderheidsgroepen, maar ook van productiewerkers uit meerderheidsgroepen, en van verschillende bedrijven en de samenleving als geheel. 


\section{Streszczenie (w języku polskim) $)^{18}$}

Niniejsza rozprawa doktorska to praca językoznawczo-etnograficzna dotycząca odlewni metali w holenderskiej prowincji Limburgia położonej przy granicy holendersko-niemieckiej. W czasie moich prac badawczych $w$ terenie w 2017 roku przy produkcji w tej odlewni pracowało ponad 300 osób mówiących różnymi językami, w tym niemieckim, limburskim, niderlandzkim, polskim, arabskim, greckim, rosyjskim i tureckim. Jedni mieszkali po holenderskiej, a drudzy po niemieckiej stronie granicy. Nieco ponad połowę stanowili pracownicy tymczasowi zatrudnieni przez biura pośrednictwa pracy. Ważnym aspektem ich obowiązków, w dzień i w nocy, była obsługa maszyn.

Przedstawione w niniejszej pracy wyniki moich obserwacji wskazują na to, że osoby posługujące się językami najsilniej reprezentowanymi w odlewni uważały różnorodność językową w miejscu pracy za bardziej problematyczną niż osoby posługujące się językami mniejszościowymi, oraz że krótkotrwałość wielu stosunków zawodowych stanowiła większą trudność, jeśli chodzi o komunikację i uczenie się w miejscu pracy, niż różnorodność językowa. W rzeczy samej, pracownikom nierzadko trudniej było zrozumieć maszyny w odlewni niż siebie nawzajem. W rozprawie omawiam te $\mathrm{i}$ inne spostrzeżenia, stosując zarówno uznane koncepcje językoznawczo-etnograficzne, jak $\mathrm{i}$ idee posthumanistyczne do opisu światów życia codziennego pracowników fizycznych, aby rzetelnie przedstawić te złożone relacje międzyludzkie oraz relacje między pracownikami a maszynami.

Ważne wnioski płynące z tych ustaleń są takie, że decydenci w sprawach językowych powinni mieć na uwadze nie tylko problemy komunikacyjne natury technicznej, ale i sposoby uzasadniania swoich językowo-politycznych interwencji, oraz że troska o 'wydajną', 'bezpieczną' i 'satysfakcjonującą' komunikację $\mathrm{w}$ środowisku pracy powinna zawsze uwzględniać interakcje na linii człowiek-maszyna. Ostatecznie dowodzę, że te rozważania mogą prowadzić do lepiej przemyślanych językowopolitycznych interwencji, co jest $\mathrm{w}$ interesie nie tylko pracowników należących do mniejszości, ale także pracowników należących do większości, różnych firm i społeczeństwa jako całości.

\footnotetext{
${ }^{18}$ The credits for this translation go to the anonymous translators from gengo.com.
} 


\section{Impact Paragraph}

\section{What is the primary aim of the dissertation and what are its most important findings?}

The primary aim of the dissertation is to better understand the life-worlds of people working in a contemporary, multilingual blue-collar work environment. A basic question about such environments is whether language diversity constitutes a 'problem', and if so, what the nature of this 'problem' is. Previous studies of multilingual workplaces have shown that people do not have to speak an 'entire' language to achieve all sorts of transactional and social purposes. Moreover, scholars from an academic field known as posthumanism have shown that machines, among others, can help to achieve certain purposes without any need for human-human interaction. Hence, the idea that language diversity constitutes a 'problem' cannot be taken for granted. This dissertation has tested this insight through a detailed ethnographic study of workplace interactions in a metal foundry in the Dutch-German borderland, and presented a complex and nuanced picture of the degree to which different kinds of interactional purposes were (not) achieved. The overall theme of this study is power dynamics, a concept that captures the human-human and human-machine interactions which produce particular effects, which hierarchise the relations among the interacting participants, and which do (not) contribute to relevant purposes such as productivity, workplace safety, and job satisfaction.

One important finding of the study is that majoritised speakers in the foundry tended to find the language diversity at work more problematic than minoritised speakers. Possibly, this was because they were less used to having to adapt to a situation where people did not speak their first language(s), or because they felt that their social-economic position was threatened by minoritised speakers, while "language problems" could be used as an argument why those speakers should not be employed. Another important finding is that the transience of many work relations posed a bigger challenge to workplace communication and workplace learning than language diversity, partly because people had less time to build up a repertoire of shared communicative resources, and partly because the transient nature of their relations made them less motivated to do so. Finally, an important finding is that human workers in the foundry often 
had more problems understanding machines than each other. Hence, it makes sense to approach the terms language and language policy more broadly, and to abandon the division between studies of human-human interaction and human-machine interaction in the fields of workplace communication and workplace learning, as studying one without the other misses an important dimension of the daily and nightly workplace reality.

What is the (potential) academic and societal contribution of these research findings?

Up until recent years, blue-collar life-worlds rarely featured in academic studies of multilingual workplaces. One likely explanation for this is the methodological challenges involved (Lønsmann and Kraft 2017, 146-147): securing access to a blue-collar work environment can be hard; the social distance between the researcher and the participants can be large (e.g., in terms of gender, ethnicity, or language); and loud sounds can make it difficult to record workplace conversations. Hence, the mere fact that this dissertation has dealt with multilingualism in a blue-collar work environment, and that it has shared and reflected upon how the author gathered relevant data there, is already a contribution to existing academic research in and of itself. Moreover, its discussion of perspectives from both majoritised and minoritised speakers, and its discussion of the interactional role of machines are unique within existing linguistic ethnographies of bluecollar work environments.

Ultimately, the dissertation has aimed to contribute to better understandings of blue-collar life-worlds in this way, which may lead to better informed (language) policies. As the COVID-19 pandemic has underlined, many blue-collar jobs are crucial, and many are done by minoritised, first-generation migrant workers. Moreover, as the metal foundry is located in Limburg, where the population is not expected to grow significantly anymore, or even to shrink (Statistics Netherlands 2020b), migrant workers can be an important asset for the economy and society. Hence, it is not only in the interests of migrant workers themselves, but also in the interests of majoritised workers, and of different companies and the wider society to develop a better understanding of power dynamics and their effects, and to discuss how power dynamics can become a force for the good, so that 'local' and migrant workers both feel happy to take on 
a blue-collar job and stay in this region, thereby contributing to the sustainability of its economy and society.

With regard to the perspective of majoritised speakers, the research has shown that many of them were dissatisfied with the language diversity in the metal foundry, despite the fact that many messages from the company's management were written in the majoritised language (Dutch) only, and despite the management's efforts to make clear that minoritised speakers were expected to learn Dutch over time. One reason for this was that they were well aware that this was not likely to happen, at least not during times of economic growth. Thus, they had to adapt to a specific linguistic diversity at work anyway. Several majoritised speakers also explained that the increased language diversity was part of a broader development, which made them feel that people had less respect for them nowadays, and that companies such as the metal foundry did not fully represent their interests anymore. Hence, it became clear that language policies should not only address communication issues, but also the issue of whether the interests of different people are sufficiently considered. My suggestion would therefore be to not only aim for a more inclusive language policy, which follows the principle that as many messages as possible should be understandable for as many workers as possible, but also for an open communication about the reasons behind this policy. Managers could state, for example, that opening up to more language diversity can help a company to increase its production and make (more) profit, which can be invested in higher wages and more permanent contracts. In and of itself, such communication is not sufficient, but if, and when, it is part of a broader set of practices, which all underline that a management cares about its workers' interests, people's job satisfaction is more likely to increase, while possible social tensions are more likely to decrease.

With regard to machines, the dissertation has identified several possible additional ways to enhance people's job satisfaction. As many workers spent a major part of their work shifts with machines, these nonhuman co-workers were clearly relevant in this respect. Besides that, the dissertation has shown that machines had a valuable potential for workplace communication, as they could (partly) take over certain human communication tasks, for example by indicating how to work safely. In this way, machines could even help to overcome possible language barriers at work. At the same time, however, the dissertation has shown several examples of people struggling to understand machines, and of machines 
negatively affecting people's job satisfaction, for example by not adjusting to someone's working speed, or by not providing a sufficient explanation for a technical problem. One fundamental question is whether machine designers should ultimately aim for a replacement of human workers, or whether machines should rather be considered a valuable addition to the human work experience. Either way, by sharing observations such as the ones from this dissertation, machine designs may be improved, so that they become better at contributing to inclusive workplace communication as well as to safe and satisfying work experiences.

All in all, it has become clear that the insights from this research may not only be relevant for this particular metal foundry, but for other companies as well, and perhaps even for organisations beyond that. In fact, building upon a common representation of cross-border regions in Europe (the so-called Euroregions), this dissertation has proposed to consider the metal foundry as a "laboratory of European integration". Indeed, many major news topics of the European Union came together in this workplace, including economic crises and recoveries, labour migration from East to West, refugees from Syria, and resistance to such migration from 'local' majoritised populations. Hence, the metal foundry could be considered a critical case for the question of whether different people in Europe, in addition to machines (or any other technology for that matter), can live, work, and become economically productive together. My ultimate answer to this question is that this is possible, as long as certain conditions are fulfilled. Inclusivity is essential in this respect, because it can make people feel that they matter and belong to a specific organisation, but it is crucial to understand that inclusivity is not just an interest of specific minoritised speakers, but an interest of everyone. Therefore, the first step is to consider whether the social-economic and sociolinguistic interests of different individuals are sufficiently represented in an organisation, and if this is so, the next step is to show them that this is indeed the case.

Finally, with regard to the process of gathering relevant fieldwork data, and with regard to (historical) management practices in the metal foundry, the research has highlighted several advantages of being able to speak Limburgish. A political implication of this finding is that it should not be considered 'useless' or 'irrational' if someone wishes to learn Limburgish as a second language, or if parents wish to raise their children in Limburgish. Hence, one recommendation is to develop a societal infrastructure in Limburg that enables people to learn and teach Limburgish if, and when, they wish to do so. 
For which target group are the research findings interesting and/or relevant?

As follows from the discussion above, the findings can be interesting and relevant for many target groups, including fellow academics, company managers, (language) policymakers, machine designers, blue-collar workers and their representatives in labour unions, as well as other workers who are dealing with diverse languages and technologies today.

In which way can this target group be informed about the research findings?

Two chapters of this dissertation have already been published as open access, peer-reviewed articles in two different well-read academic journals, and a third one has been recently submitted to another such journal. In addition, I have published an essay about language policy in Limburg in the Veldeke Jaarboek, an annual popular-scientific publication from the regional cultural and dialectological organisation Veldeke Limburg.

I have given 29 presentations about my research project during my $\mathrm{PhD}$ trajectory, ranging in duration from seven minutes to two hours. Eight of these presentations took place at national, and nine at international academic conferences, seminars, and workshops. Besides those talks, I have given four presentations for colleagues, and another four presentations for undergraduate students from Maastricht University. Finally, I have given four presentations for broader, non-specialist audiences, such as a research pitch for a political representative from the Dutch province of Limburg.

In the final year of my PhD trajectory (2020), I have suffered a few setbacks due to the ongoing COVID-19 pandemic. In March 2020, for example, my supervisors and I planned to organise a conference for different societal stakeholders at Statistics Netherlands (CBS), during which we would exchange academic and professional perspectives on the topic of multilingualism in blue-collar workplaces. Unfortunately, this turned out to be one of the very first events from CBS and Maastricht University that was cancelled due to the pandemic, but we plan to set a new date for the event once this pandemic is over. Another example is a two-months research stay at the University of Copenhagen in May and June 2020, which was cancelled for the same reason. 
When it comes to the metal foundry, I have been maintaining email contact with two Human Resource (HR) managers and two production workers since the end of my fieldwork. Overall, the foundry has had many personnel changes since then, and the COVID-19 pandemic makes it difficult to give a presentation there at the moment, but I still plan to visit it again once the circumstances allow it. Afterwards, I will also publish a popular-scientific or journalistic text about my research, so that a broader non-academic audience can learn about the findings of this dissertation as well. 


\begin{abstract}
About the Author
After having lived in the Dutch province of Limburg during the first 18 years of his life, Daan Hovens (Tegelen, 1988) went to study a BA programme in Scandinavian Languages and Cultures (Swedish track) at the University of Groningen. As part of this, he also studied a minor programme in German Language and Culture, took several additional courses in Philosophy, and spent the final year of the programme at Uppsala University (Sweden) as an Erasmus exchange student. In his BA thesis, he compared the political discourse about the 2004 EU enlargement in the Netherlands and Sweden.
\end{abstract}

After graduation, Daan managed to obtain an Erasmus Mundus scholarship, which enabled him to study an MA programme in Euroculture (i.e., European Studies with a focus on social and cultures issues), with a double degree from the Georg August University of Göttingen (Germany) and Uppsala University. Moreover, as part of this programme, he was able to follow a three-month research track at Osaka University (Japan) in 2011. For his MA thesis, he conducted a survey at one Dutch and one German secondary school in the Meuse-Rhine borderland, exploring language learning practices and language ideologies among pupils in a region where politicians have often expressed ambitions about cross-border labour market integration.

Daan's first job upon completion of this MA programme was a traineeship at the Green European Foundation in Brussels (Belgium) in 2012, a political foundation that is allied to the European Greens. Part of this job was to write reports about green political campaigns in different countries, which confirmed Daan's already existing feeling that he enjoyed working as a reporter. Therefore, he decided to start studying again, this time an international MA programme in Journalism at the University of Groningen. In his second MA thesis, he did a content analysis of Dutch newspaper articles about European asylum issues before and after the Lampedusa migrant shipwreck of 2013.

Following an internship with the Dutch public broadcasting organisation VPRO, Daan had several freelance jobs as a web editor and online journalist in 2015 and 2016. More specifically, he created online content for the websites of VPRO, NPO Radio 1, and Buitenhof, a weekly political interview programme on Dutch TV, and he also managed the newsletter and social media accounts of the latter programme. As an online journalist, Daan made a series of five "longreads" about Japan for the VPRO 
website. To this end, he spent several months in the country again, together with his partner who was doing a PhD in Japanese Colonial Literature at Osaka University at the time, and who cooperated with him on the series. Ultimately, they aimed to overcome tendencies of exoticising Japan in Dutch media by sharing their reflections about particular observations, for example about Japanese male fashion.

Daan's PhD studies at Maastricht University brought him back again to the region where he had grown up. Apart from doing research, he worked as an academic tutor and BA thesis supervisor during this time, and obtained a University Teaching Qualification in 2019. Currently, Daan is working as a part-time researcher for the Interreg project EMR-Lingua, which aims to stimulate the learning of 'neighbour' languages in Belgian, Dutch, and German schools in the Meuse-Rhine borderland. Besides that, he is teaching an online course on Dutch Sociolinguistics for students from the University of Groningen, and he is working on a voluntary basis for the regional language education platform Levende Talen Limburgs, as a board member and web editor. Once the COVID-19 pandemic is over, Daan would also love to take up his singing again for the Maastricht University Choir. 